Nicole Veldhorst-Janssen

Intranasal delivery of rapid acting drugs

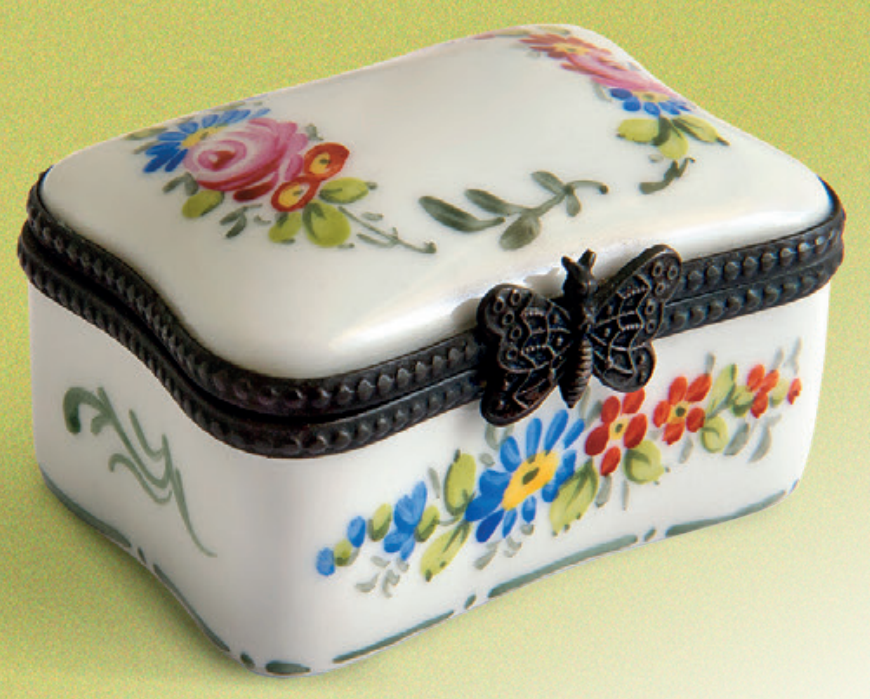


ISBN 9789461592149

C copyright NML Veldhorst-Janssen, Maastricht 2013

Porseleinen snuifdoosje uit privé collectie auteur Foto: Johannes Timmermans

Layout en druk: Datawyse / Universitaire Pers Maastricht 


\title{
Intranasal delivery of rapid acting drugs Studies of pharmacokinetics, effect, tolerability, and satisfaction
}

\author{
PROEFSCHRIFT \\ ter verkrijging van de graad van doctor aan de Universiteit Maastricht, \\ op gezag van de Rector Magnificus, Prof. dr. L.L.G. Soete, \\ volgens het besluit van het College van Decanen, \\ in het openbaar te verdedigen op vrijdag 22 maart 2013 om 14.00 uur \\ door
}

N.M.L. Veldhorst-Janssen

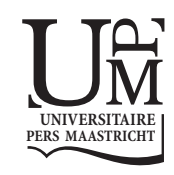




\section{Promotores}

Prof. dr. M.A.E. Marcus

Prof. dr. C. Neef

\section{Co-Promotor}

Dr. P-H. M. van der Kuy

\section{Beoordelingscommissie}

Prof. dr. R. van Oostenbrugge, voorzitter

Prof. dr. A. Bast

Prof. dr. D.M. Burger (Universitair Medisch Centrum St. Radboud)

prof. dr. R.R.W.J. van der Hulst

Prof. dr. R.P. Koopmans 


\section{Contents}

Chapter 1 General introduction 7

Chapter 2 A review of the clinical pharmacokinetics of opioids, 17 benzodiazepines, and antimigraine drugs delivered intranasally

Chapter 3 Pharmacokinetics and tolerability of nasal versus intravenous midazolam in healthy Dutch volunteers: a single-dose, randomizedsequence, open-Label, 2-period crossover pilot study

Chapter 4 Pharmacokinetics, analgesic effect, and tolerability of a single preprocedural dose of intranasal fentanyl in patients undergoing drain removal after breast reduction or augmentation surgery: a prospective, randomized, double-blind, placebo-controlled study

Chapter 5 Dual pathway absorption after intranasal drug administration: a new pharmacokinetic model

Chapter 6 Patient satisfaction with intranasal fentanyl for breakthrough pain

Chapter 7 Patient satisfaction with intranasal midazolam versus rectal diazepam as fast-working rescue medication in epilepsy

Chapter 8 General Discussion

Summary

Samenvatting

Dankwoord 



\section{CHAPTER 1}

\section{General introduction}




\section{Introduction}

Smelling salts, tobacco, and hallucinogens have been used, by inhalation, for centuries by different cultures worldwide. Unlike products that act locally in the nose, such as topical decongestants or anti-inflammatory drugs used to treat rhinitis or allergyrelated indications [1], inhaled smelling salts, tobacco, and hallucinogens are examples of agents that act systemically after being administered intranasally (IN) [2]. In the early 1950s, the first studies of IN administered systemically acting drugs, such as corticotrophin and mammary tumor milk factor, were published in peer-reviewed journals [3-8]. Since then, increasingly more IN formulations of systemically acting drugs have been developed. The IN route of drug delivery is patient friendly, with the drug being absorbed by the nasal mucosa and entering the vascular system directly, rendering invasive routes of administration unnecessary [9]. However, relatively little is known about the pharmacokinetics of many IN administered, systemically acting lipophilic compounds and many questions remain to be answered.

\section{Pharmacokinetics of intranasal drug delivery}

The pharmacokinetics of a drug reflect the sum of its absorption, distribution, metabolism and elimination. Absorption is the process by which a drug permeates one or more biological cell membranes to enter the blood [1]. Usually, this process occurs by passive diffusion, although absorption can occur by facilitated diffusion or active transport. The rate of absorption depends on the concentration and formulation, route of administration, and the physical and chemical properties of the drug, the most important being the drug's lipid solubility $[10,11]$. The distribution of a drug in the body also depends on its lipid solubility, as the ability of a drug to cross biological membranes increases with increasing lipid solubility. Lipid-soluble drugs can move into extravascular compartments, such as adipose tissue and the central nervous system (CNS). Other drugs bind to plasma proteins, especially plasma albumin. Although binding is dynamic and reversible, drugs that are bound at a particular time are necessarily confined to the vascular system and are therefore not able to exert their pharmacological action [1,11]. Drugs can be metabolized into more hydrophilic metabolites, often terminating their pharmacological activity [12]. The last factor affecting the amount of drug in the circulation is elimination. Drugs are eliminated from the body either unchanged or as more polar, inactive metabolites by the process of excretion [12].

After IN administration, drugs are absorbed through the mucosa lining the nasal cavity [13]. The nasal cavity is divided by the nasal septum into two nostrils and is connected to the oral cavity by the nasopharynx [14]. The three main areas of the nasal 
cavity are the vestibules, the respiratory region, and the olfactory region. The posterior vestibule has a folded structure and has a total surface area of about $150 \mathrm{~cm}^{2}$ in humans. The ciliated cells of the epithelium transport mucus toward the nasopharynx. The posterior vestibule is highly vascularized, rendering it permeable to small, lipophilic, molecules [14-17].

The large surface area, the mucus, and the high vascularization of the nasal cavity mean that absorbed drugs can enter the circulation directly, bypassing gastrointestinal hepatic elimination [14]. However, the ciliated cells that transport mucus toward the nasopharynx can also transport IN administered drugs into the gastrointestinal system, where the drug is absorbed [18]. In some cases, concentration-time plots of IN administered drugs show that drugs can be absorbed via both routes, $[19,20]$ which is referred to as dual absorption [21].

\section{Efficacy of intranasal drug delivery}

Several studies have shown IN drug delivery to be suitable for various indications $[14,22]$. For example, IN drug administration may be preferable when ease of dosing, without the need for assistance, and rapid drug absorption and action are essential [23]. In general, three therapeutic groups of drugs have been developed for IN administration - analgesics (mainly opioids), benzodiazepines, and antimigraine drugs. The drugs in the three groups are lipophilic and have a low molecular weight, and are mainly used as 'rescue medication' for several indications.

Most opioids formulated as an IN spray have a $\mathrm{t}_{\max }<25$ minutes and a bioavailability of $>50 \%[13,24-46]$. Fentanyl in particular lends itself to IN administration for patients undergoing short painful procedures because of its rapid onset and short duration of action [24,36,37]. These same properties make IN fentanyl suitable for patients with cancer-related breakthrough pain, which typically has a rapid onset and lasts up to 30 minutes [14]. Fentanyl is also used to treat chronic pain conditions, administered via transdermal patches that provide sustained release of fentanyl.

Benzodiazepines are often used to treat epileptic seizures in children and adults. As treatment needs to be administered acutely, and it is difficult to administer drugs intravenously during an epileptic seizure, alternative routes of drug administration are needed. In the Netherlands, rectally administered diazepam is currently used for this purpose, but it has several disadvantages such as the embarrassment, for both patients and bystanders, accompanying its use. Clonazepam [47], diazepam [48,49] and midazolam [19,50-55] have been developed as IN therapeutics for epileptic seizures. Of the three drugs, midazolam has been studied the most [19,50-55] and is as effective as rectally administered diazepam for treating epileptic seizures [56]. 
Recurrent migraine or cluster headaches are often difficult to manage with orally administered drugs, because the onset of drug action is not fast enough. Although some antimigraine drugs may have comparable concentration-time profiles when administered intranasally or orally $[57,58]$, others have better pharmacokinetics after IN administration $[20,59-66]$, and provide a rapid onset of action.

\section{Patient satisfaction}

Not only the efficacy and safety of drugs are important to improve compliance, but also their convenience and ease of use. Overall satisfaction with pharmacotherapy is determined by patients' feeling that the effectiveness of a certain treatment outweighs the side effects and inconvenience of medication use (see figure 1) $[67,68]$
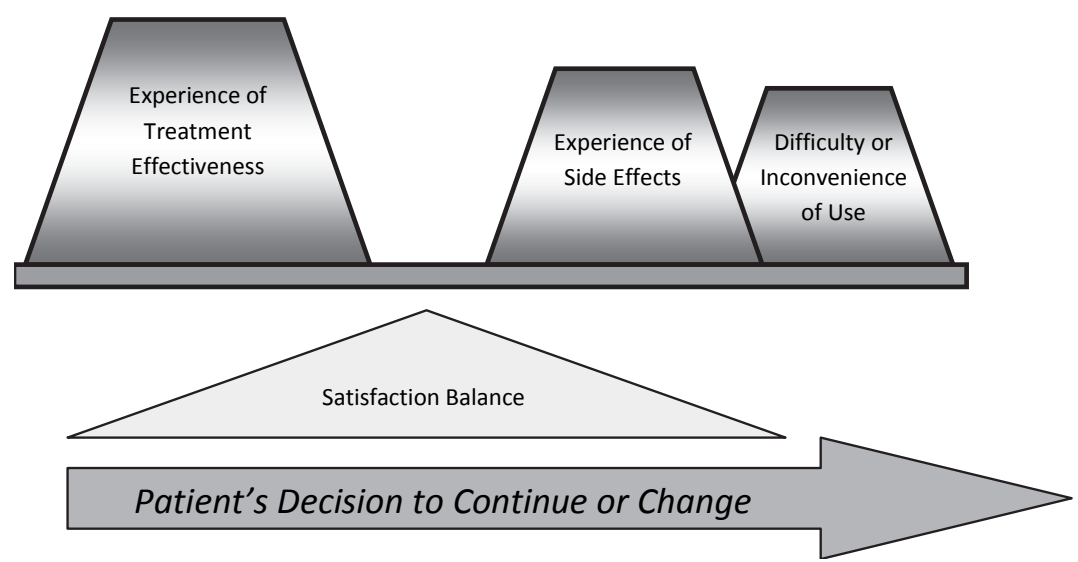

Figure 1 A Decisional Balance Model of Treatment Satisfaction depicting dimensions of treatment experience that are weighted to predict overall satisfaction and medication persistence. Adapted from Atkinson MJ et al [68]. 
Patient satisfaction is an important determinant of medication adherence $[2,67,69,70]$. If adherence is low, the treatment may be ineffective. This has implications for symptom relief and can even create new health problems. For example, the HARM study [71] has shown that non-adherence to medication regimens leads to twice as many drug-related hospitalizations than does medication adherence [71]. In the Netherlands, about 19,000 drug-related and potentially preventable hospitalizations occur each year [71]. Recognition of the importance of patient satisfaction might lead to the development of improved medications and increased satisfaction [67].

It is important to be able to demonstrate that niche products, such as a nasal spray formulation, have a place in therapy, by showing that drugs administered in this way are efficacious and safe, and by showing that treatment satisfaction, and possibly adherence, is improved. A number of studies of IN administered drugs have investigated patient satisfaction, usually with a $100-\mathrm{mm}$ visual analogue scale (VAS) [72,73]; however, these scales have not been validated as instrument to measure treatment satisfaction [74].

To date, studies of IN drug administration have not used generally validated instruments to measure patient satisfaction. A validated questionnaire to measure patients' satisfaction with medication in general, the 'treatment satisfaction questionnaire for medication' (TSQM), assesses patients' satisfaction with medication by means of 14 items covering side effects, effectiveness, convenience, and global satisfaction $[68,74,75]$. It would be interesting to use this questionnaire to investigate to what extent patients are satisfied with IN therapy.

\section{Aim and outline of the thesis}

Nasal sprays of lipophilic drugs might be particularly useful for indications that require rapid treatment. For example, cancer breakthrough pain or epileptic seizures can be treated with IN fentanyl or midazolam, respectively. The studies described in this thesis investigated several characteristics of IN administered lipophilic drugs, such as pharmacokinetics, clinical effectiveness, tolerability, and satisfaction. All these factors together determine the ability of a drug to improve a patient's health and may contribute to our knowledge of IN drugs.

In chapter 2, a systematic review provides an overview of published data on the pharmacokinetic properties of IN drugs active in the CNS. The review was performed to determine the suitability of opioids, benzodiazepines, and antimigraine drugs for IN administration. Knowledge of the pharmacokinetics of these drugs may explain differences in drug effectiveness and may identify drug formulations that are suitable for clinical use. 
The maximum volume of a drug administered IN is limited, which affects the drug's pharmacokinetic behavior. In the study described in chapter $\mathbf{3}$, the formulation of a standard IN midazolam spray was changed by concentrating the solution and minimizing the volume administered. The pharmacokinetics of this new formulation were studied in healthy volunteers in a phase 1 pilot study.

The study reported in chapter 4 describes a phase 2 study in which a small group of patients were treated with IN fentanyl, and the analgesic effect, safety, tolerability, and pharmacokinetics of the drug were investigated. A randomized clinical trial was performed in which IN fentanyl was compared with IN placebo for pain relief after the removal of surgical drains in patients who had undergone breast reduction or augmentation surgery.

In the studies described in chapters 3 and 4 , the phenomenon of dual absorption was observed, with absorption of IN administered drugs occurring via the nasal mucosa and the gastrointestinal tract. To date, this multipeak phenomenon has not been described in a pharmacokinetic model for IN drugs. In the study described in chapter 5, examples of drugs displaying dual absorption were given and a pharmacokinetic model was described and tested.

Even if all parameters, such as pharmacokinetics, efficacy, and tolerability, make the further development of a drug attractive, the final decision on whether to proceed with drug development depends on the patients using the drug. For this reason, the last part of this thesis focuses on two studies of patient satisfaction with IN fentanyl and IN midazolam, measured using a validated satisfaction questionnaire, and on possible predictors of patient satisfaction. The study described in chapter 6 investigated patient satisfaction with IN fentanyl used for breakthrough pain, and that reported in chapter 7 investigated whether patients preferred IN midazolam or rectally administrated diazepam for the management of epileptic seizures. 


\section{References}

1. Bommer R. Encyclopedia of pharmaceutical technology. In: Encyclopedia of pharmaceutical technology, Third Edition, edJ. S, New York: Informa Healthcare USA, 2007:1201-08.

2. Christensen AJ JJ. Patient adherence with medical treatment regimens: an interactive approach. Curr Dir Psychol Sci. 2002:94-97.

3. Beaudette FR, Bivins JA. The influence of passive immunity or the response to intramuscular and intranasal administration of Newcastle disease virus. Cornell Vet. 1953;43:513-31.

4. Begg AM. Intranasal administration of mammary tumour milk factor. Br J Cancer. 1949;3:88-90.

5. Mc KJ, Schwarz H, Hall M. Intranasal corticotropin; its physiological and clinical effects. Can Med Assoc J. 1954;70:244-8.

6. Nathanson $\mathrm{MH}$, Tober J, Miller $\mathrm{H}$. The cardiovascular effects of the intranasal administration of acetylbeta-methycholine chloride (Mecholyl). Am J Med Sci. 1950;219:639-47.

7. Paulsen F. [Intranasal administration of ACTH]. Sven Lakartidn. 1952;49:2998-3003.

8. Tonndorf J, Hyde RW, Chinn HI, Lett JE. Absorption from nasal mucous membrane: systemic effect of hyoscine following intranasal administration. Ann Otol Rhinol Laryngol. 1953;62:630-41.

9. Sliva Sarah BE. Intranasal Use of Drugs in the Emergency Room and Pre-Hospital Arenas (Update). In: Goodman \& Gilman's The Pharmacological Basis of Therapeutics, ed.Brunton LL, Parker KL, 2010.

10. Loenen van ASJ (editor). Farmacotherapeutisch Kompas 2010. 2010 Edition. Utrecht: VGZ, 2010.

11. Neal M. Medical Pharmacology at a Glance. second edition Editon. London: Blackwell scientific publications, 1992.

12. LB. The Pharmacological Basis of Therapeutics. New york: The McGraw-Hill Companies, 2010.

13. Dale O, Hjortkjaer R, Kharasch ED. Nasal administration of opioids for pain management in adults. Acta Anaesthesiol Scand. 2002;46:759-70.

14. Costantino HR, Illum L, Brandt G, Johnson PH, Quay SC. Intranasal delivery: physicochemical and therapeutic aspects. Int J Pharm. 2007;337:1-24.

15. Hosoya K, Kubo H, Natsume H, Sugibayashi K, Morimoto Y, Yamashita S. The structural barrier of absorptive mucosae: site difference of the permeability of fluorescein isothiocyanate-labelled dextran in rabbits. Biopharm Drug Dispos. 1993;14:685-95.

16. Fisher AN, Illum L, Davis SS, Schacht EH. Di-iodo-L-tyrosine-labelled dextrans as molecular size markers of nasal absorption in the rat. J Pharm Pharmacol. 1992;44:550-4.

17. McMartin C, Hutchinson LE, Hyde R, Peters GE. Analysis of structural requirements for the absorption of drugs and macromolecules from the nasal cavity. J Pharm Sci. 1987;76:535-40.

18. Merkus FW, Verhoef JC, Schipper NG, Marttin E. Nasal mucociliary clearance as a factor in nasal drug delivery. Adv Drug Deliv Rev. 1998;29:13-38.

19. Burstein AH, Modica R, Hatton M, Forrest A, Gengo FM. Pharmacokinetics and pharmacodynamics of midazolam after intranasal administration. J Clin Pharmacol. 1997;37:711-8.

20. Yates R, Nairn K, Dixon R, Seaber E. Preliminary studies of the pharmacokinetics and tolerability of zolmitriptan nasal spray in healthy volunteers. J Clin Pharmacol. 2002;42:1237-43.

21. Kuy van der P-H. Studies on intranasal drug delivery in migraine. Leiden: University of Leiden, 2003.

22. Chien YW, Chang SF. Intranasal drug delivery for systemic medications. Crit Rev Ther Drug Carrier Syst. 1987;4:67-194.

23. Wolfe TR, Bernstone T. Intranasal drug delivery: an alternative to intravenous administration in selected emergency cases. J Emerg Nurs. 2004;30:141-7.

24. Christrup LL, Foster D, Popper LD, Troen T, Upton R. Pharmacokinetics, efficacy, and tolerability of fentanyl following intranasal versus intravenous administration in adults undergoing third-molar extraction: A randomized, double-blind, double-dummy, two-way, crossover study. Clin Ther. 2008;30:46981. 
25. Coda BA, Rudy AC, Archer SM, Wermeling DP. Pharmacokinetics and bioavailability of single-dose intranasal hydromorphone hydrochloride in healthy volunteers. Anesth Analg. 2003;97:117-23

26. Davis GA, Rudy A, Archer SM, Wermeling DP. Bioavailability of intranasal butorphanol administered from a single-dose sprayer. Am J Health Syst Pharm. 2005;62:48-53.

27. Davis GA, Rudy AC, Archer SM, Wermeling DP. Pharmacokinetics of butorphanol tartrate administered from single-dose intranasal sprayer. Am J Health Syst Pharm. 2004;61:261-6.

28. Davis GA, Rudy AC, Archer SM, Wermeling DP, McNamara PJ. Bioavailability and pharmacokinetics of intranasal hydromorphone in patients experiencing vasomotor rhinitis. Clin Drug Investig 2004;24:6339.

29. Davis GA, Rudy AC, Archer SM, Wermeling DP, McNamara PJ. Effect of fluticasone propionate nasal spray on bioavailability of intranasal hydromorphone hydrochloride in patients with allergic rhinitis. Pharmacotherapy 2004;24:26-32.

30. Eriksen J, Jensen NH, Kamp-Jensen M, Bjarno H, Friis P, Brewster D. The systemic availability of buprenorphine administered by nasal spray. J Pharm Pharmacol 1989;41:803-5.

31. Fitzgibbon D, Morgan D, Dockter D, Barry C, Kharasch ED. Initial pharmacokinetic, safety and efficacy evaluation of nasal morphine gluconate for breakthrough pain in cancer patients. Pain. 2003; 106:30915.

32. Foster D, Upton R, Christrup L, Popper L. Pharmacokinetics and pharmacodynamics of intranasal versus intravenous fentanyl in patients with pain after oral surgery. Ann Pharmacother. 2008;42:1380-7.

33. Helmers JH, Noorduin H, Van Peer A, Van Leeuwen L, Zuurmond WW. Comparison of intravenous and intranasal sufentanil absorption and sedation. Can J Anaesth. 1989;36:494-7.

34. Illum L, Watts P, Fisher AN, Hinchcliffe M, Norbury H, Jabbal-Gill I, Nankervis R, Davis SS. Intranasal delivery of morphine. J Pharmacol Exp Ther. 2002;301:391-400.

35. Lim CB, Paech MJ, Goy R, Liu Y, Zhang G, Yao M, Doherty DA. Pharmacokinetics and bioavailability of hydromorphone nasal spray. Aust J Hosp Pharm. 2008;38:191-95.

36. Lim SCB, Paech MJ, Sunderland VB, Roberts MJ, Banks SL, Rucklidge MWM. Pharmacokinetics of nasal fentanyl. Aust J Hosp Pharm. 2003;33:59-63.

37. Moksnes K, Fredheim OM, Klepstad P, Kaasa S, Angelsen A, Nilsen T, Dale O. Early pharmacokinetics of nasal fentanyl: is there a significant arterio-venous difference? Eur J Clin Pharmacol. 2008;64:497-502.

38. Rudy AC, Coda BA, Archer SM, Wermeling DP. A multiple-dose phase I study of intranasal hydromorphone hydrochloride in healthy volunteers. Anesth Analg. 2004;99:1379-86.

39. Schwagmeier R, Boerger N, Meissner W, Striebel HW. Pharmacokinetics of intranasal alfentanil. J Clin Anesth. 1995;7:109-13.

40. Shyu WC, Mayol RF, Pfeffer M, Pittman KA, Gammans RE, Barbhaiya RH. Biopharmaceutical evaluation of transnasal, sublingual, and buccal disk dosage forms of butorphanol. Biopharm Drug Dispos. 1993;14:371-9.

41. Shyu WC, Morgenthien EA, Pittman KA, Barbhaiya RH. The effects of age and sex on the systemic availability and pharmacokinetics of transnasal butorphanol. Eur J Clin Pharmacol. 1994;47:57-60.

42. Shyu WC, Pittman KA, Robinson D, Barbhaiya RH. Multiple-dose phase I study of transnasal butorphanol. Clin Pharmacol Ther. 1993;54:34-41.

43. Shyu WC, Pittman KA, Robinson DS, Barbhaiya RH. The absolute bioavailability of transnasal butorphanol in patients experiencing rhinitis. Eur J Clin Pharmacol. 1993;45:559-62.

44. Takala A, Kaasalainen V, Seppala T, Kalso E, Olkkola KT. Pharmacokinetic comparison of intravenous and intranasal administration of oxycodone. Acta Anaesthesiol Scand. 1997;41:309-12.

45. Vachharajani NN, Shyu WC, Greene DS, Barbhaiya RH. The pharmacokinetics of butorphanol and its metabolites at steady state following nasal administration in humans. Biopharm Drug Dispos. 1997;18:191-202. 
46. Wermeling DP, Miller JL, Archer SM, Rayens MK, Rudy AC. Pharmacokinetics, bioequivalence, and spray weight reproducibility of intranasal butorphanol after administration with 2 different nasal spray pumps. J Clin Pharmacol. 2005;45:969-73.

47. Schols-Hendriks MW, Lohman JJ, Janknegt R, Korten JJ, Merkus FW, Hooymans PM. Absorption of clonazepam after intranasal and buccal administration. Br J Clin Pharmacol. 1995;39:449-51.

48. Gizurarson S, Gudbrandsson FK, Jonsson H, Bechgaard E. Intranasal administration of diazepam aiming at the treatment of acute seizures: clinical trials in healthy volunteers. Biol Pharm Bull. 1999;22:425-7.

49. Lindhardt K, Gizurarson S, Stefansson SB, Olafsson DR, Bechgaard E. Electroencephalographic effects and serum concentrations after intranasal and intravenous administration of diazepam to healthy volunteers. Br J Clin Pharmacol. 2001;52:521-7.

50. Bjorkman S, Rigemar G, Idvall J. Pharmacokinetics of midazolam given as an intranasal spray to adult surgical patients. Br J Anaesth. 1997;79:575-80.

51. Dale O, Nilsen T, Loftsson T, Hjorth Tonnesen H, Klepstad P, Kaasa S, Holand T, Djupesland PG. Intranasal midazolam: a comparison of two delivery devices in human volunteers. J Pharm Pharmacol. 2006;58:1311-8.

52. Knoester PD, Jonker DM, Van Der Hoeven RT, Vermeij TA, Edelbroek PM, Brekelmans GJ, de Haan GJ. Pharmacokinetics and pharmacodynamics of midazolam administered as a concentrated intranasal spray. A study in healthy volunteers. Br J Clin Pharmacol. 2002;53:501-7.

53. Loftsson T, Gudmundsdottir H, Sigurjonsdottir JF, Sigurdsson HH, Sigfusson SD, Masson M, Stefansson E. Cyclodextrin solubilization of benzodiazepines: formulation of midazolam nasal spray. Int J Pharm. 2001;212:29-40.

54. Wermeling DP, Record KA, Archer SM, Rudy AC. A pharmacokinetic and pharmacodynamic study, in healthy volunteers, of a rapidly absorbed intranasal midazolam formulation. Epilepsy Res. 2009;83:12432.

55. Wermeling DP, Record KA, Kelly TH, Archer SM, Clinch T, Rudy AC. Pharmacokinetics and pharmacodynamics of a new intranasal midazolam formulation in healthy volunteers. Anesth Analg. 2006;103:3449.

56. de Haan GJ, van der Geest P, Doelman G, Bertram E, Edelbroek P. A comparison of midazolam nasal spray and diazepam rectal solution for the residential treatment of seizure exacerbations. Epilepsia. 2010;51:478-82.

57. Chen J, Jiang XG, Jiang WM, Gao XL, Mei N. Intranasal absorption of rizatriptan--in vivo pharmacokinetics and bioavailability study in humans. Pharmazie. 2005;60:39-41.

58. Duquesnoy C, Mamet JP, Sumner D, Fuseau E. Comparative clinical pharmacokinetics of single doses of sumatriptan following subcutaneous, oral, rectal and intranasal administration. Eur J Pharm Sci. 1998;6:99-104.

59. Humbert H, Cabiac MD, Dubray C, Lavene D. Human pharmacokinetics of dihydroergotamine administered by nasal spray. Clin Pharmacol Ther. 1996;60:265-75.

60. Kagedal M, Zingmark PH, Hedlund C, Yates R. True nasopharyngeal absorption of zolmitriptan after administration via nasal spray in healthy male volunteers. Am J Drug Deliv. 2005;3:133-40.

61. Lonterman S, Van Asselt DZB, Olde Rikkert MGM, Russel FGM, Hoefnagels WHL, Merkus FWHM. Intranasal hydroxocobalamin administration: an attractive alternative for intramuscular cobalamin injections in geriatric patients. Drug Dev Res. 2000;51:197-99.

62. Uemura N, Onishi T, Mitaniyama A, Kaneko T, Ninomiya K, Nakamura K, Tateno M. Bioequivalence and rapid absorption of zolmitriptan nasal spray compared with oral tablets in healthy Japanese subjects. Clin Drug Investig. 2005;25:199-208.

63. Van Asselt DZ, Merkus FW, Russel FG, Hoefnagels WH. Nasal absorption of hydroxocobalamin in healthy elderly adults. Br J Clin Pharmacol. 1998;45:83-6.

64. van der Kuy PH, Lohman JJ, Hooymans PM, Ter Berg JW, Merkus FW. Bioavailability of intranasal formulations of dihydroergotamine. Eur J Clin Pharmacol. 1999;55:677-80. 
65. Van der Kuy PH, Merkus FW, Russel FGM, Lohman JJ, Hooymans PM. Bioavailability of oral hydroxocobalamin. Br J Clin Pharmacol. 2000;49:395P-96P.

66. Yates R, Nairn K, Dixon R, Kemp JV, Dane AL. Pharmacokinetics, dose proportionality, and tolerability of single and repeat doses of a nasal spray formulation of zolmitriptan in healthy volunteers. J Clin Pharmacol. 2002;42:1244-50.

67. Shikiar R, Rentz AM. Satisfaction with medication: an overview of conceptual, methodologic, and regulatory issues. Value Health. 2004;7:204-15.

68. Atkinson MJ, Kumar R, Cappelleri JC, Hass SL. Hierarchical construct validity of the treatment satisfaction questionnaire for medication (TSQM version II) among outpatient pharmacy consumers. Value Health. 2005;8 Suppl 1:S9-S24.

69. Morris LS, Schulz RM. Patient compliance--an overview. J Clin Pharm Ther. 1992;17:283-95.

70. Morris LS, Schulz RM. Medication compliance: the patient's perspective. Clin Ther. 1993;15:593-606.

71. Leendertse AJ, Egberts AC, Stoker LJ, van den Bemt PM. Frequency of and risk factors for preventable medication-related hospital admissions in the Netherlands. Arch Intern Med. 2008;168:1890-6.

72. Saunders $M$, Adelgais $K$, Nelson D. Use of intranasal fentanyl for the relief of pediatric orthopedic trauma pain. Acad Emerg Med. 2010;17:1155-61.

73. Chiaretti A, Barone G, Rigante D, Ruggiero A, Pierri F, Barbi E, Barone G, Riccardi R. Intranasal lidocaine and midazolam for procedural sedation in children. Arch Dis Child. 2010;96:160-3.

74. Atkinson MJ, Sinha A, Hass SL, Colman SS, Kumar RN, Brod M, Rowland CR. Validation of a general measure of treatment satisfaction, the Treatment Satisfaction Questionnaire for Medication (TSQM), using a national panel study of chronic disease. Health Qual Life Outcomes. 2004;2:12-25.

75. Bharmal M, Payne K, Atkinson MJ, Desrosiers MP, Morisky DE, Gemmen E. Validation of an abbreviated Treatment Satisfaction Questionnaire for Medication (TSQM-9) among patients on antihypertensive medications. Health Qual Life Outcomes. 2009;7:36-46. 


\section{CHAPTER 2}

A review of the clinical pharmacokinetics of opioids, benzodiazepines, and antimigraine drugs delivered intranasally 


\section{Abstract}

Background: Interest in the development of drug delivery devices that might improve treatment compliance is growing. A dosage formulation that is easy to use, such as intranasal application with transmucosal absorption, may offer advantages compared with other routes of drug delivery. The literature concerning intranasal application is diffuse, with a large number of published studies on this topic. Some cerebroactive pharmaceuticals delivered intranasally might follow the pathway from the nose to the systemic circulation to the brain. To determine the suitability of these drugs for intranasal drug delivery, a systematic review was performed.

Objective: The aim of this review was to compare the pharmacokinetic properties of intranasal, intravenous, and oral formulations in 3 classes of cerebroactive drugs that might be suitable for intranasal delivery - opioids, benzodiazepines, and antimigraine agents.

Methods: A search of MEDLINE, PubMed, Cumulative Index of Nursing and Allied Health Literature, EMBASE, and Cochrane Database of Systematic Reviews (dates: 1964-April 2009) was conducted for pharmacokinetic studies of drugs that might be suitable for intranasal delivery. A comparison of pharmacokinetic data was made between these 3 routes of administration.

Results: A total of 45 studies were included in this review. Most of the opioids formulated as an intranasal spray reached a $t_{\max }$ within 25 minutes. The bioavailability of intranasal opioids was high; in general, $>50 \%$ compared with opioids administered intravenously. Intranasal benzodiazepines had an overall $t_{\max }$ that varied from 10 to 25 minutes, and bioavailability was between $38 \%$ and $98 \%$. $\mathrm{T}_{\max }$ for most intranasal antimigraine drugs varied from 25 to 90 minutes. Intranasal bioavailability varied from $5 \%$ to $40 \%$.

Conclusions: This review found that intranasal administration of all 3 classes of drugs was suitable for indications of rapid delivery, and that the pharmacokinetic properties differed between the intranasal, oral, and intravenous formulations (intravenous > intranasal > oral). 


\section{Introduction}

Interest in the development of advanced drug-delivery routes, such as oral transmucosal and intranasal systems, is growing. Advanced drug-delivery systems might improve efficacy and treatment compliance. Intranasal administration with transmucosal absorption may offer advantages compared with invasive and non-invasive systems (eg, oral or rectal administration) [1-3].

The pharmacokinetic properties of intranasally administered drugs might follow a pattern that lies between those of orally and intravenously administered drugs. Intranasal drugs also offer the convenience of self-administration.

Positive attributes of intranasal systemic drug delivery are: (1) avoidance of hepatic first-pass elimination, gut wall metabolism, and/or metabolism in gastrointestinal fluids; (2) rapid absorption as measured using the plasma concentration-time profile; (3) the rich vasculature and numerous microvilli structure in the nasal cavity, which offer a feasible and desirable site for absorption of systemically effective drugs [1]; and (4) noninvasiveness. For these reasons, the comfort and thus the compliance of the patient might be maximized [2].

Based on a literature search, published studies concerning intranasal drug delivery are diffuse. It has been found that the intranasal route is suitable for local and systemic delivery of diverse therapeutic compounds that have a central or peripheral point of action $[4,5]$.

It has been hypothesized that the therapeutic pathway of the intranasal formulations of these 3 classes follows the nose-to systemic circulation-to brain pathway [1]. The aim of this review was to compare the pharmacokinetic properties of 3 cerebroactive drug classes that might be suitable for intranasal delivery - opioids, benzodiazepines, and antimigraine drugs.

\section{Materials and Methods}

\section{Literature Search}

Using MEDLINE, PubMed, Cumulative Index of Nursing and Allied Health Literature, EMBASE, and Cochrane Database of Systematic Reviews (dates: 1964-April 2009), the literature was searched for English-language pharmacokinetic studies of lowmolecular-weight, systemically delivered opioids, benzodiazepines, and antimigraine drugs with a central point of action. Low-molecular-weight drugs were chosen because they are absorbed more easily into the brain pathway. The free-text search terms were divided into 3 groups by drug class (opioids, benzodiazepines, antimigraine drugs), with the common pharmaceuticals per group being selected (Table I).

Data on orally delivered drugs were collected from Micromedex [6], substantiated with related literature or articles included in this study. 


\section{Study Selection}

Two reviewers (N.M.L.V.-J. and A.A.A.F.) independently assessed all of the studies for inclusion or exclusion. Studies were excluded if the title suggested that the study was not based on data from human subjects, the study clearly did not include an intranasally delivered drug, or the study was performed in children (pharmacokinetics are different in children than in adults) [7]. Studies that did not report original, empiric data were excluded, as were those of drugs of potential abuse. Of the titles that were not excluded based on these criteria, the abstracts were read to select studies for further review using the criteria mentioned earlier. After a full read of each article, the selection was finalized using a consensus of the 2 reviewers.

Table I. Terms used in the literature search of pharmacokinetic studies of drugs that might be suitable for intranasal delivery.

\begin{tabular}{ll}
\hline Drug class & Terms \\
\hline Opioids & $\begin{array}{l}\text { (Nasal or intranasal), pharmacokinetic* and (opioid* or opiate* or alfentan* or } \\
\text { fentanyl or remifentan* or sufentan* or hydromor* or methadone or morfin or } \\
\text { morphine or oxycodone or pentazo* or tramadol or pethid* or piritramid* or butor- } \\
\text { phanol or buprenorphine) }\end{array}$ \\
Benzodiazepines & $\begin{array}{l}\text { (Nasal or intranasal), pharmacokinetic* and (midazolam or diazepam or brotizolam } \\
\text { or flunitrazepam or flurazepam or loprazolam or lormetazepam or nitrazepam or } \\
\text { temazepam or alprazolam or clorazepate or bromazepam or clobazam or oxazepam } \\
\text { or prazepam or clonazepam) } \\
\text { (Nasal or intranasal), pharmacokinetic* and (dihydroergotamin* or ergotamin* or } \\
\text { hydroxocobalamin or hydrocobalamin or hydroxycobalamin or almotriptan or elet- } \\
\text { riptan or frovatriptan or naratriptan or rizatriptan or sumatriptan or zolmitriptan) }\end{array}$ \\
\hline
\end{tabular}

\section{Data Extraction and Analysis}

Using a data-extraction form, data were collected from all included studies by 1 reviewer (A.A.A.F.). In cases of doubt, the second reviewer was consulted. To reverify study eligibility at the time of data extraction, the study populations, the exact formulations and routes of delivery of the interventions, outcome measures, and the study designs were reviewed. Information about any differences in characteristics of the population were recorded, and interventions on which the assessment of heterogeneity will be based $[8,9]$. For these purposes, the following study characteristics were extracted: (1) research objectives/question; (2) design of the study; (3) outcome measure; (4) number of patients included; (5) spray device; (6) data analysis (ie, pharmacokinetics program); (7) formulation; (8) ionization (ie, $\mathrm{pH} / \mathrm{pKa}$ relation or partition coefficient [logP]); (9) dosage; and (10) dose volume. Inclusion and exclusion criteria, age, weight, and sex were also extracted. 


\section{Data Analysis}

For all studies included in the review, pharmacokinetic data $\left(C_{\max }, t_{\max }\right.$, and bioavailability [F]) were reported, if provided in the original article. Bioavailability was described as the pharmacokinetics of the intranasal or oral formulation relative of the intravenous formulation. To enhance the comparability of the individual study results based on the data reported in the articles, we recalculated the pharmacokinetic data to the same units (ie, minutes, $\mathrm{ng} / \mathrm{mL}, \mathrm{ng} / \mathrm{mL} * \mathrm{~min}$ ). Finally, pharmacokinetic data to oral administration were collected, because the oral delivery system is the preferred route of delivery for most drugs. Because oral administration is clinically not appropriate for some indications, the pharmacokinetic data from drugs administered intravenously were also collected because these drugs might be considered for intranasal delivery [10].

\section{Results}

\section{Study Characteristics}

In this study, the pharmacokinetic data on the intranasally delivered drugs were compared to those of drugs administered orally or intravenously.

For opioids, 341 articles were identified, of which 135 were duplicates. Of the remaining 206 articles, 163 were excluded due to irrelevance. The abstracts of the remaining 43 articles were read, with 23 articles that did not correspond with the inclusion criteria for the review [3,11-32]. For benzodiazepines, the corresponding numbers were 160 articles, 65 duplicates, 95 abstracts reviewed, 72 excluded due to irrelevance, 23 read in full, and 11 included in the review [33-43]; for antimigraine drugs, 192 titles were identified, of which 87 were duplicates. Of the remaining 105 titles, 28 were selected for further review, of which 11 were included in the review [44-54].

The demographic characteristics were not significantly different between the 3 treatment groups (Table I).

Subjects included in studies of opioids, benzodiazepines, or antimigraine drugs were healthy volunteers with good general mental and physical health. Subjects were excluded if they had a nasal condition, such as a nasal cold; cardiovascular, gastrointestinal, hepatic, renal, pulmonary, hematologic, or psychiatric disease; a history of drug allergies; and/or a history of alcohol or drug abuse. Subjects were also excluded if they were smokers or were pregnant. In all studies, regular or concurrent medications were disallowed during the study period.

Other characteristics of the included studies are shown in Table II (opioids), Table III (benzodiazepines), and Table IV (antimigraine drugs). 


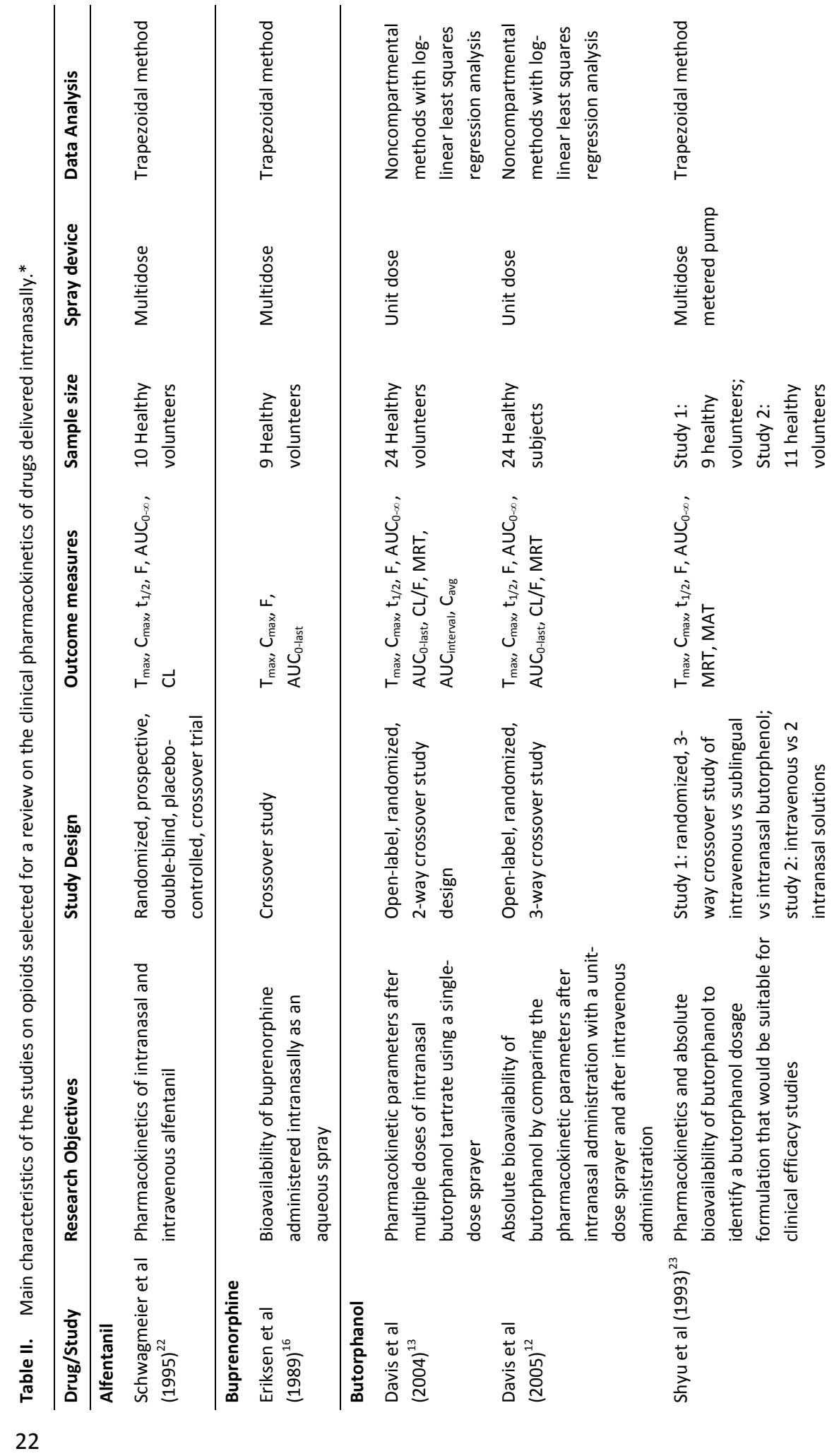


CHAPTER 2 | REVIEW

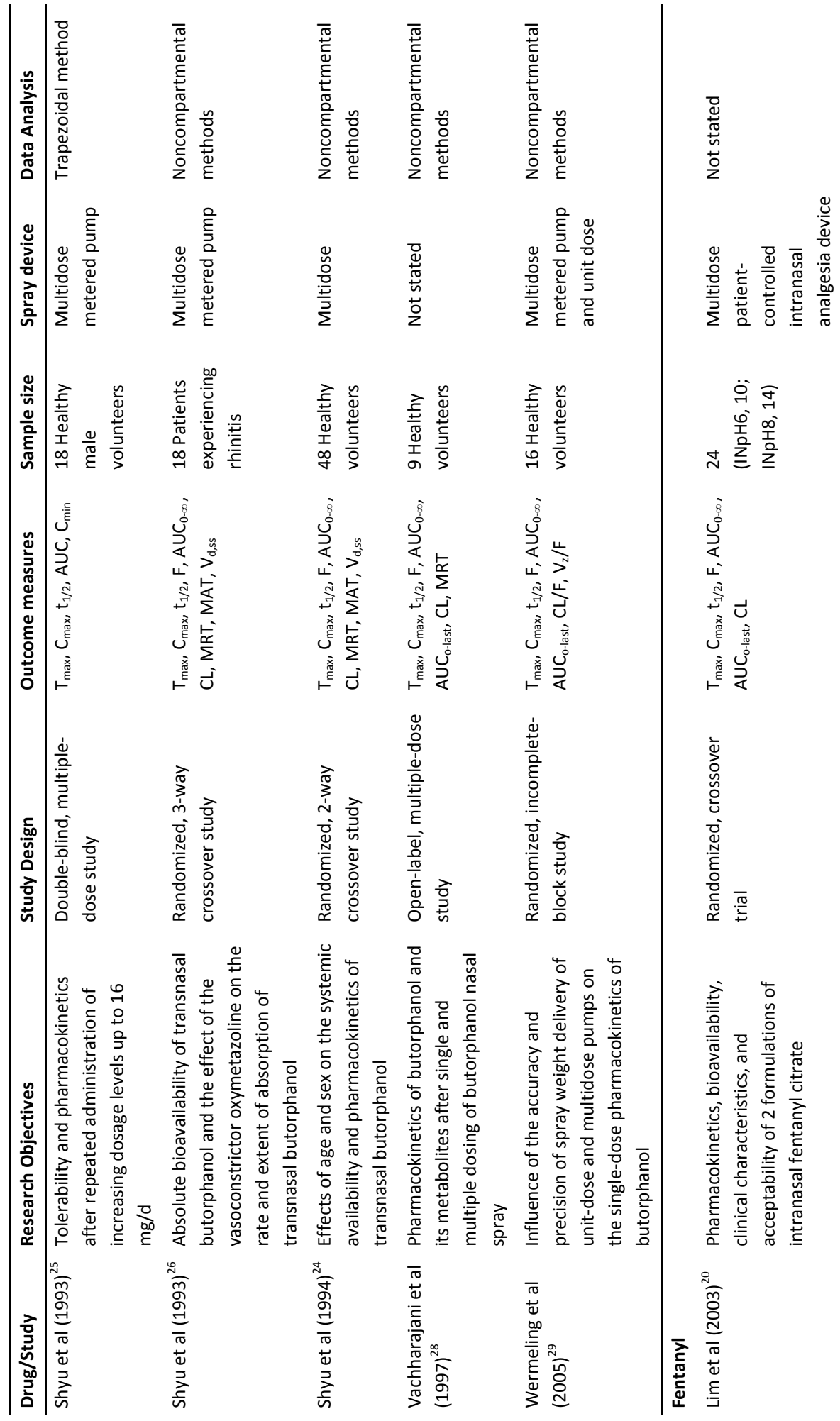




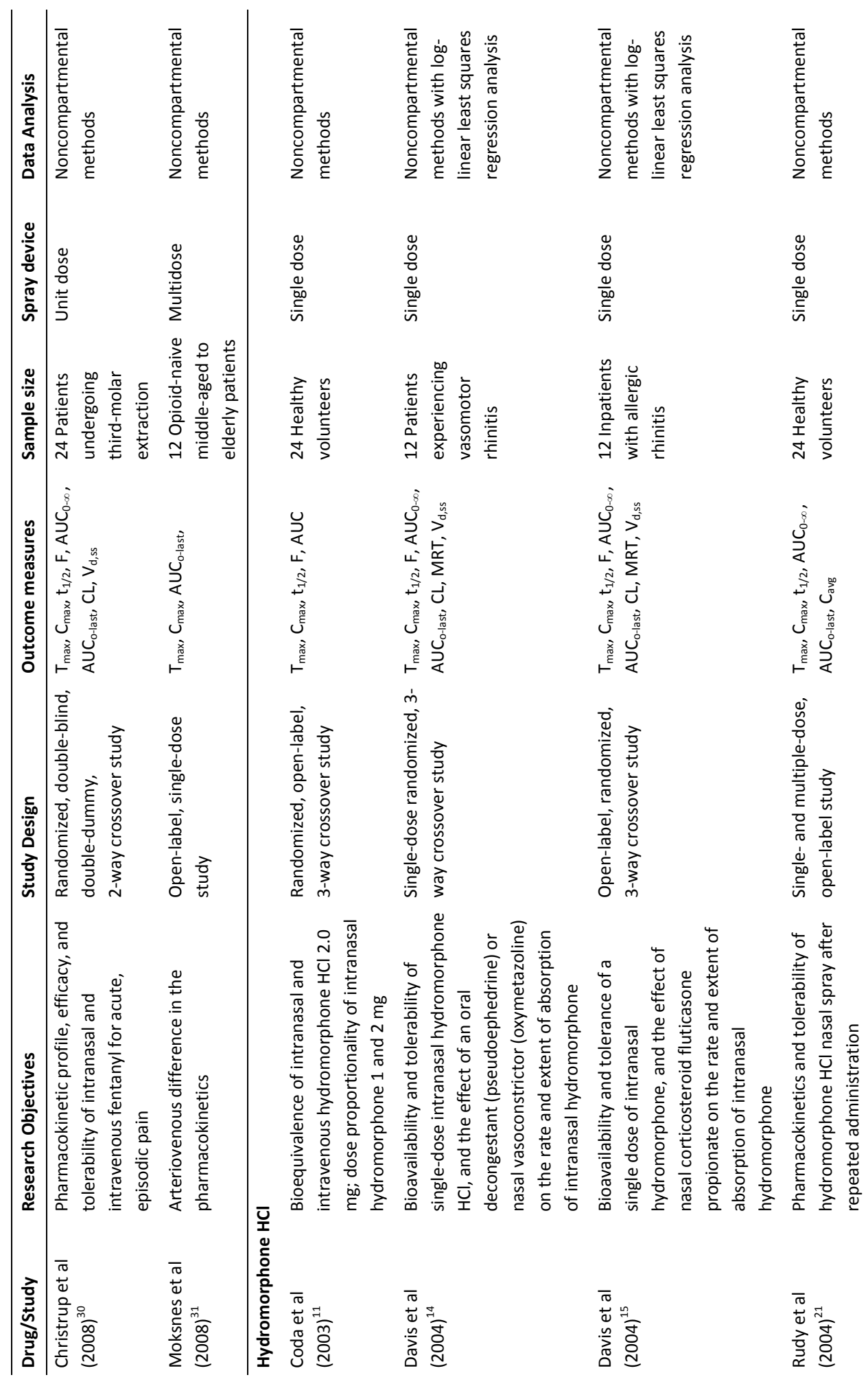


CHAPTER 2 | REVIEW

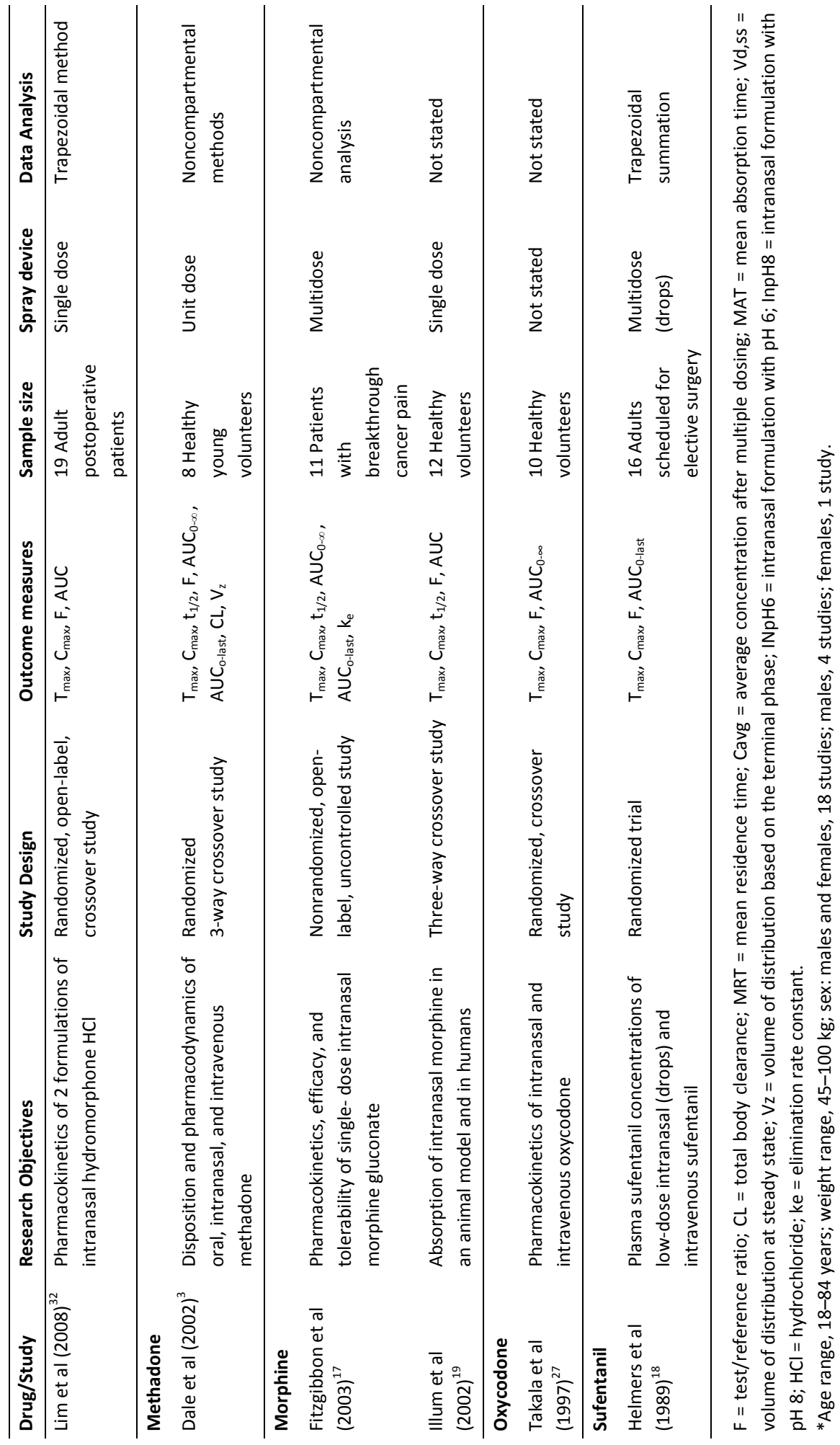




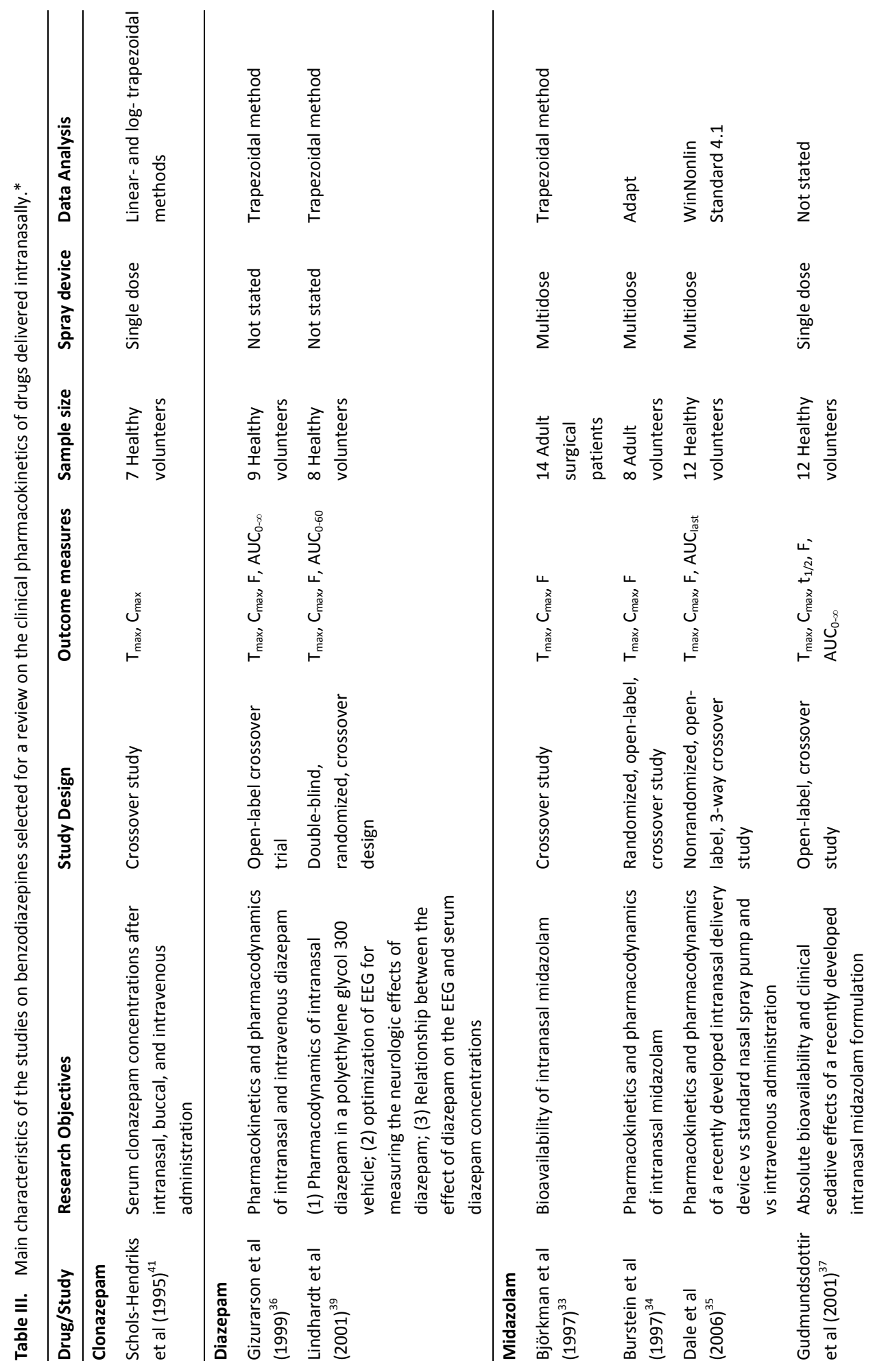


CHAPTER 2 | REVIEW

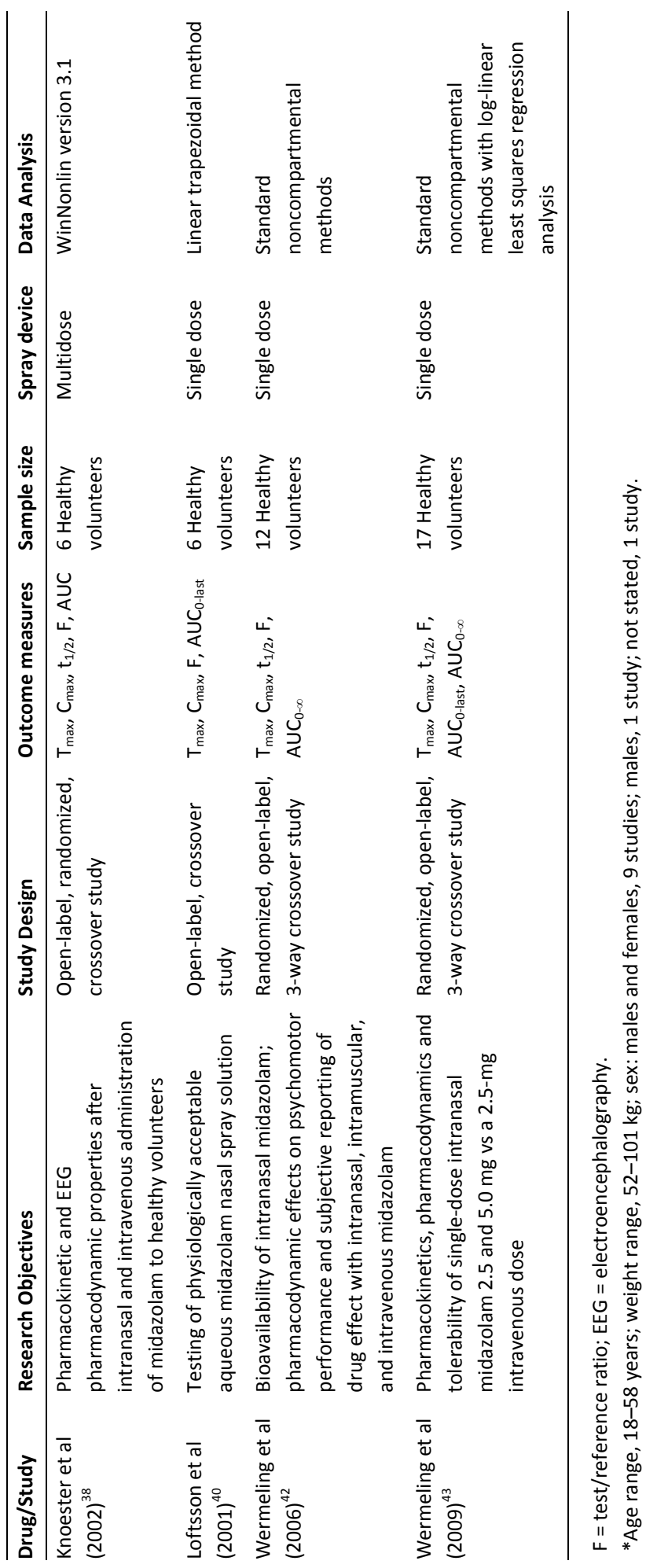




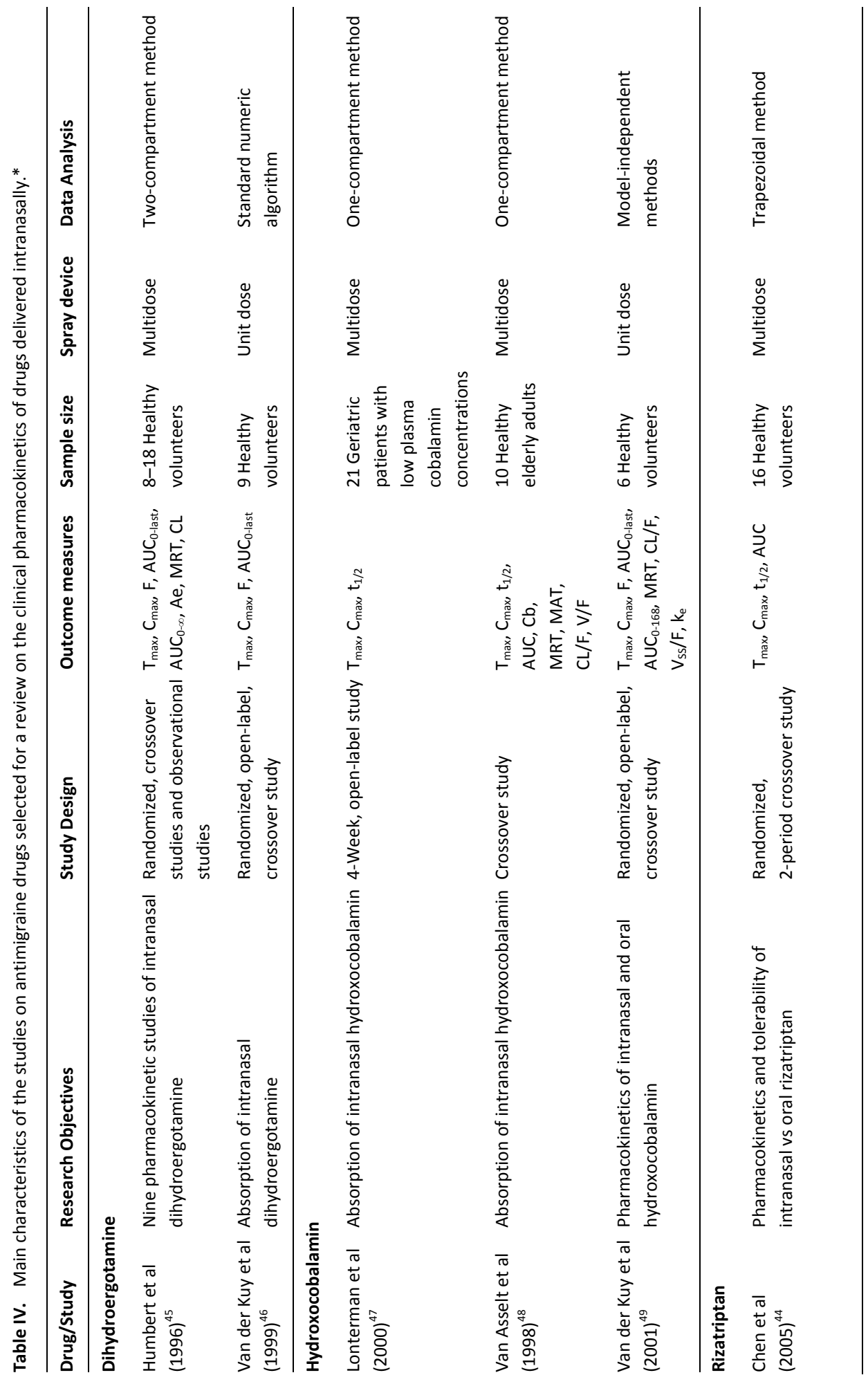


CHAPTER 2 | REVIEW

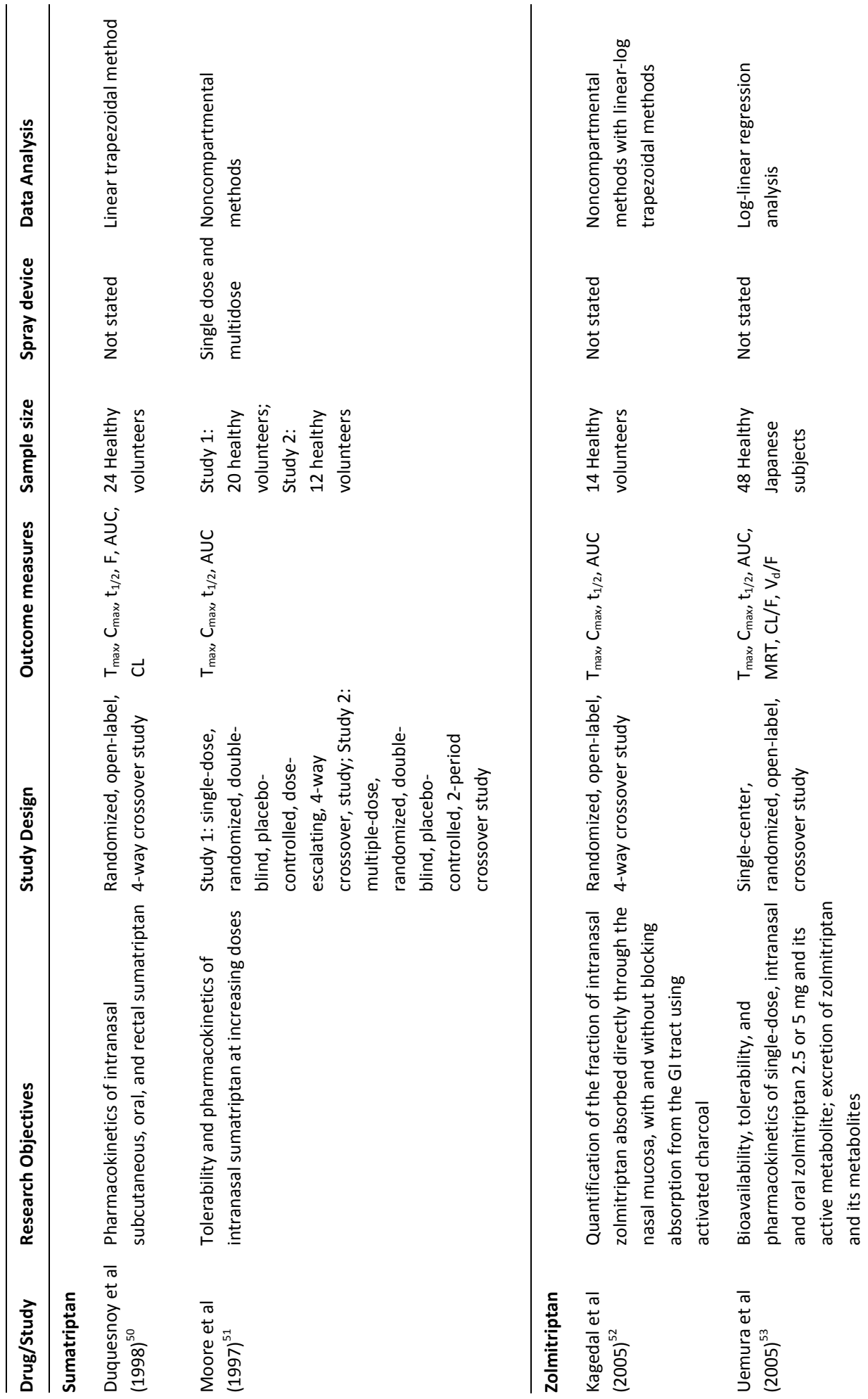




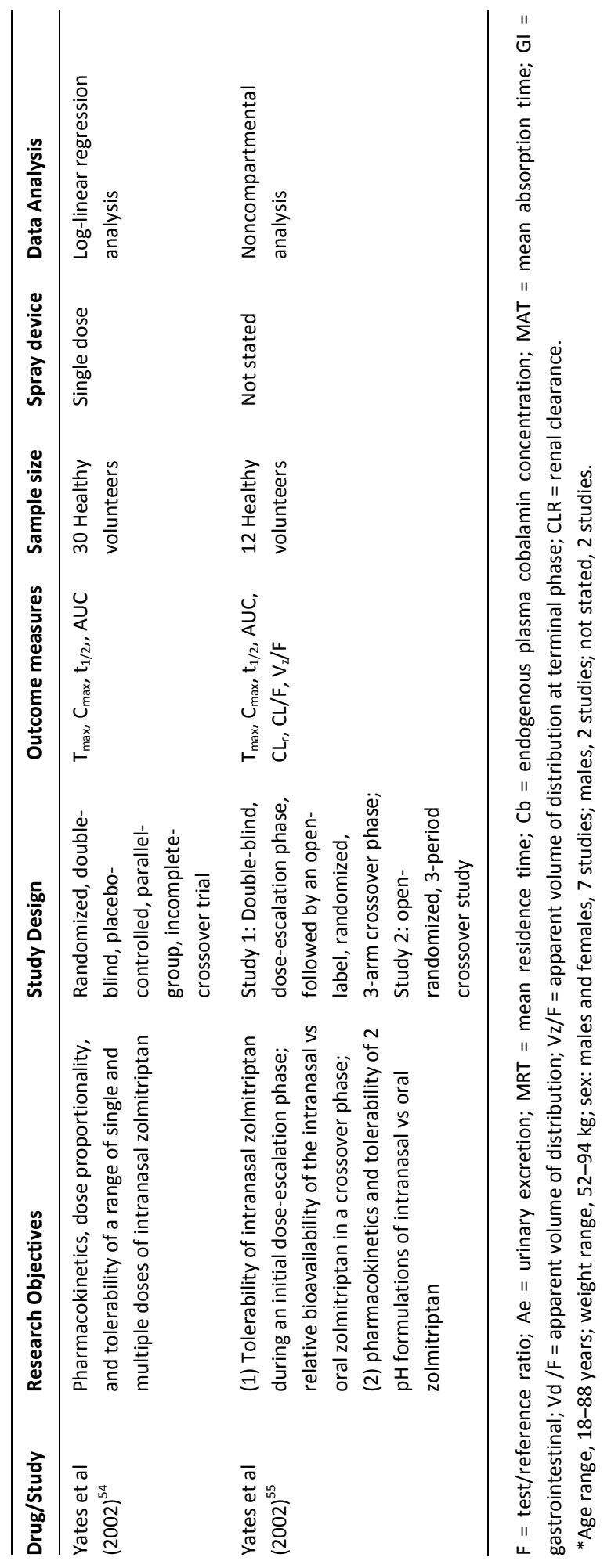




\section{Pharmacokinetics of intranasal formulations}

\section{Opioids}

Studies of 9 opioids administered intranasally were included in this review. The pharmacokinetic parameters of each opioid are summarized in Table V. Most of the opioids formulated as an intranasal spray generated a $t_{\max }$ within 25 minutes. Furthermore, the bioavailability of intranasally administered opioids was high, in general $>50 \%$. Three drugs were found to have differences in pharmacokinetics. Intranasal butorphanol had a $t_{\max }$ that ranged from 15 to 55 minutes and a $C_{\max }$ that ranged from 1.56 to 5.56 $\mathrm{ng} / \mathrm{mL}$. Intranasal fentanyl had a $\mathrm{t}_{\max }$ of 5 to 16 minutes, and a bioavailability of $55 \%$ to $89 \%$ was observed. Bioavailability also varied with intranasal morphine (range, 22\%$56 \%$ ). Overall, the pharmacokinetic properties of opioids ranked intravenous $>$ intranasal > oral on the parameters $t_{\max }, C_{\max }$ and bioavailability.

Assessment of the different opioids found that $t_{\max }$ values with the intranasal formulations were more comparable to that of the intravenous formulation than with that of the oral formulation $t_{\max }$. The most substantial difference between intranasal and oral $t_{\max }$ was found with methadone (7.2 and 126 minutes after intranasal and oral administration, respectively). The similarities between intranasal $C_{\max }$ and intravenous $C_{\max }$ or oral $C_{\max }$ depended on the drug. Methadone $C_{\max }$ values were 135,114 , and 43 $\mathrm{ng} / \mathrm{mL}$ with the intravenous, intranasal, and oral formulations, respectively. Oral bioavailability exceeded intranasal bioavailability only with oxycodone; the opioids had similar or lower oral bioavailability.

\section{Benzodiazepines}

The pharmacokinetic parameters of the benzodiazepines are shown in Table VI. Intranasally administered benzodiazepines were found to have an overall $t_{\max }<25$ minutes and an intranasal bioavailability that ranged from $42 \%$ to $83 \%$. With intranasal diazepam, differences in studies were found only in $t_{\max }$ (18-42 minutes).

With midazolam, however, intranasal pharmacokinetics were similar between several studies [33,35,37,38,40,42,43]. However, one study [34] reported a lower bioavailability (50\%) compared with those in other studies (range 60\%-83\%).

Also for benzodiazepines, in general, the pharmacokinetic properties were ranked intravenous > intranasal > oral. However, for diazepam, oral bioavailability (98\%) was higher compared with intranasal bioavailability (42\%-50\%).

\section{Antimigraine drugs}

Pharmacokinetic data of antimigraine drugs are shown in Table VII. For most antimigraine drugs, the $t_{\max }$ after intranasal administration was between 25 and 90 minutes. Intranasal hydroxocobalamin $t_{\max }$ differed between studies $[2,44,48]$ (range, 28 
minutes to 1 week), as did that for intranasal zolmitriptan (range, 15-240 minutes) $[43,45,51,53]$. Finally, a difference in intranasal bioavailability $(19 \%-41 \%)[42,47]$ was seen with dihydroergotamine.

With antimigraine drugs, no data on intravenous formulations were available. Therefore, only data from intranasal and oral administration were compared. With dihydroergotamine and hydroxocobalamin, the pharmacokinetics of the intranasal formulation were better (ie, shorter $\mathrm{t}_{\max }$, greater $\mathrm{C}_{\max }$, greater $\mathrm{F}$ ) than those found with the oral formulations. With the triptans, on the other hand, most pharmacokinetic parameters were similar after intranasal and oral administration. However, with rizatriptan, $\mathrm{t}_{\max }$ was apparently shorter after intranasal than after oral administration (32 vs 75 minutes, respectively). 
Table V. Reported outcomes in studies on opioids selected for a review on the clinical pharmacokinetics of drugs delivered intranasally.

\begin{tabular}{|c|c|c|c|c|c|}
\hline Drug/Route/Study/Dose & $\begin{array}{c}\text { Volume } \\
\text { (mL) }\end{array}$ & $\begin{array}{l}\text { No. of } \\
\text { Sprays }\end{array}$ & $\begin{array}{l}\text { Tmax } \\
\text { (min) }\end{array}$ & $\begin{array}{c}\text { Cmax } \\
(\mathrm{ng} / \mathrm{mL})\end{array}$ & $\begin{array}{c}F \\
(\%)\end{array}$ \\
\hline
\end{tabular}

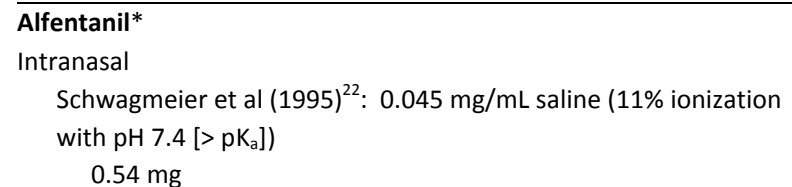

\section{Buprenorphine $\mathrm{HCl}$ \\ Intranasal}

Eriksen et al $(1989)^{16}: 2 \mathrm{mg} / \mathrm{mL} 5 \%$ dextrose

(adjusted to $\mathrm{pH} 5\left[<\mathrm{pK}_{\mathrm{a}}\right]$ )
$0.3 \mathrm{mg}$
$0.15 \mathrm{~mL}$
3
31
1.77
48.2

Oral (sublingual)

Bullingham et al (1981)

$0.4 \mathrm{mg}$

Two 0.2-

150

0.74

31

mg tablets

Intravenous

Eriksen et al $(1989)^{16}: 2 \mathrm{mg} / \mathrm{mL} 5 \%$ dextrose

(adjusted to $\mathrm{pH} 5\left[<\mathrm{pK}_{\mathrm{a}}\right]$ )

$$
0.3 \mathrm{mg}
$$

$0.15 \mathrm{~mL}$

60.69

\section{Butorphanol tartrate}

Intranasal

Davis et al $(2004)^{13}: 0.2 \%$ in sodium citrate and $0.2 \%$ citric acid

(buffered to $\mathrm{pH} 5\left[<\mathrm{pK}_{\mathrm{a}}\right]$ )

$1 \mathrm{mg}$

$2 \mathrm{mg}$

Davis et al $(2005)^{12}$ : 0.1-mg intranasal spray or $0.2 \%$ sodium citrate, and $0.2 \%$ citric acid (buffered to $\mathrm{pH} 5\left[<\mathrm{pK}_{\mathrm{a}}\right]$ )

$$
\begin{aligned}
& 1 \mathrm{mg} \\
& 2 \mathrm{mg}
\end{aligned}
$$

Shyu et al $(1993)^{23}: 10-\mathrm{mg} / \mathrm{mL}$ solution

(adjusted to $\mathrm{pH} 5\left[<\mathrm{pK}_{\mathrm{a}}\right]$ )

Standard solution, $2 \mathrm{mg}$

With benzethonium chloride as a preservative, $2 \mathrm{mg}$

With thimerosal, $2 \mathrm{mg}$

Shyu et al $(1993)^{25}: 10-\mathrm{mg} / \mathrm{mL}$ in a preservative solution packaged in 15-mL amber glass bottles (adjusted to $\mathrm{pH} 5[<\mathrm{pKa}]$ ) $2 \mathrm{mg}$

Shyu et al $(1993)^{26}: 10-\mathrm{mg} / \mathrm{mL}$ solution packaged in $15-\mathrm{mL}$ amber glass bottles (adjusted to $\mathrm{pH} 5[<\mathrm{pKa}]$ )

$$
2 \mathrm{mg}^{\dagger}
$$

Shyu et al $(1994)^{24}: 10-\mathrm{mg} / \mathrm{mL}$ solution

(adjusted to $\mathrm{pH} 5[<\mathrm{pKa}]$ )

$$
1 \mathrm{mg}
$$

$\begin{array}{llll}0.1 \mathrm{~mL} & 1 & 20 & 1.46 \\ 0.2 \mathrm{~mL} & 2 & 15 & 4.13\end{array}$

$\begin{array}{lllll}0.1 \mathrm{~mL} & 1 & 26 & 1.67 & 80.2\end{array}$

$\begin{array}{lllll}0.2 \mathrm{~mL} & 2 & 23 & 3.38 & 77.6\end{array}$

$\begin{array}{lllll}0.2 \mathrm{~mL} & 2 & 53 & 1.51 & 48 \\ 0.2 \mathrm{~mL} & 2 & 49 & 1.68 & 71 \\ 0.2 \mathrm{~mL} & 2 & 55 & 1.56 & 69\end{array}$

$\begin{array}{llll}0.2 \mathrm{~mL} & 1 & 15 & 2.74\end{array}$

$\begin{array}{ccccc}0.2 \mathrm{~mL} & 2 & 15 & 3.01 & 72 \\ 0.2 \mathrm{~mL} & 2 & 45 & 1.61 & 69 \\ & & & & \\ 0.1 \mathrm{~mL} & 2 & 38-52 & 0.89-1.04 & 48-75\end{array}$




\begin{tabular}{|c|c|c|c|c|c|}
\hline Drug/Route/Study/Dose & $\begin{array}{l}\text { Volume } \\
\text { (mL) }\end{array}$ & $\begin{array}{l}\text { No. of } \\
\text { Sprays }\end{array}$ & $\begin{array}{l}\text { Tmax } \\
(\min )\end{array}$ & $\begin{array}{c}\text { Cmax } \\
(\mathrm{ng} / \mathrm{mL})\end{array}$ & $\begin{array}{l}F \\
(\%)\end{array}$ \\
\hline $\begin{array}{l}\text { Vachharajani et al }(199 \\
{[<\text { pKa]) }}\end{array}$ & \multicolumn{4}{|c|}{ Vachharajani et al $(1997)^{28}: 10-\mathrm{mg} / \mathrm{mL}$ solution (adjusted to $\mathrm{pH} 5$} & \\
\hline $1 \mathrm{mg}$ & $0.1 \mathrm{~mL}$ & 1 & 15 & 1.54 & - \\
\hline \multicolumn{6}{|c|}{$\begin{array}{l}\text { Wermeling et al }(2005)^{29}: 10-\mathrm{mg} / \mathrm{mL} \text { solution (adjusted to } \mathrm{pH} 5 \\
[<\mathrm{pKa}])\end{array}$} \\
\hline $2 \mathrm{mg}$ & $0.2 \mathrm{~mL}$ & 2 & 10 & 5.56 & - \\
\hline \multicolumn{6}{|l|}{ Oral } \\
\hline \multicolumn{6}{|c|}{ Pachter and Evens $(1985)^{57}$} \\
\hline $8 \mathrm{mg}$ & - & - & $60-90$ & 0.07 & 17 \\
\hline \multicolumn{6}{|l|}{ Intravenous } \\
\hline \multicolumn{6}{|l|}{ Davis et al $(2005)^{12}$} \\
\hline $2.0 \mathrm{mg}$ & $2 \mathrm{~mL}$ & - & 17 & 10.32 & - \\
\hline \multicolumn{6}{|l|}{ Shyu et al $(1994)^{24}$} \\
\hline $1.0 \mathrm{mg}$ & $1 \mathrm{~mL}$ & - & - & $2.94-5.50$ & - \\
\hline
\end{tabular}

\section{Fentanyl}

Intranasal

Lim et al $(2003)^{20}: 10-\mathrm{mg} / \mathrm{mL}$ aqueous nasal solution of 0.3

$\mathrm{mg} / \mathrm{mL}$ (as fentanyl base) adjusted with sodium chloride

(buffered to $\mathrm{pH} 6[<\mathrm{pKa}]$ and $\mathrm{pH} 8[\sim \mathrm{pKa}]$ )

$\mathrm{pH}$ 6: $0.05 \mathrm{mg}$
$\mathrm{pH}$ 8: $0.05 \mathrm{mg}$

Christrup et al $(2008)^{30}: 0.75$ and $1.0 \mathrm{mg} / \mathrm{mL}$ fentanyl citrate in isotonic phosphate buffer (buffered to $\mathrm{pH} 6.4$ and 6.3 [<pKa])
$0.075 \mathrm{mg}$
$0.10 \mathrm{mg}$
$0.15 \mathrm{mg}$
$0.20 \mathrm{mg}$

Moksnes et al $(2008)^{31}: 0.50 \mathrm{mg} / \mathrm{mL}$ fentanyl citrate solution (ionization not stated)

$0.05 \mathrm{mg}$

$\begin{array}{lllll}0.18 \mathrm{~mL} & 1 & 5 & 0.36 & 55 \\ 0.18 \mathrm{~mL} & 1 & 5 & 0.38 & 71\end{array}$

Oral (transmucosal)

Darwish et al (2007) $)^{58}$

$0.8 \mathrm{mg}$

Intravenous

Christrup et al (2008)

$0.075 \mathrm{mg}$
$0.10 \mathrm{mg}$
$0.15 \mathrm{mg}$
$0.20 \mathrm{mg}$

\section{Hydromorphone $\mathrm{HCl}$}

Intranasal

Coda et al (2003) ${ }^{11}$ : $10 \mathrm{mg}$ hydromorphone $\mathrm{HCl}$ per milliliter with

$0.2 \%$ sodium citrate and $0.2 \%$ citric acid solution (buffered to $\mathrm{pH}$

6.4 and $6.3[<\mathrm{pKa}])$

$\begin{array}{llllll}1 \mathrm{mg} & 0.1 \mathrm{~mL} & 1 & 20 & 1.743 & 52.4 \\ 2 \mathrm{mg} & 0.2 \mathrm{~mL} & 2 & 25 & 3.543 & 57.5\end{array}$




\begin{tabular}{|c|c|c|c|c|c|}
\hline Drug/Route/Study/Dose & $\begin{array}{c}\text { Volume } \\
(\mathrm{mL})\end{array}$ & $\begin{array}{l}\text { No. of } \\
\text { Sprays }\end{array}$ & $\begin{array}{l}T \max \\
(\min )\end{array}$ & $\begin{array}{c}\text { Cmax } \\
(\mathrm{ng} / \mathrm{mL})\end{array}$ & $\begin{array}{c}F \\
(\%)\end{array}$ \\
\hline No pre ${ }^{\dagger}: 2 \mathrm{mg}$ & $0.1 \mathrm{~mL}$ & 2 & 20 & 3.69 & 59.8 \\
\hline $\operatorname{Pre}^{+}: 2 \mathrm{mg}$ & $0.2 \mathrm{~mL}$ & 2 & 21.5 & 3.38 & 54.4 \\
\hline \multicolumn{6}{|c|}{$\begin{array}{l}\text { Davis et al }(2004)^{13}: 1 \mathrm{mg} / 0.1 \mathrm{~mL} \text { spray with } 0.2 \% \text { sodium citrate } \\
\text { and } 0.2 \% \text { citric acid } \\
\text { (buffered to } \mathrm{pH} 5[<\mathrm{pKa}] \text { ) }\end{array}$} \\
\hline No pre ${ }^{\ddagger}: 2 \mathrm{mg}$ & $0.2 \mathrm{~mL}$ & 2 & 15 & 3.56 & 46.9 \\
\hline $\operatorname{Pre}^{\ddagger}: 2 \mathrm{mg}$ & $0.2 \mathrm{~mL}$ & 2 & 30 & 3.02 & 51.9 \\
\hline \multicolumn{6}{|c|}{ Rudy et al $(2004)^{21}: 10 \mathrm{mg}$ hydromorphone $\mathrm{HCl}$ per milliliter with } \\
\hline \multicolumn{6}{|c|}{$0.2 \%$ sodium citrate and $0.2 \%$ citric acid solution (buffered to $\mathrm{pH}$} \\
\hline $1 \mathrm{mg}$ & $0.1 \mathrm{~mL}$ & 1 & 20 & 2.4 & - \\
\hline $2 \mathrm{mg}$ & $0.2 \mathrm{~mL}$ & 2 & 20 & 4.1 & - \\
\hline \multicolumn{6}{|c|}{$\begin{array}{l}\text { Lim et al }(2008)^{32} \text { : Hydromorphone } \mathrm{HCl} 50 \mathrm{mg} / 5 \mathrm{~mL} \text { injection was } \\
\text { used as the nasal solution in one group; } 0.5 \% \mathrm{CHI} \text { was added to } \\
\text { the same solution in the other group (ionization not stated) }\end{array}$} \\
\hline No $\mathrm{CHI}^{\S}: 2 \mathrm{mg}$ & $0.2 \mathrm{~mL}$ & 1 & 15 & 0.87 & 50 \\
\hline $\mathrm{CHI}^{\S}: 2 \mathrm{mg}$ & $0.2 \mathrm{~mL}$ & 1 & 10 & 1.30 & 68 \\
\hline \multicolumn{6}{|l|}{ Oral } \\
\hline \multicolumn{6}{|l|}{ Vallner et al $(1981)^{59}$ : } \\
\hline $4 \mathrm{mg}$ & - & - & 60 & 22.0 & 62 \\
\hline \multicolumn{6}{|l|}{ Intravenous } \\
\hline \multicolumn{6}{|l|}{ Coda et al $(2003)^{11}$} \\
\hline $2 \mathrm{mg}$ & $0.2 \mathrm{~mL}$ & - & 10 & 33.21 & - \\
\hline \multicolumn{6}{|c|}{ Davis et al $(2004)^{14}$ : Formulation not stated } \\
\hline $2 \mathrm{mg}$ & $0.2 \mathrm{~mL}$ & - & 10 & 32.48 & - \\
\hline \multicolumn{6}{|c|}{$\begin{array}{l}\text { Davis et al }(2004)^{13}: 1-\mathrm{mg} / 0.1 \mathrm{~mL} \text { spray with } 0.2 \% \text { sodium citrate } \\
\text { and } 0.2 \% \text { citric acid } \\
\text { (buffered to } \mathrm{pH} 5[<\mathrm{pKa}] \text { ) }\end{array}$} \\
\hline $2 \mathrm{mg}$ & $0.2 \mathrm{~mL}$ & - & 10 & 34.76 & - \\
\hline
\end{tabular}

\begin{tabular}{l} 
Methadone \\
Intranasal \\
$\quad \begin{array}{l}\text { Dale et al }(2002)^{3}: \text { Dissolved methadone in sterile water to a } \\
\text { concentration of } 50 \mathrm{mg} / \mathrm{mL} \\
\quad \text { pH } 5.4[<\mathrm{pKa}]) \\
\quad 10 \mathrm{mg}\end{array}$ \\
$\begin{array}{l}\text { Oral } \\
\text { Dale et al (2002) } \\
\quad 10 \mathrm{mg}\end{array}$ \\
$\begin{array}{l}\text { Intravenous } \\
\text { Dale et al (2002) } \\
\quad 10 \mathrm{mg}\end{array}$ \\
\hline
\end{tabular}

\section{Morphine}

Intranasal

Fitzgibbon et al $(2003)^{17}$ : Contained a soluble morphine

gluconate salt, citrate buffer, antioxidant (sodium

metabisulfite), humectant (glycerine), benzalkonium chloride,

oleic acid, and polysorbate 20 (buffered) 


\begin{tabular}{|c|c|c|c|c|c|}
\hline Drug/Route/Study/Dose & $\begin{array}{c}\text { Volume } \\
(\mathrm{mL})\end{array}$ & $\begin{array}{l}\text { No. of } \\
\text { Sprays }\end{array}$ & $\begin{array}{l}\text { Tmax } \\
(\min )\end{array}$ & $\begin{array}{c}\mathrm{Cmax} \\
(\mathrm{ng} / \mathrm{mL})\end{array}$ & $\begin{array}{l}F \\
(\%)\end{array}$ \\
\hline $40 \mathrm{mg}$ & $0.2 \mathrm{~mL}$ & 2 & 21.6 & 64 & 22 \\
\hline \multicolumn{6}{|l|}{ Illum et al $(2002)^{19}$} \\
\hline \multicolumn{6}{|l|}{$\begin{array}{l}0.25 \mathrm{~g} \mathrm{CHI} \text { glutamate in ultrapure water, adding } 2.0 \mathrm{~g} \\
\text { morphine } \mathrm{HCl} \text { and } 0.185 \mathrm{~g} \text { sodium chloride and adjusting } \\
\text { the } \mathrm{pH} \text { to } 4 \text { with } 1 \mathrm{M} \text { hydrochloric acid (adjusted to } \mathrm{pH} 4 \\
{[<\mathrm{pKa}] \text { ) }}\end{array}$} \\
\hline \multicolumn{6}{|l|}{$\begin{array}{l}\text { based on } \mathrm{CHI} \text { powder was prepared by blending manually } \\
1.3 \mathrm{~g} \text { morphine } \mathrm{HCl} \text { and } 6.7 \mathrm{~g} \mathrm{CHI} \text { glutamate (adjusted to } \\
\mathrm{pH} 4[<\mathrm{pKa}])^{\pi}\end{array}$} \\
\hline \multicolumn{6}{|l|}{ Oral } \\
\hline \multicolumn{6}{|l|}{ Micromedex ${ }^{6}$} \\
\hline $100 \mathrm{mg}$ & - & - & 54 & 64.4 & 20.40 \\
\hline \multicolumn{6}{|l|}{ Illum et al $(2002)^{19}$} \\
\hline $10 \mathrm{mg}$ & - & - & - & 96.1 & - \\
\hline \multicolumn{6}{|l|}{ Oxycodone } \\
\hline \multicolumn{6}{|l|}{ Intranasal } \\
\hline \multicolumn{6}{|l|}{ Takala et al $(1997)^{27}$} \\
\hline \multicolumn{6}{|l|}{ Oxycodone $\mathrm{HCl} 10 \mathrm{mg} / \mathrm{mL}$ (ionization not stated) } \\
\hline $6.7 \mathrm{mg}$ & $0.67 \mathrm{~mL}$ & - & 25 & 13 & 46 \\
\hline \multicolumn{6}{|l|}{ Oral } \\
\hline \multicolumn{6}{|l|}{ Mandema et al (1996) $)^{60}$} \\
\hline $20 \mathrm{mg}$ & - & - & 90 & 41.6 & - \\
\hline \multicolumn{6}{|l|}{ Micromedex ${ }^{6}$} \\
\hline Two $10-\mathrm{mg}$ controlled-release tablets & - & - & - & - & $60-87$ \\
\hline \multicolumn{6}{|l|}{ Sufentanil $^{\#}$} \\
\hline \multicolumn{6}{|l|}{ Intranasal } \\
\hline \multicolumn{6}{|l|}{ Helmers et al $(1989)^{18}$ : Formulation and ionization not stated } \\
\hline $0.015 \mathrm{mg}$ & 6 drops & 6 drops & 10 & 0.080 & 78 \\
\hline \multicolumn{6}{|l|}{ Intravenous } \\
\hline \multicolumn{6}{|l|}{ Helmers et al $(1989)^{18}$} \\
\hline $0.015 \mathrm{mg}$ & - & - & - & 0.20 & - \\
\hline
\end{tabular}

$\mathrm{F}=$ treatment ratio; $\mathrm{HCl}=$ hydrochloride; $\mathrm{pKa}=$ negative logarithm of the acid ionization constant; $\mathrm{CHI}=$ chitosan.

*No oral or intravenous formulations were administered.

† Nasal butorphanol without pretreatment of the vasoconstrictor oxymetazoline.

₹ Nasal butorphanol without pretreatment of fluticasone propionate $200 \mu \mathrm{g}$.

$\S$ No chitosan added to hydromorphone solution.

"Nasal solution formulation of morphine-containing $\mathrm{CHI}$.

I Nasal morphine formulation based on $\mathrm{CHI}$ powder.

\# No oral formulation was administered. 
Table VI. Reported outcomes in studies on benzodiazepines selected for a review on the clinical pharmacokinetics of drugs delivered intranasally.

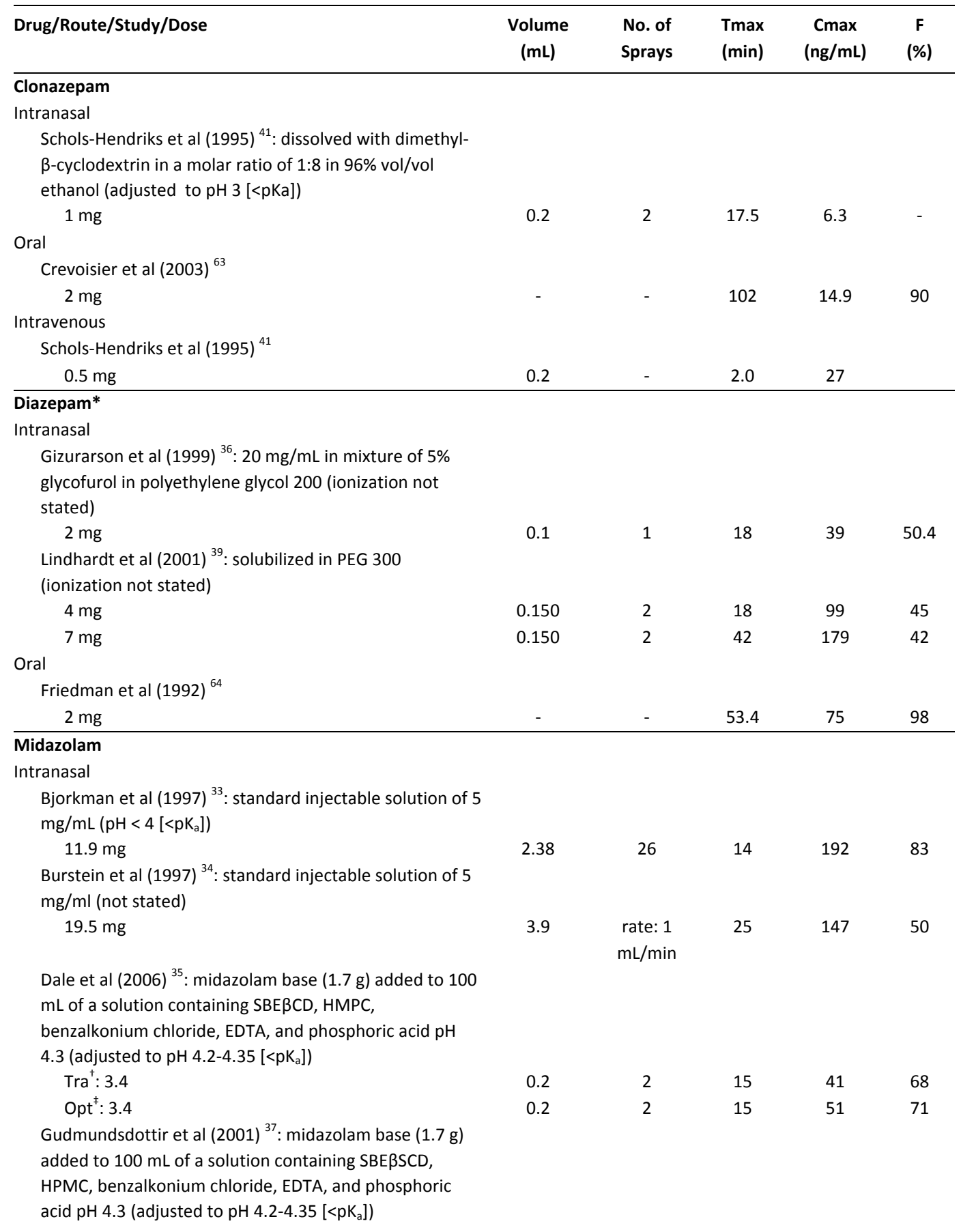




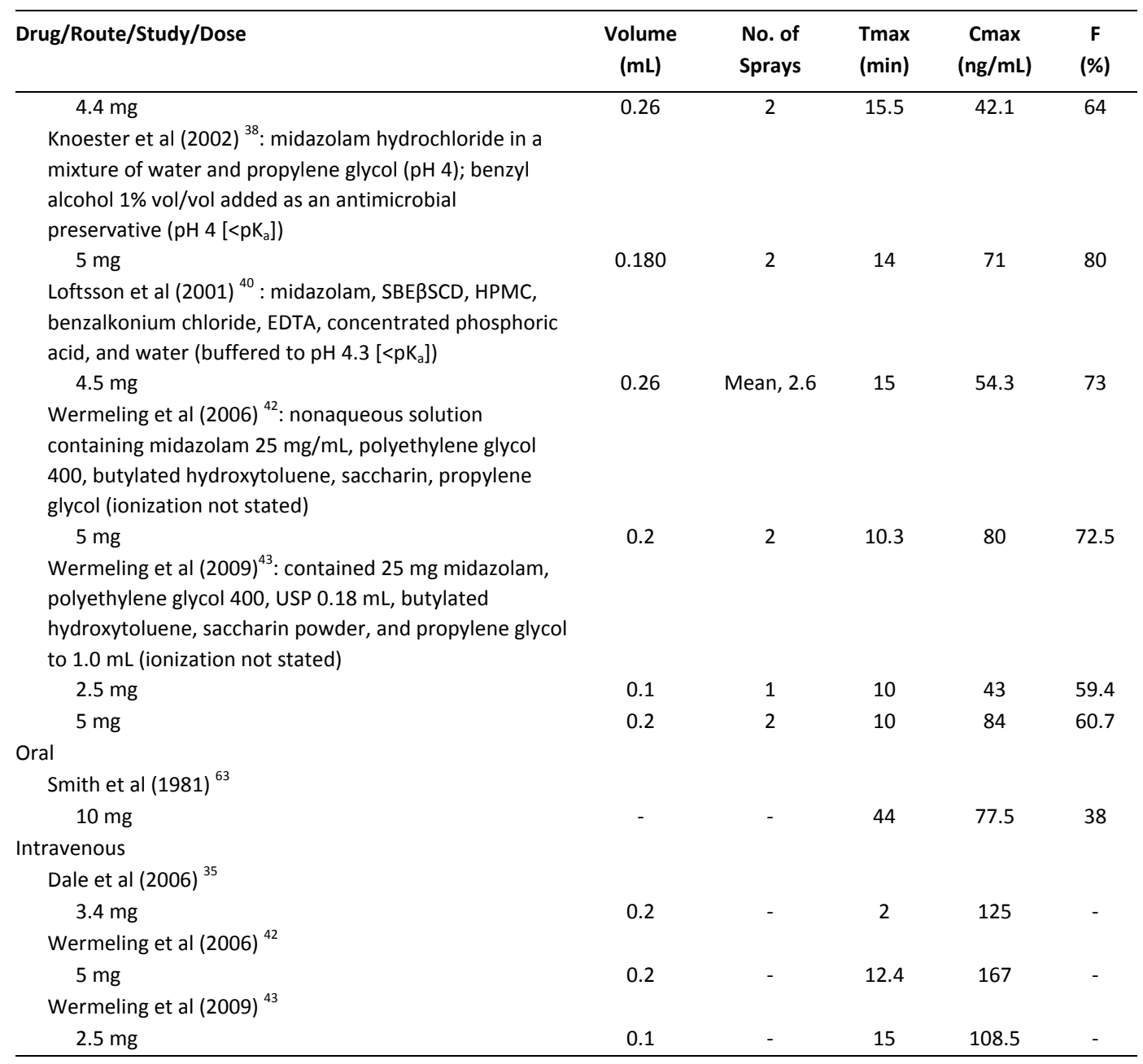

$\mathrm{SBE} \beta C D=$ sulfobutylether $-\beta$-cyclodextrin; $\mathrm{HMPC}=$ hydroxypropyl methylcellulose $4000 ; \mathrm{F}=$ treatment ratio; USP = US Pharmacopeia.

*No intravenous formulation was administered.

† Nasal administration by a standard (conventional) multidose spray pump.

‡ Nasal administration by Optimist ${ }^{\circledR}$ (Optinose, Oslo, Norway). 
Table VII Reported outcomes in studies on antimigraine drugs selected for a review on the clinical pharmacokinetics of drugs delivered intranasally.

\begin{tabular}{|c|c|c|c|c|c|}
\hline Drug/Route/Study/Dose & $\begin{array}{l}\text { Volume } \\
\text { (mL) }\end{array}$ & $\begin{array}{l}\text { No. of } \\
\text { Sprays }\end{array}$ & $\begin{array}{l}\text { Tmax } \\
(\min )\end{array}$ & $\begin{array}{c}\text { Cmax } \\
(\mathrm{ng} / \mathrm{mL})\end{array}$ & $\begin{array}{c}F \\
(\%)\end{array}$ \\
\hline \multicolumn{6}{|l|}{ Dihydroergotamine } \\
\hline \multicolumn{6}{|l|}{ Intranasal } \\
\hline \multicolumn{6}{|l|}{ Humbert et al (1996) ${ }^{45}$} \\
\hline $1 \mathrm{mg}$ & 0.25 & 2 & 56 & 1.02 & $38.4-40.7$ \\
\hline \multicolumn{6}{|c|}{$\begin{array}{l}\text { Van der Kuy et al }(1999)^{46}: \text { DHEM/RAMEB (ionization } \\
\text { not stated) }\end{array}$} \\
\hline 2 mg* & 0.5 & 4 & 42 & 1.8 & 21 \\
\hline $2 \mathrm{mg}^{\dagger}$ & 0.2 & 2 & 52 & 2.0 & 25 \\
\hline 2 mg powder $\ddagger$ & - & - & 33 & 1.3 & 19 \\
\hline \multicolumn{6}{|l|}{ Oral } \\
\hline \multicolumn{6}{|l|}{ Van der Kuy et al (1999) ${ }^{46}$} \\
\hline $2 \mathrm{mg} *$ & - & - & 75 & 0.4 & 8 \\
\hline
\end{tabular}

\section{Hydroxocobalamin}

Intranasal

Lonterman et al $(2000)^{47}$ : hydroxocobalamin $750 \mu \mathrm{g} / 70$

$\mu \mathrm{L}$ preservative solution (ionization not stated)

$1.5 \mathrm{mg} /$ day for 7 days followed by $1.5 \mathrm{mg} / \mathrm{wk}$ for 3 weeks

Van Asselt et al (1998) ${ }^{48}$ : hydroxocobalamin 750

$\mu \mathrm{g} / 70 \mu \mathrm{L}$ preservative solution (ionization not stated)

$\begin{array}{lllll}0.75 \mathrm{mg} & 0.07 & 1 & 35 & 1.9 \mathrm{nmol} / \mathrm{L} \\ 1.5 \mathrm{mg} & 0.14 & 2 & 28 & 3.5 \mathrm{nmol} / \mathrm{L}\end{array}$

Van der Kuy et al (2001) $)^{495}$ : hydroxocobalamin nasal spray containing (per milliliter) hydroxocobalamin $50 \mathrm{mg}$, sodium acetate $2.7 \mathrm{mg}$, sodium chloride $5.5 \mathrm{mg}$, sodium edetate $1 \mathrm{mg}$, and benzalkonium chloride $0.1 \mathrm{mg}(\mathrm{pH} 4.5)$

$10 \mathrm{mg}$

Oral van der Kuy et al (2001) $)^{49}$

$$
10 \mathrm{mg}
$$

0

\section{Rizatriptan}

Intranasal

Chen et al (2005) ${ }^{44}$

$5 \mathrm{mg}$

0.14

2

31.8

14.36

38

Oral

Chen et al (2005) ${ }^{44}$

$$
5 \mathrm{mg}
$$

$-$

75

14.26

40

\section{Sumatriptan}

Intranasal

Duquesnoy et al (1998)

$20 \mathrm{mg}$

0.1

1

90

12.9

15.8

Moore et al $(1997)^{51}$ :aqueous formulation of the hemisulfate salt ( $20 \mathrm{mg}$ base equivalent $/ 100 \mu \mathrm{L}$ ) (ionization not stated) 


\begin{tabular}{|c|c|c|c|c|c|}
\hline Drug/Route/Study/Dose & $\begin{array}{l}\text { Volume } \\
(\mathrm{mL})\end{array}$ & $\begin{array}{l}\text { No. of } \\
\text { Sprays }\end{array}$ & $\begin{array}{l}\operatorname{Tmax} \\
(\min )\end{array}$ & $\begin{array}{c}\mathrm{Cmax} \\
(\mathrm{ng} / \mathrm{mL})\end{array}$ & $\begin{array}{l}F \\
(\%)\end{array}$ \\
\hline $5 \mathrm{mg}$ & 0.1 & 1 & 60 & 4.7 & - \\
\hline $10 \mathrm{mg}$ & 0.1 & 1 & 90 & 8.5 & - \\
\hline $20 \mathrm{mg}$ & 0.1 & 1 & 60 & 14.4 & - \\
\hline \multicolumn{6}{|l|}{ Oral } \\
\hline \multicolumn{6}{|l|}{ Duquesnoy et al $(1998)^{50}$} \\
\hline $25 \mathrm{mg}$ & 0.1 & - & 90 & 16.5 & 14.3 \\
\hline \multicolumn{6}{|l|}{ Zolmitriptan } \\
\hline \multicolumn{6}{|l|}{ Intranasal } \\
\hline \multicolumn{6}{|l|}{ Kagedal et al $(2005)^{52}$} \\
\hline 5-mg AC (ionization not stated) & 0.1 & 1 & 15 & 3.3 & - \\
\hline 5-mg NAC (ionization not stated) & 0.1 & 1 & 120 & 7.3 & - \\
\hline \multicolumn{6}{|c|}{ Uemura et al $(2005)^{53}$ : ionization not stated } \\
\hline $2.5 \mathrm{mg}$ & 0.1 & 1 & 240 & 3.31 & - \\
\hline $5 \mathrm{mg}$ & 0.1 & 1 & 240 & 6.61 & - \\
\hline \multicolumn{6}{|l|}{$\begin{array}{l}\text { Yates et al }(2002)^{54} \text { : spray solution } \\
\text { (buffered to } \mathrm{pH} 5[<\mathrm{pKa}] \text { ) }\end{array}$} \\
\hline $0.5 \mathrm{mg}$ & 0.1 & 1 & 90 & 0.91 & - \\
\hline $1 \mathrm{mg}$ & 0.1 & 1 & 150 & 0.99 & - \\
\hline $2.5 \mathrm{mg}$ & 0.1 & 1 & 120 & 3.63 & - \\
\hline $5 \mathrm{mg}$ & 0.1 & 1 & 105 & 6.51 & - \\
\hline \multicolumn{6}{|l|}{ Yates et al $(2002)^{55}$} \\
\hline pH 7.4: 2.5 mg (<pKa) & 0.1 & 1 & 180 & 4.13 & - \\
\hline pH 5.0: 2.5 mg (<pKa) & 0.1 & 1 & 165 & 3.93 & - \\
\hline \multicolumn{6}{|l|}{ Oral } \\
\hline \multicolumn{6}{|l|}{ Kagedal et al $(2005)^{52}$} \\
\hline \multirow[t]{2}{*}{$5-m g A C^{\prime \prime}$} & - & - & \multicolumn{2}{|c|}{ ConcentrationConcentration } & - \\
\hline & & & $<$ LLOQ & $<L L O Q$ & \\
\hline 5-mg NAC & - & - & 120 & 6.4 & - \\
\hline \multicolumn{6}{|l|}{ Uemura et al $(2005)^{53}$} \\
\hline $2.5 \mathrm{mg}$ & - & - & 90 & 4.28 & - \\
\hline $5 \mathrm{mg}$ & - & - & 120 & 7.51 & - \\
\hline \multicolumn{6}{|l|}{ Yates et al $(2005)^{55}$} \\
\hline $2.5 \mathrm{mg}$ & - & - & 105 & 4.48 & - \\
\hline
\end{tabular}

$\mathrm{F}=$ treatment ratios; $\mathrm{DHEM} / \mathrm{RAMEB}=$ dihydroergotamine mesilate/randomly methylated $\beta$-cyclodextrin; $\mathrm{AC}=$ activated charcoal; $\mathrm{NAC}=$ no activated charcoal; $\mathrm{pKa}=$ negative logarithm of the acid ionization constant; $L L O Q=$ lower limit of quantitation.

*Contains dihydroergotamine $4 \mathrm{mg} / \mathrm{mL}$, dextrose $50 \mathrm{mg} / \mathrm{mL}$, and caffeine $10 \mathrm{mg} / \mathrm{mL}$.

+Contains dihydroergotamine $10 \mathrm{mg} / \mathrm{mL}$, RAMEB $20 \mathrm{mg} / \mathrm{mL}$, and mannitol $50 \mathrm{mg} / \mathrm{mL}$.

‡Contains dihydroergotamine $2 \mathrm{mg}$, RAMEB $4 \mathrm{mg}$, and lactose $4 \mathrm{mg}$.

$\S$ Parameters could not be calculated because per-oral curve was not significantly different from baseline.

"All concentrations were below LLOQ. 


\section{Discussion}

An alternative noninvasive method of drug administration, with the opportunity to titrate to individual needs, is desirable in clinical practice. The intranasal formulation might offer a noninvasive delivery formulation with rapid absorption. The rich vasculature and numerous microvilli of the nasal cavity might enhance the rate and extent of absorption of systemically effective drugs. Avoiding first-pass elimination, intranasal drug delivery may improve the pharmacokinetic parameters. Three groups of drugs (opioids, benzodiazepines, and antimigraine drugs) that are systemically delivered and have a central point of action were studied in this review.

All of the opioids included in this review had a short $t_{\max }$ ( $\leq 25$ minutes), which may be correlated with a rapid onset of action. However, because most of the study drugs were tested in healthy volunteers, pharmacodynamic results could not be researched. Bioavailability in general was good, $>50 \%$, suggesting that most of the study drugs were suitable for intranasal drug delivery.

For 3 drugs - butorphanol, fentanyl, and morphine - there were apparent differences in pharmacokinetic parameters between studies. With butorphanol, the differences in $t_{\max }$ and $C_{\max }$ between studies were likely the result of the use of different spray devices. Butorphanol in unit-dose sprayers was found to have faster $[12,13]$ and greater [29] absorption compared with administration through multidose sprayers $[23,24,26,29]$.

Furthermore, some studies used a buffer to set the desired $\mathrm{pH}[12,13]$ whereas others only adjusted the $\mathrm{pH}[23-26,28,29]$. Also, differences might have been the result of the use of different formulations, differences in doses administered, and the ages of the subjects. Differences in $t_{\max }$ and bioavailability between studies of intranasal fentanyl were found. The study by Lim et al [20] reported a difference in intranasal fentanyl $\mathrm{F}$ ( $55 \%$ and $71 \%$ ), which may have been related to differences in $\mathrm{pH}$ value. The pKa of fentanyl is 8.4. At pH 6, all of the fentanyl in the solution would have been ionized, whereas at $\mathrm{pH} 8,60 \%$ would have been ionized. The non-ionized fentanyl would be expected to cross the mucosal membrane more readily, resulting in a higher bioavailability. With intranasal morphine, a difference between studies was seen in $C_{\max }$ and $F(22 \%$ vs $56 \%)$ - likely the result of a difference between the formulations administered. The study by Fitzgibbon et al [17] used a buffer, and the study by Illum et al [19] adjusted the $\mathrm{pH}$. Another possible explanation for the observed differences in pharmacokinetics might have been the differences in the patient populations between studies, as the study by Fitzgibbon et al [17] included patients with chronic pain, whereas Illum et al [19] included healthy volunteers.

With all opioids, all pharmacokinetic parameters ( $t_{\max }, C_{\max }$, and $F$ ) of the intravenous formulations were ranked highest, followed by the intranasal and oral formula- 
tions. Oral bioavailability was greater compared with intranasal bioavailability only with oxycodone. The pharmacokinetic data of all of the studies of opioids support the use of noninvasive intranasal drug delivery when a fast onset is indicated.

With the intranasal benzodiazepines, a $t_{\max }$ of $\leq 25$ minutes was reported. Because bioavailability was $42 \%$ to $90 \%$, all of the drugs in this class might be suitable for intranasal delivery when fast, noninvasive delivery is indicated.

Pharmacokinetic data were consistent between most of the studies of the benzodiazepines. With diazepam, the differences in $t_{\max }$ might have been related to differences in the dosages administered [39]. With midazolam, one study reported a lower bioavailability [34] compared with those found in other studies. That study used a commercially available solution of midazolam $5 \mathrm{mg} / \mathrm{mL}$. Likely because intranasal midazolam was applied quickly (5 mg/min) in that study, bioavailability was $50 \%$ [34]. However, in another study of the commercially available solution, $\mathrm{F}$ was $83 \%$, likely as a result of slow administration $(0.27 \mathrm{mg} / \mathrm{min})$ [34]. The large volumes required for the delivery of a therapeutic dose and the different administration rates exceeded the capacity of the nasal cavity in the study of the intranasal formulation by Burstein et al [34]. The consequence likely was pharyngeal deposition, swallowing, gut absorption, and possible presystemic metabolism of the swallowed part of the dose [33].

$\mathrm{T}_{\max }$ was shorter with all 3 substances (clonazepam, diazepam, and midazolam) when they were administered intranasally compared with orally (range, 10-25 vs 24102 minutes, respectively). The oral bioavailabilities for clonazepam and diazepam were found to be high ( $90 \%$ and $98 \%$, respectively). With midazolam, on the other hand, intranasal bioavailability was higher than oral bioavailability. The pharmacokinetic properties (all pharmacokinetic parameters were better with intranasal administration compared with oral administration) reported with intranasal midazolam suggest that intranasal delivery is more suitable for indications of fast delivery compared with the oral formulation. An advantage of intranasal midazolam compared with, for example, rectal administration of a benzodiazepine, such as diazepam, is the ease of administration of an intranasal spray. During epileptic seizures, a patient might not be able to self-administer a medication. For patients and their families, a nasal spray may be preferable to a rectal formulation.

With the antimigraine drugs, differences in the pharmacokinetic properties between studies of intranasal dihydroergotamine, intranasal hydroxocobalamin, and intranasal zolmitriptan were found. With dihydroergotamine, differences in bioavailability were found between 2 studies $[45,46]$, which might have been related to the use of different methods of analysis. A difference in $\mathrm{C}_{\max }$ was seen with hydroxocobalamin, likely resulting from the different doses administered.

With zolmitriptan, a difference in $t_{\max }$ was found between 2 studies [52,33]. In a study by Kagedal et al [52], the pharmacokinetics of zolmitriptan with and without activated 
charcoal was studied. Activated charcoal has been used to prevent drug absorption in overdoses or poisonings and has also been used to assess pulmonary bioavailability of inhalational drugs. When zolmitriptan was administered intranasally with orally administered charcoal, $t_{\max }$ was shorter compared with zolmitriptan without charcoal (15 vs 120 minutes). Uemura et al [53] reported a longer $t_{\max }$ (240 minutes) compared with those found in other studies (range, 90-180 minutes). This difference might have been related to the inclusion of Japanese subjects $[64,65]$.

With dihydroergotamine, $C_{\max }$ was reached faster and bioavailability was greater after intranasal administration compared with oral administration. Thus administration of this drug appeared suitable. No significant differences in baseline values were found between oral and intranasal hydroxocobalamin. In general, with the triptans, pharmacokinetic data were similar with intranasal and oral administration. This finding might have been the result of intranasal absorption after first-pass metabolism, followed by second-phase absorption in the gastrointestinal tract, which was studied by Kagedal et al [52]. The study reported that $30 \%$ of total exposure to zolmitriptan after single-dose intranasal administration was attributable to intranasal absorption. During the first hours after administration, intranasal absorption contributed most to the pharmacokinetic parameters. Those data supported the hypothesis that intranasally administered triptans mostly follow the same route as oral treatment, also referred to as a naso-oral effect [66] because most of the drug was found to have been absorbed through the gastrointestinal tract. Although triptan intranasal sprays offered comparable naso-oral characteristics, they may be useful in patients with gastrointestinal disturbances during their migraine attacks and in those with difficulties in swallowing an oral formulation (eg, tablet).

\section{Conclusions}

The findings from this review of data from the available literature suggest that intranasal administration of compounds of all 3 therapeutic groups is suitable for indications of fast delivery. Concerning different parameters, however, it depends on the intended effect which kind of drug and drug device is preferred. This review describes that the pharmacokinetic parameters differ between drugs administered intranasally, orally, and intravenously (intravenous $>$ intranasal $>$ oral). 


\section{References}

1. Chien YW, Chang SF. Intranasal drug delivery for systemic medications. Crit Rev Ther Drug Carrier Syst. 1987;4:67-194.

2. Costantino HR, Illum L, Brandt G, et al. Intranasal delivery: Physicochemical and therapeutic aspects. Int J Pharm. 2007;337:1-24.

3. Dale O, Hoffer C, Sheffels P, Kharasch ED. Disposition of nasal, intravenous, and oral methadone in healthy volunteers. Clin Pharmacol Ther. 2002;72:536-545.

4. Illum L. Nasal drug delivery-possibilities, problems and solutions. J Control Release. 2003;87:187-198.

5. Costantino HR, Sileno AP, Johnson PH. Pharmacokinetic attributes of intranasal delivery: Case study and new opportunities. http://www.ondrugdelivery.com/publications/ NASAL\%20FINAL\%20Lo-res.pdf. Accessed April 2009.

6. Micromedex. www.micromedex.com. Accessed April 2009.

7. Beers MH, Porter RS, Jones TV, et al, eds. The Merck Manual of Diagnosis and Therapy. 18th ed. Whitehouse Station, NJ: Merck Research Laboratories; 2006.

8. Drummond M, Sculpher M, Torrance G, et al. Methods for the Economic Evaluation of Health Care Programmes. 3rd ed. New York, NY: Oxford University Press; 2005.

9. Centre for Reviews and Dissemination. Undertaking systematic reviews on effectiveness: CRD's guidance for those carrying out or commissioning reviews. CRD Report 4 (2nd edition). www.york.ac.uk/inst/crd/report4. htm. Accessed April 2009.

10. Neef C, van Laar T. Pharmacokinetic-pharmacodynamic relationships of apomorphine in patients with Parkinson's disease. Clin Pharmacokinet. 1999;37:257-271.

11. Coda BA, Rudy AC, Archer SM, Wermeling DP. Pharmacokinetics and bioavailability of single-dose intranasal hydromorphone hydrochloride in healthy volunteers. Anesth Analg. 2003;97:117-123.

12. Davis GA, Rudy AC, Archer SM, Wermeling DP. Bioavailability of intranasal butorphanol administered from a single-dose sprayer. Am J Health Syst Pharm. 2005;62:48-53.

13. Davis GA, Rudy AC, Archer SM, Wermeling DP. Pharmacokinetics of butorphanol tartrate administered from single-dose intranasal sprayer. Am J Health Syst Pharm. 2004;61:261-266.

14. Davis GA, Rudy AC, Archer SM, et al. Bioavailability and pharmacokinetics of intranasal hydromorphone in patients experiencing vasomotor rhinitis. Clin Drug Investig. 2004;24:633-639.

15. Davis GA, Rudy AC, Archer SM, et al. Effect of fluticasone propionate nasal spray on bioavailability of intranasal hydromorphone hydrochloride in patients with allergic rhinitis. Pharmacotherapy. 2004;24:26-32.

16. Eriksen J, Jensen $\mathrm{NH}$, Kamp-Jensen $\mathrm{M}$, et al. The systemic availability of buprenorphine administered by nasal spray. J Pharm Pharmacol. 1989;41:803-805.

17. Fitzgibbon D, Morgan D, Dockter D, et al. Initial pharmacokinetic, safety and efficacy evaluation of nasal morphine gluconate for breakthrough pain in cancer patients. Pain. 2003;106:309-315.

18. Helmers $\mathrm{JH}$, Noorduin $\mathrm{H}$, Van Peer A, et al. Comparison of intravenous and intranasal sufentanil absorption and sedation. Can J Anaesth. 1989;36:494-497.

19. Illum L, Watts P, Fisher AN, et al. Intranasal delivery of morphine. J Pharmacol Exp Ther. 2002;301:391400.

20. Lim SC, Paech MJ, Sunderland VB, et al. Pharmacokinetics of nasal fentanyl. J Pharm Pract Res. 2003;33:59-63.

21. Rudy AC, Coda BA, Archer SM, Wermeling DP. A multiple-dose phase I study of intranasal hydromorphone hydrochloride in healthy volunteers. Anesth Analg. 2004;99:1379-1386.

22. Schwagmeier R, Boerger N, Meissner W, Striebel HW. Pharmacokinetics of intranasal alfentanil. J Clin Anesth. 1995;7:109-113. 
23. Shyu WC, Mayol RF, Pfeffer M, et al. Biopharmaceutical evaluation of transnasal, sublingual, and buccal disk dosage forms of butorphanol. Biopharm Drug Dispos. 1993;14:371-379.

24. Shyu WC, Morgenthien EA, Pittman KA, Barbhaiya RH. The effects of age and sex on the systemic availability and pharmacokinetics of transnasal butorphanol. Eur J Clin Pharmacol. 1994;47:57-60.

25. Shyu WC, Pittman KA, Robinson D, Barbhaiya RH. Multiple-dose phase I study of transnasal butorphanol. Clin Pharmacol Ther. 1993;54:34-41.

26. Shyu WC, Pittman KA, Robinson DS, Barbhaiya RH. The absolute bioavailability of transnasal butorphanol in patients experiencing rhinitis. Eur J Clin Pharmacol. 1993;45:559-562.

27. Takala A, Kaasalainen V, Seppälä $T$, et al. Pharmacokinetic comparison of intravenous and intranasal administration of oxycodone. Acta Anaesthesiol Scand. 1997;41:309-312.

28. Vachharajani NN, Shyu WC, Greene DS, Barbhaiya RH. The pharmacokinetics of butorphanol and its metabolites at steady state following nasal administration in humans. Biopharm Drug Dispos. 1997;18:191-202.

29. Wermeling DP, Miller JL, Archer SM, et al. Pharmacokinetics, bioequivalence, and spray weight reproducibility of intranasal butorphanol after administration with 2 different nasal spray pumps. J Clin Pharmacol. 2005;45:969-973.

30. Christrup LL, Foster D, Popper LD, et al. Pharmacokinetics, efficacy, and tolerability of fentanyl following intranasal versus intravenous administration in adults undergoing third-molar extraction: A randomized, double-blind, double-dummy, two-way, crossover study. Clin Ther. 2008;30:469-481.

31. Moksnes K, Fredheim OM, Klepstad P, et al. Early pharmacokinetics of nasal fentanyl: Is there a significant arterio-venous difference? Eur J Clin Pharmacol. 2008;64:497-502.

32. Lim CB, Paech MJ, Goy R, et al. Pharmacokinetics and bioavailability of hydromorphone nasal spray. J Pharm Pract Res. 2008;38:191-195.

33. Björkman S, Rigemar G, Idvall J. Pharmacokinetics of midazolam given as an intranasal spray to adult surgical patients. Br J Anaesth. 1997;79:575-580.

34. Burstein AH, Modica R, Hatton M, et al. Pharmacokinetics and pharmacodynamics of midazolam after intranasal administration. J Clin Pharmacol. 1997;37:711-718.

35. Dale $\mathrm{O}$, Nilsen $\mathrm{T}$, Loftsson $\mathrm{T}$, et al. Intranasal midazolam: A comparison of two delivery devices in human volunteers. J Pharm Pharmacol. 2006;58:1311-1318.

36. Gizurarson S, Gudbrandsson FK, Jónsson H, Bechgaard E. Intranasal administration of diazepam aiming at the treatment of acute seizures: Clinical trials in healthy volunteers. Biol Pharm Bull. 1999;22:425-427.

37. Gudmundsdottir H, Sigurjonsdottir JF, Masson M, et al. Intranasal administration of midazolam in a cyclodextrin based formulation: Bioavailability and clinical evaluation in humans. Pharmazie. 2001;56:963-966.

38. Knoester PD, Jonker DM, Van Der Hoeven RT, et al. Pharmacokinetics and pharmacodynamics of midazolam administered as a concentrated intranasal spray. A study in healthy volunteers. Br J Clin Pharmacol. 2002;53:501-507.

39. Lindhardt K, Gizurarson S, Stefánsson SB, et al. Electroencephalographic effects and serum concentrations after intranasal and intravenous administration of diazepam to healthy volunteers. $\mathrm{Br} \mathrm{J}$ Clin Pharmacol. 2001;52:521-527.

40. Loftsson T, Gudmundsdóttir H, Sigurjónsdóttir JF, et al. Cyclodextrin solubilization of benzodiazepines: Formulation of midazolam nasal spray. Int J Pharm. 2001;212:29-40.

41. Schols-Hendriks MW, Lohman JJ, Janknegt R, et al. Absorption of clonazepam after intranasal and buccal administration. Br J Clin Pharmacol. 1995;39:449-451.

42. Wermeling DP, Record KA, Kelly TH, et al. Pharmacokinetics and pharmacodynamics of a new intranasal midazolam formulation in healthy volunteers. Anesth Analg. 2006;103:344-349.

43. Wermeling DP, Record KA, Archer SM, Rudy AC. A pharmacokinetic and pharmacodynamic study, in healthy volunteers, of a rapidly absorbed intranasal midazolam formulation. Epilepsy Res. 2009;83:124-132. 
44. Chen J, Jiang XG, Jiang WM, et al. Intranasal absorption of rizatriptan - in vivo pharmacokinetics and bioavailability study in humans. Pharmazie. 2005;60:39-41.

45. Humbert H, Cabiac MD, Dubray C, Lavène D. Human pharmacokinetics of dihydroergotamine administered by nasal spray. Clin Pharmacol Ther. 1996;60:265-275.

46. Van der Kuy PH, Lohman JJ, Hooymans PM, et al. Bioavailability of intranasal formulations of dihydroergotamine. Eur J Clin Pharmacol. 1999;55:677-680.

47. Lonterman S, Van Asselt DZ, Olde Rikkert MG, et al. Intranasal hydroxocobalamin administration: An attractive alternative for intramuscular cobalamin injections in geriatric patients. Drug Develop Res. 2000;51:197-199.

48. Van Asselt DZ, Merkus FW, Russel FG, Hoefnagels WH. Nasal absorption of hydroxocobalamin in healthy elderly adults. Br J Clin Pharmacol. 1998;45:83-86.

49. Van der Kuy PH, Merkus FW, Russel FG, et al. Pharmacokinetics of intranasal and oral hydroxocobalamin in healthy subjects. Br J Clin Pharmacol. 2001;51:505P.

50. Duquesnoy C, Mamet JP, Sumner D, Fuseau E. Comparative clinical pharmacokinetics of single doses of sumatriptan following subcutaneous, oral, rectal and intranasal administration. Eur J Pharm Sci. 1998;6:99-104.

51. Moore KH, Hussey EK, Shaw S, et al. Safety, tolerability, and pharmacokinetics of sumatriptan in healthy subjects following ascending single intranasal doses and multiple intranasal doses. Cephalalgia. 1997;17:541-550.

52. Kagedal M, Zingmark PH, Hedlund C, Yates R. True nasopharyngeal absorption of zolmitriptan after administration via nasal spray in healthy male volunteers. Am J Drug Deliv. 2005;3:133-140.

53. Uemura N, Onishi T, Mitaniyama A, et al. Bioequivalence and rapid absorption of zolmitriptan nasal spray compared with oral tablets in healthy Japanese subjects. Clin Drug Investig. 2005;25:199-208.

54. Yates R, Nairn K, Dixon R, et al. Pharmacokinetics, dose proportionality, and tolerability of single and repeat doses of a nasal spray formulation of zolmitriptan in healthy volunteers. J Clin Pharmacol. 2002;42:1244-1250.

55. Yates R, Nairn K, Dixon R, Seaber E. Preliminary studies of the pharmacokinetics and tolerability of zolmitriptan nasal spray in healthy volunteers. J Clin Pharmacol. 2002;42:1237-1243.

56. Bullingham RE, McQuay HJ, Dwyer D, et al. Sublingual buprenorphine used postoperatively: Clinical observations and preliminary pharmacokinetic analysis. Br J Clin Pharmacol. 1981;12:117-122.

57. Pachter IJ, Evens RP. Butorphanol. Drug Alcohol Depend. 1985;14:325-338.

58. Darwish M, Kirby M, Robertson P Jr, et al. Absolute and relative bioavailability of fentanyl buccal tablet and oral transmucosal fentanyl citrate. J Clin Pharmacol. 2007;47:343-350.

59. Vallner JJ, Stewart JT, Kotzan JA, et al. Pharmacokinetics and bioavailability of hydromorphone following intravenous and oral administration to human subjects. J Clin Pharmacol. 1981;21:152-156.

60. Mandema JW, Kaiko RF, Oshlack B, et al. Characterization and validation of a pharmacokinetic model for controlled-release oxycodone. Br J Clin Pharmacol. 1996;42:747-756.

61. Crevoisier C, Delisle MC, Joseph I, Foletti G. Comparative single-dose pharmacokinetics of clonazepam following intravenous, intramuscular and oral administration to healthy volunteers. Eur Neurol. 2003;49:173-177.

62. Friedman H, Greenblatt DJ, Peters GR, et al. Pharmacokinetics and pharmacodynamics of oral diazepam: Effect of dose, plasma concentration, and time. Clin Pharmacol Ther. 1992;52:139-150.

63. Smith MT, Eadie MJ, Brophy TO. The pharmacokinetics of midazolam in man. Eur J Clin Pharmacol. 1981;19:271-278.

64. Benowitz NL, Pérez-Stable EJ, Herrera B, Jacob P III. Slower metabolism and reduced intake of nicotine from cigarette smoking in Chinese - Americans. J Natl Cancer Inst. 2002; 94:108-115.

65. Zhou HH, Liu ZQ. Ethnic differences in drug metabolism. Clin Chem Lab Med. 2000;38:899-903.

66. Van der Kuy PH, Lohman JJ, Veldhorst-Janssen NML, et al. Intranasal drug delivery in migraine: State of the art. Nederlands Tijdschrift voor Neurologie. 1998;1:49-56. 


\section{CHAPTER 3}

Pharmacokinetics and tolerability of nasal versus intravenous midazolam in healthy Dutch volunteers:

a single-dose, randomized-sequence, open-Label, 2-period crossover pilot study

Veldhorst-Janssen NML, Fiddelers AAA, van der Kuy P-HM, Theunissen HMS, de Krom MCTFM, Neef C, Marcus MAE

Clin Ther. 2011;33:2022-8 


\section{Abstract}

Background: Intranasal (IN) midazolam is a potential alternative to rectal diazepam for the acute treatment of epileptic seizures.

Objective: The purpose of this pilot study was to investigate the pharmacokinetics and tolerability of IN midazolam (50 mg/mL) compared with intravenous (IV) midazolam $(2.5 \mathrm{mg})$ in healthy adult volunteers.

Methods: In this single-dose, randomized-sequence, open-label, 2-period crossover pilot study subjects were randomly assigned to receive IN or IV midazolam, with a washout period of at least 5 days between treatments. The $50-\mathrm{mg} / \mathrm{mL}$ IN midazolam formulation consisted of $5 \mathrm{mg}$ midazolam base per $0.1 \mathrm{~mL}$ ( 1 spray) and was administered once in 1 nostril. The IV midazolam solution $(2.5 \mathrm{mg})$ was infused over $10 \mathrm{sec}$ onds. Blood samples were taken before and at regular intervals up to 240 minutes after dosing. Pharmacokinetic data (ie, $C_{\max }, t_{\max }, t_{1 / 2}$, and AUC) were analyzed using a 2-compartment model.

Results: Of 9 volunteers screened and enrolled, 7 completed the study (mean (SD) age 34.1 (9.0) years; mean (SD) weight 68.6 (10.4) kg, range 53-89 kg; 6 men, 3 women; all white). The mean $C_{\max }$ of $78(40) \mathrm{ng} / \mathrm{mL}$ was reached 44 minutes after IN administration, whereas the mean $C_{\max }$ was 51 (5) $\mathrm{ng} / \mathrm{mL}$ after IV administration. The mean estimated $\mathrm{C}_{\mathrm{t}=5}$ min was $31.4(28.1) \mathrm{ng} / \mathrm{mL}$ after $\mathrm{IN}$ administration. The elimination $\mathrm{t}_{1 / 2}$ was 1.9 (0.41) hours for IN midazolam and $2.3(0.19)$ hours for IV midazolam. The bioavailability of IN midazolam was $82 \%$. There were few adverse events, with a local burning feeling in the nose being the most reported event ( 6 of 7 subjects).

Conclusions: In this select group of healthy volunteers, concentrations of midazolam $>30 \mathrm{ng} / \mathrm{mL}$ were reached within 5 minutes of IN administration at a dose of $5 \mathrm{mg} / 0.1$ $\mathrm{mL}$. A burning feeling in the nostril was the main adverse effect. Additional research is needed to evaluate the safety profile, convenience, satisfaction, and efficacy of nasal midazolam in the treatment of adults with seizures. This trial is registered at www.isrctn.org, No. ISRCTN79059168. 


\section{Introduction}

Epilepsy is characterized by acute episodes of seizures that can last 5 minutes or longer or develop into status epilepticus. Seizures can cause brain damage as a result of metabolic abnormalities and can lead to significant morbidity and mortality [1]. Drugs with a rapid onset of action are needed to control acute and/or continuing seizures. In The Netherlands, rectal diazepam is currently used for this purpose. Although rectal diazepam is effective [2], it also has several disadvantages. Namely, it has a long halflife (20-40 hours), which may result in prolonged sedation [3]; it is difficult to selfadminister during an epileptic seizure; and its use can be socially embarrassing to both patients and bystanders.

A possible alternative rescue medication for acute treatment of epileptic seizures is midazolam, which is water soluble and can be administered by noninvasive routes, such as intranasally or buccally $[2,4]$. Intranasal (IN) midazolam might be a suitable mode of treatment because of its rapid onset of action [5-7], relatively short duration of action, and noninvasive route of administration. Moreover IN delivery may improve the pharmacokinetic profile compared with other noninvasive routes of administration, such as oral or rectal administration [8].

Drugs are absorbed via the rich vasculature and numerous microvilli in the nasal cavity [4,9-12], thereby avoiding first-pass hepatic elimination, which can influence the rate and extent of absorption. IN midazolam can be administered by patients when they are able or by bystanders, has a rapid onset of action, and has no significant effect on respiration and oxygen saturation [13]. However, many patients, especially children, experience IN administration of midazolam as painful, possibly because of the low $\mathrm{pH}$ (ie, 3.5) of the formulation [14-16] and the large volume $(>0.15 \mathrm{~mL}$ ) that needs to be administered to achieve a therapeutic concentration in systemic circulation. The maximum single spray volume per nostril is $0.15 \mathrm{~mL}$ (larger volumes may lead to irritation and run-off into the pharynx, which can lead to first-pass effects) [13], and the dose is based on a patient's body weight, with adults weighing $<50 \mathrm{~kg}$ receiving $5 \mathrm{mg}$ and heavier adults $10 \mathrm{mg}$ [12].

Several studies have investigated IN midazolam in healthy volunteers $[6,7,14,15,17-22]$. Four studies investigated the pharmacokinetics of the most concentrated nasal sprays available at the time of study initiation $(25-30 \mathrm{mg} / \mathrm{mL}$ midazolam) $[6,7,20,21]$. A spray volume of 0.167 to $0.200 \mathrm{~mL}$ per nostril in two divided doses would be needed to achieve the dose of $10 \mathrm{mg}$ required for heavier adults. This large volume could lead to spillage and potentially altered pharmacokinetics $[23,24]$. The purpose of our pilot study was to investigate the pharmacokinetic parameters and tolerability of a more concentrated $50 \mathrm{mg} / \mathrm{mL}$ formulation compared with $2.5 \mathrm{mg}$ intravenous (IV) midazolam in healthy adult volunteers. 


\section{Materials and methods}

\section{Participants}

Healthy nonsmoking men and healthy, non-pregnant, nonsmoking women were considered eligible for inclusion in the study if they were aged $\geq 18$ years and if they met American Society of Anesthesiology patient classification status I or II (ie, healthy or with mild systemic disease but no functional limitations). Potential participants were excluded if they had a runny nose or were allergic to benzodiazepines. The use of benzodiazepines and grapefruit juice was prohibited for a week before the intervention.

\section{Study Design}

Our randomized, nonblinded crossover study was performed at the Maastricht University Medical Centert, Maastricht, The Netherlands. Both treatments were administered by the study nurse (MT), with a washout period of at least 5 days between treatments. The newly developed IN midazolam formulation consisted of $5 \mathrm{mg}$ midazolam base per $0.1 \mathrm{~mL}$ ( 1 spray) and was administered once in 1 nostril. The IV midazolam dose (2.5 mg administered over 10 seconds) was chosen to avoid side effects. The study nurse (MT) administered IN midazolam with the subject sitting upright; IV midazolam was administered with the subject lying down. Subjects fasted overnight and were not allowed to eat 4 hours after study drug administration.

The study protocol was approved by the Medical Ethics Committee of Maastricht University Medical Center+ and written informed consent was obtained from all participants before enrolment.

\section{Study Drugs}

Study medications were developed and prepared by the Department of Clinical Pharmacology and Toxicology at Maastricht University Medical Center+. The midazolam nasal spray consisted of $556.2 \mathrm{mg}$ midazolam hydrochloride, $8 \mathrm{~mL}$ propylene glycol, and $2 \mathrm{~mL}$ water for injection; midazolam was administered in a single spray of $0.1 \mathrm{~mL}$. The spray device came from Pfeiffer (Radolfzell, Germany). The IV injection consisted of a single 2.5-mg midazolam dose administered over 10 seconds; the cannula was flushed with $4 \mathrm{~mL}$ saline.

\section{Tolerability Assessments}

Participants were asked to report any untoward effects experienced during the study, including both local adverse events (eg, burning feeling, nasal itching, irritation, pain, and change of taste) and systemic adverse events (eg, drowsiness, amnesia effect, and headache). The severity of the most common side effects, namely drowsiness and local 
burning feeling, was scored on a visual analogue scale (VAS) ranging from $0=$ no complaint at all to $100=$ worst complaint possible.

\section{Blood Sampling}

Blood samples for pharmacokinetic analysis were collected from an IV cannula at baseline and at 3, 5, 15, 20,30, 40, 60, 90, 120, 180, and 240 minutes after dosing. The IV cannula was placed in the arm opposite to the arm where midazolam was injected. At least $3 \mathrm{~mL}$ blood was collected using Vacutainer tubes (Becton Dickinson, Plymouth, United Kingdom) at each sampling time. The first $2 \mathrm{~mL}$ blood drawn at each sampling time was discarded. The IV cannula was flushed with $2 \mathrm{~mL}$ physiologic saline after blood sampling during the first half-hour and with heparin solution $(250 \mathrm{IU} / \mathrm{mL})$ thereafter. Blood samples were centrifuged (4000 RPM [3506g] for 6 minutes) after collection and plasma was stored at $-20^{\circ} \mathrm{C}$ at the study site until analyzed.

\section{Analytic Techniques}

Midazolam plasma concentrations were measured by fluorescence polarization immunoassay [25], using a COBAS INTEGRA 800 system (Roche Diagnostics, Mannheim, Germany). Serum concentrations were measured using an immunoassay kit (Roche Diagnostics, Mannheim, Germany) according to manufacturer's instructions. The test range was 10 to $200 \mu \mathrm{g} / \mathrm{L}$ and the lower limit of quantification was $3 \mu \mathrm{g} / \mathrm{L}$. Reproducibility was determined by repeatability (within-run precision; intraday) (\%CV 2.2) and by intermediate precision (between-run precision; interday) (\%CV 3.5). The crossreactivity of the assay was $81.8 \%$ for midazolam.

All analyses were performed at the University Hospital Maastricht Clinical Pharmacology Laboratory, Maastricht, The Netherlands, which is certified by the National Coordination Committee for Quality Assurance for Health Care Laboratories in The Netherlands.

\section{Pharmacokinetic Analysis}

Population pharmacokinetic parameters of midazolam were calculated using a 2compartment open model with an iterative 2-stage Bayesian fitting procedure using MWPHARM 3.60 software (Mediware, Groningen, The Netherlands) [26]. Individual pharmacokinetic parameters were calculated by maximum a posteriori Bayesian fitting. The Bayesian fitting procedure uses measured drug concentrations, populationbased pharmacokinetic parameters, and the expected variability associated with each measurement to determine individualized pharmacokinetic parameters of a subject [26-28]. The pharmacokinetic models were developed using standard IV data in MW/PHARM [29] and were validated by Monte Carlo analysis [30]. MW/PHARM was used to generate 100 sets of 50 simulated subjects based on the 7 volunteers. Individ- 
ual and population pharmacokinetic parameters for these 5000 simulated sets were calculated using iterative 2-stage Bayesian fitting. The calculated individual pharmacokinetic parameters were compared with the actual measured individual pharmacokinetic parameters and the bias (mean error) and root mean square error were determined. The smaller the bias and root mean square error, the better the performance of the model. In addition, the calculated population pharmacokinetic parameters for the 5000 simulated sets were compared with the pharmacokinetic parameters of the original population.

\section{Statistical Analysis}

Statistical analyses were performed using the Statistical Package for Social Sciences version 15.0 (SPSS, Chicago, Illinois). For pharmacokinetic parameters, descriptive statistics were determined.

\section{Results}

\section{Participants}

Nine healthy volunteers (6 men, 3 women), all American Society of Anesthesiology patient classification status I, mean age 34.1 (9.0) years, range 25 to 55 years, and weighing mean 68.6 (10.4) kg (range 53-89 kg) were included in the study. Seven participants completed the study. Two subjects were lost to follow-up after they received an IN dose of midazolam and were excluded from the analyses.

\section{Tolerability Assessments}

After IN administration, 6 of 7 subjects reported a burning feeling in their nostrils, (mean (SD) VAS score 44.3 (29.6), range 15-82), 4 reported a runny nose, 2 reported tearing, and 2 reported a bitter taste; 1 subject swallowed some of the IN midazolam solution. As for systemic adverse events, 6 subjects reported drowsiness (mean (SD) VAS score 39.5 (23.8), range 17-77) and 1 subject reported blurred vision and slight dizziness. After IV administration, all subjects reported drowsiness (mean (SD) VAS score 57.3 (27.9), range 20-100), 1 subject reported diplopia and felt less alert, 1 reported blurred vision, and 1 reported feeling sweaty. 
Table I. Mean (SD) pharmacokinetic parameters of intravenous (IV) and intranasal (IN) midazolam (N=7).

\begin{tabular}{lll}
\hline & Mean (SD) & \\
Parameter & $2.5 \mathrm{mg} \mathrm{IV}$ & $5.0 \mathrm{mg} \mathrm{IN}$ \\
\hline $\mathrm{T}_{\max }(\mathrm{min})$ & - & $43.8(18.8)$ \\
$\mathrm{C}_{\max }(\mathrm{ng} / \mathrm{mL})$ & $51.2(5.3)$ & $78.4(40.2)$ \\
$\mathrm{AUC}_{0-4}\left(\mathrm{ng}{ }^{*} \mathrm{~h} / \mathrm{mL}\right)$ & $120.0(14.7)$ & $197.6(94.3)$ \\
$\mathrm{t}_{1 / 2}(\mathrm{~min})$ & $138.6(11.5)$ & $116.6(24.5)$ \\
$\mathrm{Cl} \mathrm{cr}(\mathrm{mL} / \mathrm{min} / 1.73)$ & $105.7(18.3)$ & $95.0(19.7)$ \\
$\mathrm{F}(\%)$ & - & $82.4(38.2)$ \\
\hline
\end{tabular}

\section{Pharmacokinetic Analysis}

Pharmacokinetic parameters are listed in Table I. Mean estimated $C_{\max }$ of 78.4 (40.2) $\mathrm{ng} / \mathrm{mL}$ was reached at mean 43.8 (18.8) minutes after administration of IN midazolam; mean $\mathrm{C}_{\max }$ was $51.2(5.3) \mathrm{ng} / \mathrm{mL}$ after administration of IV midazolam. Mean estimated $\mathrm{C}_{\mathrm{t}=5 \min }$ was $31.4(28.1) \mathrm{ng} / \mathrm{mL}$ after administration of $\mathrm{IN}$ midazolam. The $\mathrm{t}_{1 / 2}$ was 116.6 (24.5) minutes after IN midazolam and 138.6 (11.5) minutes after IV midazolam administration. Mean $\mathrm{AUC}_{0-4}$ was 197.6 (94.3) and 120.0 (14.7) $\mathrm{ng} * \mathrm{~h} / \mathrm{mL}$ for IN and IV administration of midazolam, respectively.

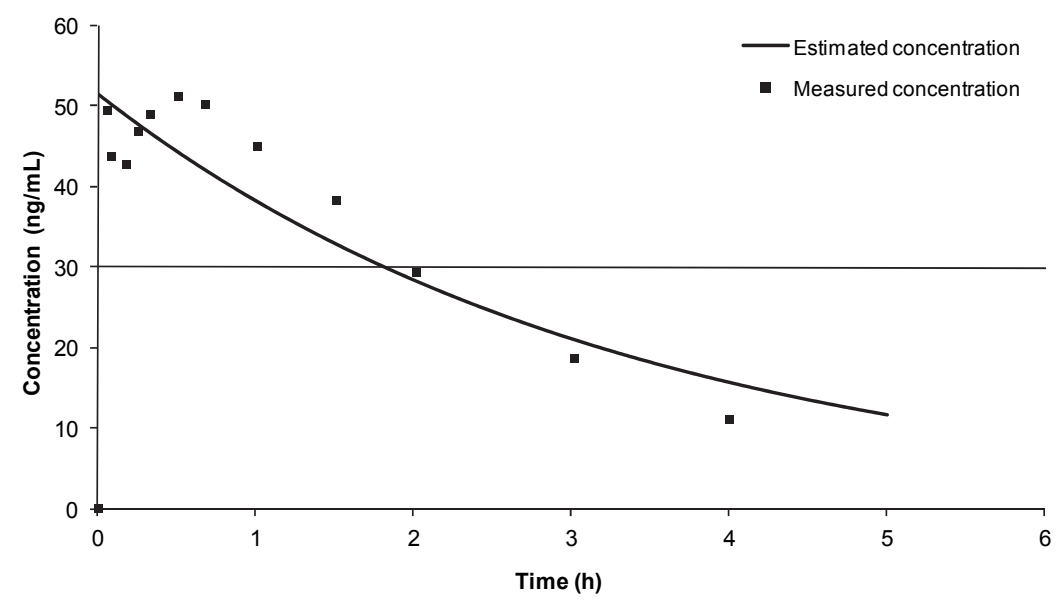

Figure 1. Mean estimated and measured concentration-time profile of intravenous midazolam (2.5 mg). The therapeutic concentration is indicated at $30 \mathrm{ng} / \mathrm{mL}$. 


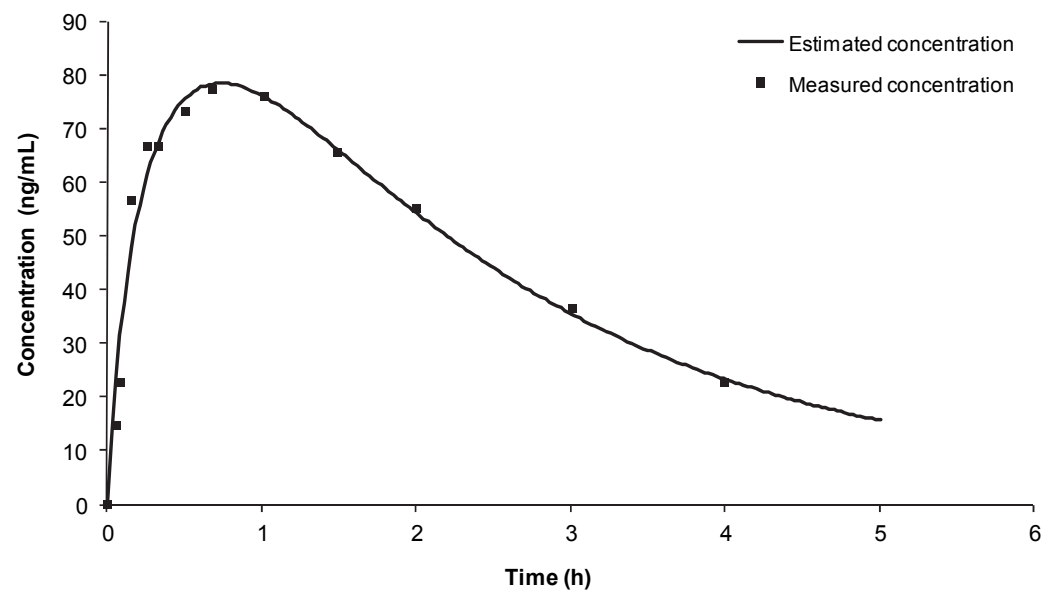

Figure 2. Mean estimated and measured concentration-time profile of intranasal midazolam (5.0 mg). The therapeutic concentration is indicated at $30 \mathrm{ng} / \mathrm{mL}$.

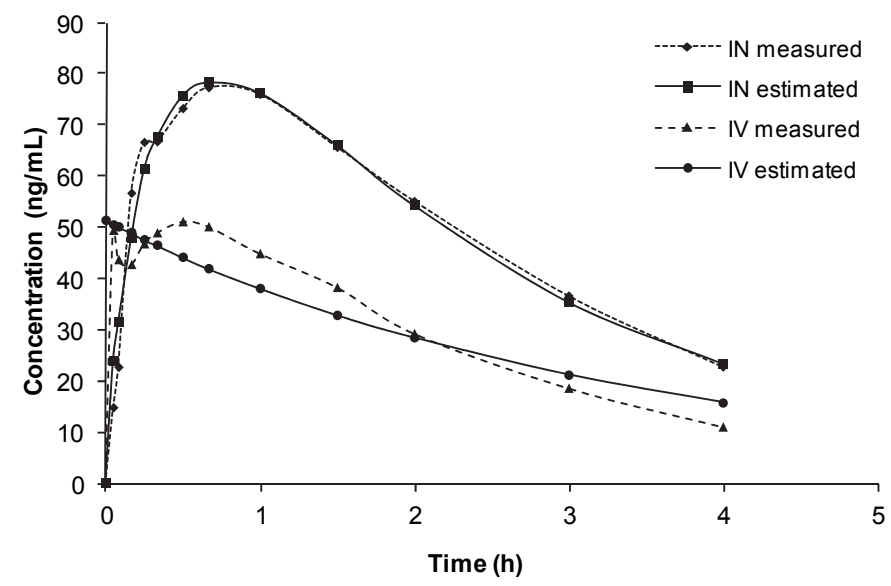

Figure 3. Mean estimated and measured concentration-time profile of intravenous (IV) (2.5 mg) and intranasal (IN) $(5.0 \mathrm{mg})$ midazolam.

The mean bioavailability of IN midazolam was $82.4 \%$ (38.2\%). Figures 1 through 3 illustrate the estimated and measured concentrations of midazolam after IN and IV administration over time. The concentration-time profile for 4 subjects exhibited a double peak, with the first peak occurring within 20 minutes after administration and the second peak occurring 30 to 60 minutes after administration (Figure 2).

The mean population pharmacokinetic parameters of IN midazolam, estimated using Monte Carlo analysis, were $\mathrm{K}_{\mathrm{e}} 0.32(0.05) \mathrm{h}^{-1}$ and $\mathrm{V}_{\mathrm{d}} 0.37(0.04) \mathrm{L} / \mathrm{kg}$. The bias was $10.3 \%$ and root mean square error was $17.0 \%$ for midazolam $\mathrm{K}_{\mathrm{e}}$ whereas the bias 
was $9.0 \%$ and root mean square error was $9.0 \%$ for the midazolam $V_{d}$. Figures 4 and 5 show the correlation between the measured midazolam concentrations and the estimated midazolam concentrations after IN $(r=0.98 ; P<0.001)$ and IV $(r=0.92, P<$ 0.001) administration.

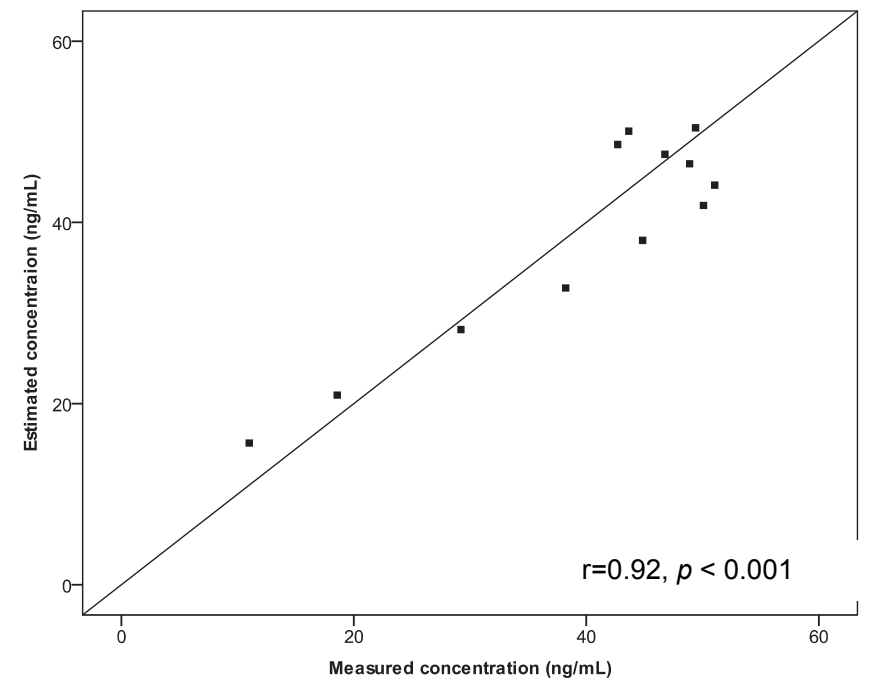

Figure 4. Correlation between measured and estimated concentrations of intravenous midazolam.

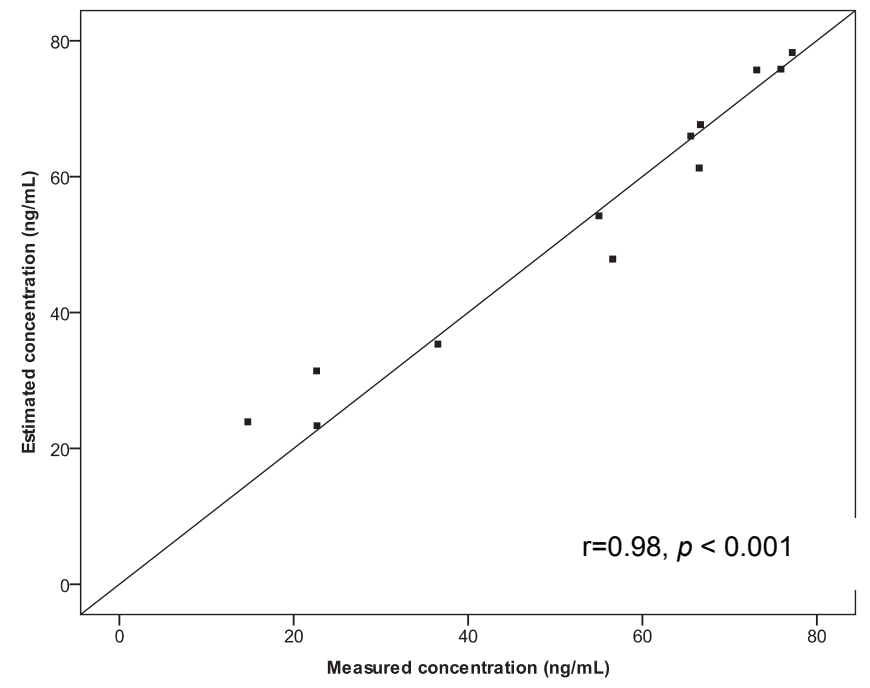

Figure 5. Correlation between measured and estimated concentrations of intranasal midazolam. 


\section{Discussion}

This randomized, nonblinded crossover pilot study investigated the pharmacokinetics and tolerability of midazolam ( $0.1 \mathrm{~mL}$ of a solution containing $50 \mathrm{mg} / \mathrm{mL}$ midazolam) compared with IV midazolam $(2.5 \mathrm{mg}$ ) in healthy adult volunteers. Our results are comparable to those of other pharmacokinetic studies of intranasal midazolam $[6,7,14,15,17-22]$, with a mean bioavailability of $82.4 \%(38.2 \%)$ and a mean $C_{\max }$ of 78.4 (40.2) $\mathrm{ng} / \mathrm{mL}$ (compared with $50 \%-92 \%$ and $62-84 \mathrm{ng} / \mathrm{mL}$, respectively, after administration of $5 \mathrm{mg}$ in the earlier studies). However, we observed a mean $t_{\max }$ of 43.8 (18.8) minutes, compared with $<25$ minutes reported in earlier studies.

This delay to reach $t_{\max }$ may be because of the double-peaked (within 20 minutes and 30-60 minutes) concentration-time profiles measured in 4 subjects, with the first peak being lower than the second peak (Figure 2). This oronasal effect was described previously by Burstein et al [14], but is not taken into account in the MwPharm model used to estimate IN midazolam concentrations. However, the correlation between the measured and estimated concentration was very high $(r=0.98 ; p<0.001)$ after IN administration (Figure 3), indicating that the MwPharm model provided a good fit.

Epilepsy rescue medications should have a rapid therapeutic effect. Recently, De Haan et al [31] published a study in which a $2.5 \mathrm{mg} / 0.09 \mathrm{~mL}$ IN midazolam spray, also used in the study by Knoester et al [7], was compared with rectal diazepam for treatment of seizures. In this study, IN midazolam successfully stopped seizures after 4.6 minutes [31]. According to the pharmacokinetic data reported by Knoester et al [7], IN midazolam reached a concentration of $30 \mathrm{ng} / \mathrm{mL}$ within 5 minutes of drug administration. Our study also suggested a comparable midazolam concentration (mean (SD) 31.4 (28.1) $\mathrm{ng} / \mathrm{mL}$ ) within 5 minutes of IN midazolam administration, despite the mean $\mathrm{t}_{\max }$ of 43.8 (18.8) minutes.

Midazolam undergoes oxidative hydroxylation by CYP3A to form its metabolites 1'- and 4-hydroxymidazolam [32]. Several studies have reported that the plasma concentration of 1'-hydroxymidazolam are relatively low compared with those of midazolam $[6,7,17,18,20,21]$. For example, 5 minutes after midazolam administration, midazolam concentrations of 30 and $74 \mathrm{ng} / \mathrm{mL}$ were detected in two studies, whereas the metabolite was not detectable; the metabolite accounted for $12.5 \%$ of midazolam levels at 8 hours and $4.5 \%$ thereafter [7,21]. For these reasons, we measured both compounds together in one assay. The correlation between measured and estimated IV midazolam concentrations (Figure 2 ) was lower $(r=0.92 ; P<0.001$ ) probably because of a distribution effect [33]. Wermeling et al [20] reported $t_{\max }$ at 15 minutes after IV administration of $2.5 \mathrm{mg}$ midazolam.

The severity of the 2 most common adverse effects of IN midazolam reported in our study (ie, local burning feeling and drowsiness) was measured with a VAS. The local 
burning feeling had a VAS score $>40$, which is considered high [34]. The formulation we used consists of water for injection, propylene glycol, and midazolam. Propylene glycol has been reported to cause irritation of the nasal cavity [6]. However, De Haan et al [31] reported no serious local side effects of midazolam nose spray containing propylene glycol after 10 years of use. Wermeling et al [6], who used a formulation containing propylene glycol, reported mild-to-moderate nasal irritation and suggested that the drug itself was the offending agent. The severity of drowsiness after drug administration had a mean VAS score of 39.5 (23.8) after IN midazolam (5 mg) and 57.3 (27.9) after IV midazolam ( $2.5 \mathrm{mg}$ ). Although the VAS scores for these 2 side effects are high, it should be noted that most patients who had experienced an epileptic seizure or status epilepticus did not report a local burning effect, whereas healthy volunteers did [32]. The local burning feeling will probably limit the widespread use of IN midazolam as premedication.

\section{Conclusions}

Serum concentrations $>30 \mathrm{ng} / \mathrm{mL}$ midazolam were reached within 5 minutes of IN midazolam ( $0.1 \mathrm{~mL}$ of a $50-\mathrm{mg} / \mathrm{mL}$ solution) administration in this select group of healthy volunteers. Additional research is needed to evaluate the safety profile, convenience, satisfaction, and efficacy of IN midazolam in the treatment of adults with seizures. 


\section{References}

1. Vespa PM, McArthur DL, Xu Y, et al. Nonconvulsive seizures after traumatic brain injury are associated with hippocam- pal atrophy. Neurology. 2010;75:792-798.

2. Scott RC, Besag FM, Neville BG. Buccal midazolam and rectal diazepam for treatment of prolonged seizures in childhood and adolescence: a randomised trial. Lancet. 1999;353:623-626.

3. Betts T. Epilepsy, Psychiatry and Learning Difficulty. M. London: The Livery House; 1998.

4. Lahat E, Goldman M, Barr J, et al. Comparison of intranasal midazolam with intravenous diazepam for treating febrile seizures in children: prospective randomised study. BMJ. 2000;321:83-86.

5. Wermeling DP. Intranasal delivery of antiepileptic medications for treatment of seizures. Neurotherapeutics. 2009;6:352-358.

6. Wermeling DP, Record KA, Kelly TH, et al. Pharmacokinetics and pharmacodynamics of a new intranasal midazolam formulation in healthy volunteers. Anesth Analg. 2006;103:344 -349.

7. Knoester PD, Jonker DM, Van Der Hoeven RT, et al. Pharmacokinetics and pharmacodynamics of midazolam administered as a concentrated intranasal spray. A study in healthy volunteers. Br J Clin Pharmacol. 2002;53:501-507.

8. Beran RG. An alternative perspective on the management of status epilepticus. Epilepsy Behav. 2008;12:349-353.

9. Kendall JL, Reynolds M, Goldberg R. Intranasal midazolam in patients with status epilepticus. Ann Emerg Med. 1997;29:415- 417.

10. O'Regan ME, Brown JK, Clarke M. Nasal rather than rectal benzodiazepines in the management of acute childhood seizures? Dev Med Child Neurol. 1996;38:1037-1045.

11. Scheepers $M$, Scheepers $B$, Clarke $M$, et al. Is intranasal midazolam an effective rescue medication in adolescents and adults with severe epilepsy? Seizure. 2000;9:417-22.

12. Scheepers M, Scheepers B, Clough P. Midazolam via the intranasal route: an effective rescue medication for severe epilepsy in adults with learning disability. Seizure. 1998;7:509 -512.

13. Bhattacharyya M, Kalra V, Gulati S. Intranasal midazolam vs rectal diazepam in acute childhood seizures. Pediatr Neurol. 2006;34:355-359.

14. Burstein $\mathrm{AH}$, Modica $\mathrm{R}$, Hatton $\mathrm{M}$, et al. Pharmacokinetics and pharmacodynamics of midazolam after intranasal administration. J Clin Pharmacol. 1997;37:711-718.

15. Loftsson T, Gudmundsdottir H, Sigurjonsdottir JF, et al. Cyclodextrin solubilization of benzodiazepines: formulation of midazolam nasal spray. Int J Pharm. 2001;212:29-40.

16. Lugo RA, Fishbein M, Nahata MC, Lininger B. Complication of intranasal midazolam. Pediatrics. 1993;92:638.

17. Bjorkman S, Rigemar G, Idvall J. Pharmacokinetics of midazolam given as an intranasal spray to adult surgical patients. Br J Anaesth. 1997; 79:575-580.

18. Dale $\mathrm{O}$, Nilsen $\mathrm{T}$, Loftsson $\mathrm{T}$, et al. Intranasal midazolam: a comparison of two delivery devices in human volunteers. J Pharm Pharmacol. 2006; 58:1311-1318.

19. Gudmundsdottir H, Sigurjonsdottir JF, Masson M, et al. Intranasal administration of midazolam in a cyclodextrin based formulation: bioavailability and clinical evaluation in humans. Pharmazie. 2001;56:963-966.

20. Wermeling DP, Record KA, Archer SM, Rudy AC. A pharmacokinetic and pharmacodynamic study, in healthy volunteers, of a rapidly absorbed intranasal midazolam formulation. Epilepsy Res. 2009;83:124 -132 .

21. Haschke M, Suter K, Hofmann S, et al. Pharmacokinetics and pharmacodynamics of nasally delivered midazolam. Br J Clin Pharmacol. 2010;69:607-616.

22. Ivaturi VD, Riss JR, Kriel RL, Cloyd JC. Pharmacokinetics and tolerability of intranasal diazepam and midazolam in healthy volunteers. Acta Neurol Scand. 2009;120:353-357. 
23. Humbert H, Cabiac MD, Dubray C, Lavene D. Human pharmacokinetics of dihydroergotamine administered by nasal spray. Clin Pharmacol Ther. 1996;60:265-275.

24. Veldhorst-Janssen N, Van der Kuy P-H, Neef C, et al. Optimalisation of intranasal midazolam. Anesthesiology. 2006;105:A628.

25. Dandliker WB, Kelly RJ, Dandliker J, Farquahar J, Levin J. Fluorescence polarization immunoassay. Theory and experimental method. Immunochemistry. 1973;10:219-227.

26. Proost JH, Meijer DK. MW/Pharm, an integrated software package for drug dosage regimen calculation and therapeutic drug monitoring. Comput Biol Med. 1992;22:155-163.

27. Jelliffe RW, Schumitzky A, Bayard D, et al. Model-based, goal-oriented, individualised drug therapy. Linkage of population modelling, new 'multiple model' dosage design, Bayesian feedback and individualised target goals. Clin Pharmacokinet. 1998;34:57-77.

28. Jelliffe RW, Schumitzky A, Van Guilder M, et al. Individualizing drug dosage regimens: roles of population pharmacokinetic and dynamic models, Bayesian fitting, and adaptive control. Ther Drug Monit. 1993;15:380-393.

29. Hardman J, Limbird L, Gilman A. Goodman \& Gilman's The Pharmacological Basis of Therapeutics. 10th ed. New York, NY: McGraw-Hill; 2001.

30. Bonate PL. A brief introduction to Monte Carlo simulation. Clin Pharmacokinet. 2001;40:15-22.

31. De Haan GJ, Van der Geest P, Doelman G, et al. A comparison of midazolam nasal spray and diazepam rectal solution for the residential treatment of seizure exacerbations. Epilepsia. 2010;51:478-482.

32. Seo KA, Bae SK, Choi YK, et al.Metabolism of 1'- and 4-hydroxy- midazolam by glucuronide conjugation is largely mediated by UDP- glucuronosyltransferases 1A4, 2B4, and 2B7. Drug Metab Dispos. 2010;38:2007-2013.

33. Spier L, Wright I, Saylor L. A new method for determining the circulation time throughout the vascular system. Am Heart J. 1936;12:511-520.

34. Jensen MP, Karoly P, Braver S. The measurement of clinical pain intensity: a comparison of six methods. Pain. 1986;27:117-126. 



\section{CHAPTER 4}

Pharmacokinetics, analgesic effect, and tolerability of a single preprocedural dose of intranasal fentanyl in patients undergoing drain removal after breast reduction or augmentation surgery: a prospective, randomized, double-blind, placebocontrolled study

Veldhorst-Janssen NML, Fiddelers AAA, van der Kuy P-HM, Kessels AGH, Theunissen HMS, van der Hulst RRWJ, Neef C, Marcus MAE

Clin Ther. 2010;7:1427-1436 


\section{Abstract}

Background: Although acetaminophen is used to reduce pain after breast reduction or augmentation surgery, pain during the removal of the surgical drains is typically not specifically treated. Intranasally administered fentanyl may be suitable for pain control during removal of drains. The reported therapeutic window of fentanyl is between 0.2 and $1.2 \mathrm{ng} / \mathrm{mL}$.

Objective: The aim of this study was to evaluate the analgesic effect, tolerability, and pharmacokinetics of a single preprocedural dose of intranasal fentanyl administered before removal of surgical drains in patients who had undergone breast reduction or augmentation surgery.

Methods: This was a randomized, double-blind, prospective study in healthy women (American Society of Anesthesiologists physical status I or II) between the ages of 18 and 65 years who were scheduled to undergo removal of surgical drains 1 to 4 days after breast reduction or augmentation surgery. A single dose of fentanyl nasal spray $0.05 \mathrm{mg} / 0.1 \mathrm{~mL}$ or placebo (preserved normal saline) $0.1 \mathrm{~mL}$ was administered 10 minutes before removal of drains. Because drain removal is generally carried out without specific analgesia, no rescue medication was provided. Pain intensity was measured on a visual analog scale (VAS) from $0=$ no pain at all to $100=$ worst pain possible. Pain intensity was evaluated immediately before administration of study medication ( $t$ $=0$ ), at the time of drain removal $(t=10)$, and at $15,20,25,40$, and 70 minutes after administration of study medication. Safety measures included oxygen saturation, respiratory rate, heart rate, and blood pressure. Local and systemic adverse events were elicited by direct questioning throughout the study. Blood samples for pharmacokinetic analysis were collected at baseline and at 5, 10, 15, 30, 60, and 120 minutes after administration of study medication. The population pharmacokinetic parameters of fentanyl were calculated according to a 1-compartment open model with an iterative 2-stage Bayesian fitting procedure.

Results: Thirty-six women were randomized to treatment, and 33 completed the study. Their mean (SD) age was 39.2 (13.0) years, and their mean weight was 68.9 (10.7) kg. Mean VAS scores at baseline were 14.8 (17.8) for the fentanyl group and 6.0 (9.7) for the placebo group ( $p=N S$ ); at the time of drain removal, the corresponding VAS scores were 31.0 (20.6) and 33.8 (25.7) ( $p=$ NS). Analysis of a random-effects model with mean VAS scores as a function of time as the dependent variable indicated a significant difference in mean VAS scores between the fentanyl and placebo groups $(P=0.006)$. The overall incidence of adverse events was 39.4\% (13/33). Among the 17 patients in 
the fentanyl group, 8 reported $\geq 1$ adverse event; among the 16 patients in the placebo group, 9 reported $\geq 1$ adverse event. A mean estimated $C_{\max }$ of $0.184(0.069) \mathrm{ng} / \mathrm{mL}$ was reached at 13.76 (3.56) minutes after administration of intranasal fentanyl. The mean measured $C_{\max }$ was $0.22(0.088) \mathrm{ng} / \mathrm{mL}$.

Conclusions: In these women who had undergone breast reduction or augmentation surgery, a single preprocedural dose of intranasal fentanyl was significantly more effective than placebo in reducing pain intensity over the hour after removal of surgical drains. However, there was no significant difference in pain intensity between fentanyl at the time of drain removal and placebo. Intranasal fentanyl was generally well tolerated. At the dose used $(0.05 \mathrm{mg})$, plasma fentanyl concentrations were below the reported therapeutic window. 


\section{Introduction}

Hospitalization sometimes involves short painful procedures, such as removal of surgical drains, wound dressing, and administration of injections. Acetaminophen is generally given for 1 to 4 days to reduce pain after breast reduction or augmentation surgery. However, no specific treatment is provided for the brief additional pain caused by the removal of surgical drains.

Orally or parenterally administered opioids are strong pain medications [1-3]. After oral administration, the onset of effect usually occurs within 30 minutes and the achievement of maximal effect within 1 hour [3], making it difficult to titrate doses to patients' requirements. Parenterally administered opioids have an onset of effect within 5 minutes. However, parenteral administration requires an intravenous bolus, which is an invasive mode of delivering medication [1-3].

Intranasally administered fentanyl may be suitable for use in short painful procedures, as it is rapid acting and noninvasive. In an open-label pilot study, Striebel et al [4] evaluated the pharmacokinetics of intranasal fentanyl 0.054 to $0.216 \mathrm{mg}$ in 5 patients with chronic malignant pain and found that intranasal fentanyl was $71 \%$ bioavailable, presumably because venous outflow from the nasal mucosa enters the systemic circulation, bypassing the liver and thus bypassing hepatic first-pass metabolism [5]. Striebel et al [6] also conducted a randomized, open-label, prospective study comparing intranasal fentanyl 0.33 to $0.83 \mathrm{mg}$ and intravenous fentanyl 0.13 to $0.83 \mathrm{mg}$ (maximum dose in both groups, $0.025 \mathrm{mg} / \mathrm{mL}$ per 6 minutes) for relief of pain after orthopedic surgery in 50 patients. No significant difference in pain intensity was observed between groups at any measurement time. However, these studies were not placebo controlled, which may have biased the results.

The aim of the present study was to evaluate the analgesic effect, tolerability, and pharmacokinetics of a single preprocedural dose of intranasal fentanyl administered before removal of surgical drains in patients who had undergone breast reduction or augmentation surgery.

\section{Patients and methods}

\section{Patients}

Eligible patients were healthy (American Society of Anesthesiologists physical status I or II) women aged 18 to 65 years scheduled to undergo removal of surgical drains 1 to 4 days after breast reduction or augmentation surgery. Exclusion criteria were sleeping disorders, opioid allergy, chronic use of opioids, pregnancy, and acute or chronic nasal problems such as rhinitis or sinusitis. 


\section{Study Design}

This randomized, double-blind, placebo-controlled, prospective study was performed at the Maastricht University Medical Centre+, Maastricht, The Netherlands, in 20022004. A computer-generated table of random numbers was used to assign patients in a $1: 1$ ratio to receive a single intranasally administered dose of fentanyl $0.05 \mathrm{mg}(0.1 \mathrm{~mL}$ total volume) or placebo $0.1 \mathrm{~mL}$. Ten minutes before drain removal, the investigator administered the nasal spray, with the patient in a semirecumbent position with the back and head at a $45^{\circ}$ angle. No rescue medication was provided, as drain removal is typically carried out without analgesia.

The study protocol was approved by the Medical Ethical Committee of Maastricht University Medical Centre+, and written informed consent was obtained from all participants before they underwent surgery. The pain-intensity rating scale was explained to patients before obtaining their consent.

\section{Study Drugs}

As no intranasal formulation was commercially available at the time of the study, fentanyl nasal spray was compounded by adding $0.078 \mathrm{mg}$ fentanyl citrate and $0.9 \mathrm{mg}$ $\mathrm{NaCl}$ to $0.1 \mathrm{~mL}$ water; the $\mathrm{pH}$ was adjusted to 6.3 using $0.001 \mathrm{M} \mathrm{NaOH}$. Placebo nasal spray was compounded by adding $0.9 \mathrm{mg} \mathrm{NaCl}, 0.1 \mathrm{mg}$ edetate sodium, $0.1 \mu \mathrm{g}$ benzalkonium chloride, and sterile water to achieve an end volume of $0.1 \mathrm{~mL}$; the $\mathrm{pH}$ was 4.8. A single-dose intranasal spray device that delivers $0.1 \mathrm{~mL}$ of solution per spray was prefilled with $0.12 \mathrm{~mL}$ of solution. The device was weighed before and after use to control dose administration. Both formulations were prepared by the Department of Clinical Pharmacology and Toxicology at Maastricht University Medical Centre+.

\section{Efficacy Assessments}

Patients rated their pain intensity using a visual analog scale (VAS) from $0=$ no pain at all to $100=$ worst pain possible. Pain intensity was evaluated at 7 time points: immediately before administration of study medication ( 0 minute), at the time of drain removal (10 minutes), and at 15, 20, 25, 40, and 70 minutes after administration of study medication.

\section{Tolerability Assessments}

Oxygen saturation was measured before administration of study medication through 60 minutes after drain removal by pulse oximetry (Datex Division, Instrumentarium Corp., Helsinki, Finland). The respiratory rate was measured visually, and heart rate was recorded continuously by pulse oximetry. Blood pressure was measured in the upper arm using the Riva-Rocci-Korotkoff method, with the patient in a semirecumbent position with the back and head at a $45^{\circ}$ angle. Measurements were obtained 
before administration of study medication and every 5 minutes through 60 minutes after drain removal.

Patients were instructed to inform the investigator of any untoward effects occurring during the study, including both local adverse events (eg, nasal itching, irritation, pain, burning, change in taste) and systemic adverse events (ie, dizziness, nausea, vomiting, feeling hot, euphoria). Treatment-emergent adverse events, including their start and stop time, were recorded from the time of administration of study medication through 60 minutes after drain removal.

\section{Blood Sampling}

Blood samples for pharmacokinetic analysis were collected from an intravenous cannula at baseline and at 5, 10, 15, 30, 60, and 120 minutes after administration of study medication. Two blood samples of at least $3 \mathrm{~mL}$ each were collected into Vacutainer tubes (Becton Dickinson, Plymouth, United Kingdom) at each sampling time. The first 2 $\mathrm{mL}$ of blood drawn at each sampling time was discarded. The intravenous cannula was flushed with $2 \mathrm{~mL}$ physiologic saline solution after each sample obtained in the first half-hour and with heparin solution $(250 \mathrm{IU} / \mathrm{mL})$ thereafter. Blood samples were centrifuged at $4000 \mathrm{rpm}$ for 6 minutes. The plasma was then separated and stored at $-20^{\circ} \mathrm{C}$ at the study site until analyzed.

\section{Analytic Techniques}

Fentanyl plasma concentrations were measured by HPLC-MS/MS (Waters 2795 Alliance HPLC system, Waters Ltd., Watford, United Kingdom). The sample was injected onto a solid-phase extraction column (Oasis HLB cartridge column, Waters Ltd.; $2.1 \mathrm{x}$ $20 \mathrm{~mm}, 25 \mu \mathrm{m}$ ). After flushing for 1.5 minutes with a 90:10 mixture of eluent $A$ ( $2 \mathrm{mM}$ ammonium acetate in water $+0.1 \%[\mathrm{v} / \mathrm{v}]$ formic acid) and eluent $B(2 \mathrm{mmol}$ ammonium acetate in methanol $+0.1 \%$ [v/v] formic acid) at a flow rate of $1.5 \mathrm{~L} / \mathrm{min}$, the analytes were foreflushed to the analytic column (Atlantis dC18, Waters Ltd.; $3.0 \times 100$ $\mathrm{mm}, 5 \mu \mathrm{m})$ with another mixture of eluents $A$ and $B(10: 90)$ at a flow rate of 0.75 $\mathrm{mL} / \mathrm{min}$. Four minutes after starting the cycle, the flow rate was set to $1.0 \mathrm{~mL} / \mathrm{min}$. After 6 minutes, the column switching device was switched to the starting position to equilibrate for the next injection 30 seconds later. The analytic column was heated at $60^{\circ} \mathrm{C}$, and the concentration column was at room temperature. The total cycle time was 6.5 minutes for each injection.

A tandem mass spectrometer (Quattro Micro, Waters Ltd.) fitted with a Z-spray ion source was operated in the electrospray positive-ionization mode and directly coupled to the HPLC system. System control and data acquisition were performed using MassLynx 4.0 software (Waters Ltd., Manchester, United Kingdom). 
Tuning of the spectrometer was done by infusion of a solution of fentanyl or bupivacaine $(1 \mathrm{mg} / \mathrm{L})$ in mobile phase into the ion source, and the cone voltage was optimized to maximize the intensity of the precursor ions of fentanyl and bupivacaine $(\mathrm{m} / \mathrm{z}, 337.3$ and 289.5 , respectively). The collision energy was then adjusted to optimize the signal for the most intense product ions (m/z, 188.0 and 140.2). Typical tuning conditions were as follows: electrospray capillary voltage, $0.4 \mathrm{kV}$; sample cone voltage, $35 \mathrm{~V}$; and collision energy, $23 \mathrm{eV}$. The source temperature was $80^{\circ} \mathrm{C}$ and the desolvation temperature was $250^{\circ} \mathrm{C}$. Desolvation gas (nitrogen) flow was set to $475 \mathrm{~L} / \mathrm{h}$ and cone gas was set to $85 \mathrm{~L} / \mathrm{h}$. The collision gas was argon.

Sample analysis was performed in the multiple-reaction-monitoring mode of the mass spectrometer, with a dwell time of 0.2 second per transition. The lower limit of quantitation for fentanyl was $0.05 \mu \mathrm{g} / \mathrm{L}$, based on $20 \mu \mathrm{L}$ of human serum. The standard curves were linear from 0.05 to $1.5 \mu \mathrm{g} / \mathrm{L}$ using weighted linear regression analysis $(1 / \mathrm{x}$ concentration weighting).

The bioanalytic assay method was developed internally using the method described by Huynh et al [7]. Internal standard solution ( $300 \mu \mathrm{L} ; 20 \mu \mathrm{L}$ bupivacaine 1 $\mathrm{mg} / \mathrm{L}$ in $25 \mathrm{~mL}$ acetonitrile:water:zinc sulfate hepta-hydrate [25:32:0.5 v/v]) was added to $100 \mu \mathrm{L}$ of plasma. The solution was vortex-mixed for 1 minute and centrifuged at $10,900 \mathrm{rpm}$ for 5 minutes. The supernatant $(20 \mu \mathrm{L})$ was injected into the LC-MS/MS system. Standard solutions were made from a stock solution (10 $\mathrm{mg} / \mathrm{L}$ in methanol) containing $0.05,0.1,0.3,0.5,1.0$, and $1.5 \mu \mathrm{g} / \mathrm{L}$ fentanyl and were freshly prepared on the day of analysis. Standard plasma samples were processed in the same way as patient samples. Three control plasma samples containing $0.14,0.75$, and $1.25 \mu \mathrm{g} / \mathrm{L}$ fentanyl were measured in each run.

Calibration data, quality-control (QC) data, and chromatograms indicated acceptable performance of the method during sample analysis. The calibration curves of fentanyl were linear, with correlation coefficients of 0.993484; the \%CV for interassay accuracy was 0.6 . In the analysis of QC samples, the interday reliability was in the range from $100 \%$ to $101 \%$ for fentanyl, and the intraday accuracy was in the range from $106 \%$ to $112 \%$.

HPLC-grade methanol (CH4O, CAS [Chemical Abstracts Service] 67-56-1) was obtained from Biosolve B.V. (Valkenswaard, The Netherlands). Ammonium acetate $\left(\mathrm{C}_{2} \mathrm{H}_{7} \mathrm{NO}_{2}\right.$, CAS 631-61-8), formic acid $\left(\mathrm{CH}_{2} \mathrm{O}_{2}\right.$, CAS 64-18-6), absolute ethanol $\left(\mathrm{C}_{2} \mathrm{H}_{6} \mathrm{O}\right.$, CAS 64-17-5), zinc sulfate heptahydrate $\left(\mathrm{ZnSO}_{4} \cdot 7 \mathrm{H}_{2} \mathrm{O}, \mathrm{CAS} 7446-20-0\right)$, and acetonitrile $\left(\mathrm{C}_{2} \mathrm{H}_{3} \mathrm{~N}\right.$, CAS 75-08-8) were obtained from Merck KGaA (Darmstadt, Germany). Fentanyl citrate and the internal standard bupivacaine $\left(\mathrm{Cl}_{8} \mathrm{H}_{28} \mathrm{~N}_{2} \mathrm{O}\right.$, CAS 2180-92-9) were obtained from Bufa B.V. (IJsselstein, The Netherlands). Ultrapure water was used in all preparations. All chemicals were of analytic grade. Human EDTA plasma for standard 
and control samples was obtained from the Red Cross Blood Bank (Maastricht, The Netherlands).

\section{Statistical and Pharmacokinetic Analysis}

The number of patients required for this study was based on an expected $15 \%$ difference in reduction in pain intensity. It was determined that 28 patients (14 per group) would be needed to reach an effect size [8] and an estimated deviation of $20 \%$ [9-11], and to have $80 \%$ power to detect a difference in pain intensity (VAS) at a 2-tailed significance level of 0.05 .

The main outcome parameter was changed in mean pain intensity (VAS) from the time of drain removal ( $t=10$ minutes) until 1 hour after drain removal ( $t=70$ minutes). Differences between groups were analyzed using a t-test or paired t-test. A randomeffects model was used to determine the difference between groups in mean VAS scores as a function of time, with intervention, time (ie, points at which VAS scores were measured), and baseline VAS score as fixed effects. To correct for the fact that the time points at which VAS scores were measured were not linear, "time squared" was also entered as a covariate in the model $[8,12,13]$. In addition, the confounding effect of tolerability scores, age, body mass index, time from surgery to removal of drains, oxygen saturation, heart rate, blood pressure, and respiratory rate was tested. Population pharmacokinetic parameters of fentanyl were calculated according to a 1compartment open model with an iterative 2-stage Bayesian fitting procedure using MW/PHARM 3.60 software (Mediware, Groningen, The Netherlands) [14]. Individual pharmacokinetic parameters were calculated by maximum a posteriori Bayesian fitting. The Bayesian fitting procedure uses measured drug concentrations, populationbased pharmacokinetic parameters, and expected variability in each parameter to determine the pharmacokinetic parameters for an individual patient [14-16].

As derived from Lim et al [5], the fentanyl pharmacokinetic parameters used to create the model were $k_{e} 2.4(1.8) \mathrm{h}^{-1}$ and $V_{d} 0.8896(0.6776) \mathrm{L} / \mathrm{kg}$. The population pharmacokinetic model was validated by Monte Carlo analysis [17]. MW/PHARM was used to generate 100 sets of 50 simulated patients based on the 14 patients who received intranasal fentanyl and provided evaluable samples. Individual and population pharmacokinetic parameters for these 5000 simulated sets were calculated using iterative 2-stage Bayesian fitting. The calculated individual pharmacokinetic parameters were compared with the actual measured individual pharmacokinetic parameters, and the bias (mean error) and root mean square error (RMSE) were determined. The smaller the bias and RMSE, the better the performance of the model. In addition, the calculated population pharmacokinetic parameters for the 5000 simulated sets were compared with the actual population pharmacokinetic parameters for the 14 patients with evaluable data. 
Use of this model also permitted comparison of the fentanyl dose against blood concentrations to predict the dose necessary to reach therapeutic blood concentrations $(0.2-1.2 \mathrm{ng} / \mathrm{mL})[18,19]$.

\section{Results}

\section{Patients}

Thirty-six women (mean (SD) age, 39.2 (13.0) years; mean (SD) weight, 68.9 (10.7) kg) were enrolled and randomized. After randomization, 3 patients ( 2 in the fentanyl group, 1 in the placebo group) declined to participate for personal reasons. Thus, 33 patients completed the study. There was a significant difference in mean (SD) systolic blood pressure between the fentanyl and placebo groups (131 (10.7) vs 121 (16.6) mm $\mathrm{Hg}$, respectively; $p=0.046)$. Baseline characteristics of the study population are summarized in Table I.

Table I Patient characteristics at baseline

\begin{tabular}{llll}
\hline Variable & & $\begin{array}{l}\text { Fentanyl } \\
(\mathrm{n}=17)\end{array}$ & $\begin{array}{l}\text { Placebo } \\
(\mathrm{n}=16)\end{array}$ \\
\hline Age, $\mathrm{y}$ & Mean (SD) & $38.9(13.7)$ & $39.6(12.8)$ \\
& Range & $18-59$ & $20-59$ \\
Body weight, kg & Mean (SD) & $69.8(6.8)$ & $68.0(13.9)$ \\
Body mass index, kg/m ${ }^{2}$ & Range & $59.0-83.0$ & $44.0-90.5$ \\
Oxygen saturation, \% & Mean (SD) & $25.0(2.2)$ & $24.1(3.9)$ \\
& Range & $21.2-28.6$ & $17.6-31.3$ \\
Respiratory rate, breaths/min & Mean (SD) & $97.3(1.0)$ & $97.4(1.9)$ \\
Hart rate, beats/min & Range & $95-99$ & $94-100$ \\
Systolic blood pressure, $\mathrm{mm} \mathrm{Hg}$ & Mean (SD) & $19.7(5.02)$ & $18.5(2.6)$ \\
& Range & $11-32$ & $14-22$ \\
Diastolic blood pressure, $\mathrm{mm} \mathrm{Hg}$ & Mean (SD) & $84.4(11.5)$ & $78.7(14.4)$ \\
& Range & $57-103$ & $55-101$ \\
& Mean (SD) & $131(10.7)^{*}$ & $121(16.6)^{*}$ \\
& Range & $58-96$ & $46-88$ \\
& Mean (SD) & $73(10.8)$ & $66(11.6)$ \\
& Range & $115-156$ & $98-153$
\end{tabular}

*P-value 0.046

\section{Efficacy Assessment}

Mean (SD) VAS scores at baseline were 14.8 (17.8) in the fentanyl group and 6.0 (9.7) in the placebo group ( $p=$ NS) (Table II). At the time of drain removal, VAS scores were $31.0(20.6)$ and $33.8(25.7)$, respectively $(p=N S)$. Thus, at the time of drain removal, 
the fentanyl group had a $200 \%$ increase in VAS score from baseline, compared with a $560 \%$ increase from baseline in the placebo group. The change in VAS scores over time is illustrated in Figure 1.

Table II Mean visual analog scale scores for pain intensity*

\begin{tabular}{llll}
\hline Assessment time, min & & Fentanyl & Placebo \\
\hline 0 (Administration of nasal spray) & Mean (SD) & $14.8(17.8)$ & $6.0(9.7)$ \\
& Range & $0-53$ & $6-29$ \\
10 (Drain removal) & Mean (SD) & $31.0(20.6)$ & $33.8(25.7)$ \\
& Range & $0-70$ & $1-98$ \\
15 & Mean (SD) & $10.9(10.0)$ & $14.8(21.3)$ \\
& Range & $0-30$ & $0-74$ \\
20 & Mean (SD) & $8.3(10.5)$ & $8.0(14.4)$ \\
& Range & $0-36$ & $0-50$ \\
25 & Mean (SD) & $6.5(9.5)$ & $8.6(13.0)$ \\
& Range & $0-33$ & $0-41$ \\
40 & Mean (SD) & $5.6(7.3)$ & $5.9(9.9)$ \\
70 & Range & $0-24$ & $0-32$ \\
& Mean (SD) & $4.7(8.9)$ & $6.3(9.6)$ \\
\end{tabular}

*Scale from $0=$ no pain at all to $100=$ worst pain possible

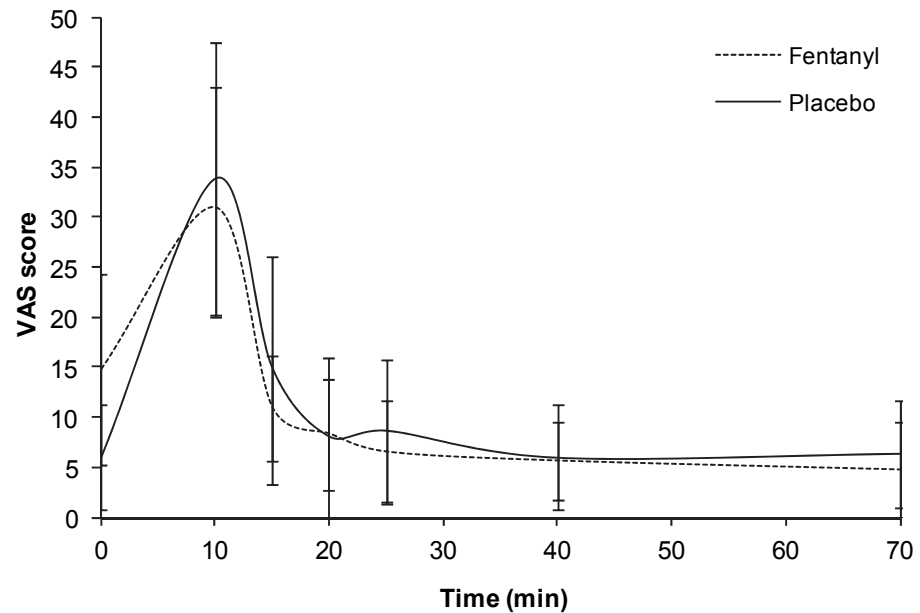

Figure 1. Mean (SD) visual analog scale (VAS) scores for fentanyl and placebo over the hour after removal of surgical drains. Study medication was administered at 0 minute, and drains were removed at 10 minutes after administration of study medication. 
In the fentanyl group, the mean (SD) VAS score had decreased to 10.9 (10.0) at 5 minutes after drain removal; in the placebo group, the VAS score was 5.9 (9.9) at 30 minutes after drain removal, almost returning to baseline values (Table II). At 1 hour after drain removal, mean VAS scores were 4.7 (8.9) in the fentanyl group and 6.3 (9.6) in the placebo group; the change in pain intensity from $t=0$ to $t=70$ was significantly different between groups ( $p=0.037$ ).

Analysis of the random-effects model with mean VAS scores as a function of time as the dependent variable indicated a significant difference in mean VAS scores between the fentanyl and placebo groups ( $F=7.64 ; p=0.006)$, and significant effects of baseline VAS score $(F=41.11 ; p<0.001)$, time $(F=45.46 ; p<0.001)$, and time squared $(F=32.67 ; p<0.001)$. Addition of other covariates did not indicate a relevant confounding effect on the VAS score.

\section{Tolerability Assessments}

At baseline, oxygen saturation ranged from $95 \%$ to $99 \%$. The lowest oxygen saturation in any patient was 92\%, measured 15 minutes after administration of fentanyl nasal spray. The mean (SD) heart rate at baseline was 84.4 (11.5) beats/min in the fentanyl group and 78.7 (14.4) beats/min in the placebo group. Mean blood pressure at baseline was 131/73 (10.7/10.8) $\mathrm{mm} \mathrm{Hg}$ in the fentanyl group and 121/66 (16.6/11.6) mm $\mathrm{Hg}$ in the placebo group; the difference in systolic blood pressure was statistically significant between groups ( $p=0.046)$. Ten minutes after administration of fentanyl, mean blood pressure had decreased to 125/71 (15.1/12.9) $\mathrm{mm} \mathrm{Hg}$. The respiratory rate in the respective groups was 19.7 (5.0) and 18.5 (2.6) breaths/min. There was no significant difference between groups on any tolerability parameter after administration of study drug.

Thirteen of the 33 patients (39.4\%) who completed the study reported adverse events. No differences in adverse events were observed between groups. Of 17 patients in the fentanyl group, 8 reported $\geq 1$ adverse event: dizziness ( 5 patients), sleepiness (3), nausea (2), weakness (2), feeling stressed and hot (1), and a pulsation in the arm (1). Of 16 patients in the placebo group, 9 reported $\geq 1$ adverse event: sleepiness (5), dizziness (3), nausea (2), weakness (1), headache (1), breathlessness (1), feeling stressed (1), and intense pain (VAS score, 51) at the time of drain removal (1). Local adverse events in the fentanyl group included nasal tingling in 2 patients, nasal mucus in 1 patient, and dry feeling in the nose in 1 patient; local adverse events in the placebo group included an "open" feeling in the nose, sniffling, and nasal tickling in 1 patient each. 


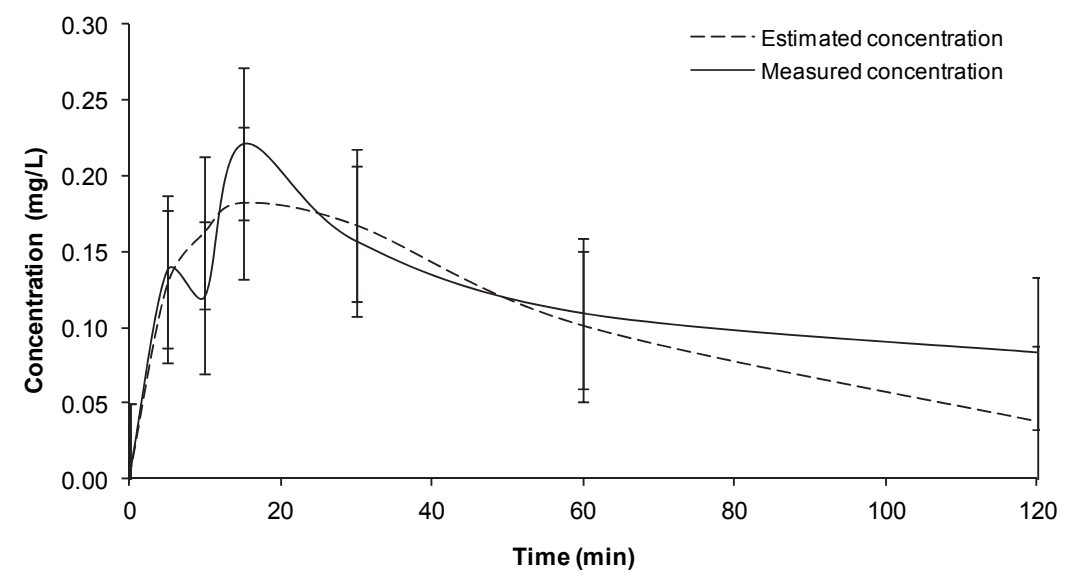

Figure 2. Mean (SD) estimated and measured fentanyl concentrations over time.

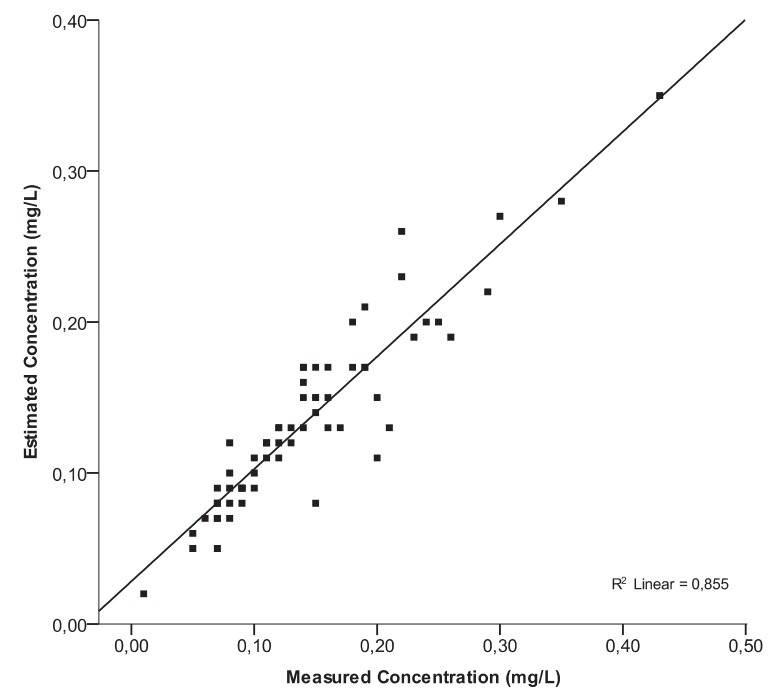

Figure 3. Correlation between measured and estimated concentrations of fentanyl using 2-stage Bayesian fitting.

\section{Pharmacokinetic Analysis}

The mean (SD) fitted fentanyl $C_{\max } 0.184(0.069) \mathrm{ng} / \mathrm{mL}$ was reached at 13.76 (3.56) minutes after administration of intranasal fentanyl. The $t_{1 / 2}$ was 65.83 (61.87) minutes, and the AUC was $17.18(14.50) \mathrm{ng} / \mathrm{mL}$ * $\min$.

The mean (SD) population pharmacokinetic parameters of fentanyl estimated using Monte Carlo analysis were $k_{e}=1.0571(7.0860) \mathrm{h}^{-1}$ and $\mathrm{V}_{d} 1.6869(0.4966) \mathrm{L} / \mathrm{kg}$, almost identical to the population pharmacokinetic parameters from the 14 patients who provided evaluable data $k_{e}=1.0696(0.7746) h^{-1}$ and $V_{d} 1.68(0.5155) \mathrm{L} / \mathrm{kg}$, respec- 
tively). The bias and RMSE were $8.6 \%$ and $12.2 \%$, respectively, for the fentanyl $\mathrm{k}_{\mathrm{e}}$ and $0.4 \%$ and $4.4 \%$ for the fentanyl $V_{d}$. Figure 2 illustrates the estimated and measured fentanyl concentrations over time. Figure 3 shows the correlation between the actual measured fentanyl concentrations and the estimated fentanyl concentrations with 2stage Bayesian fitting $\left(R^{2}=0.85\right)$. According to the population pharmacokinetic model, a fentanyl dose of $100 \mu \mathrm{g}$ was predicted to provide fentanyl plasma concentrations between 0.2 and $0.3 \mathrm{ng} / \mathrm{mL}$.

\section{Discussion}

This prospective, randomized, double-blind study compared the analgesic effectiveness and tolerability of a single preprocedural dose of intranasal fentanyl with those of placebo in women undergoing removal of drains after breast reduction or augmentation surgery, and evaluated the pharmacokinetics of intranasal fentanyl.

Contrary to expectations, this study did not clearly demonstrate a significant analgesic effect for intranasal fentanyl dosed at $0.05 \mathrm{mg}$. Baseline pain intensity was more than twice as high in the fentanyl group as in the placebo group ( $p=N S$ ), and no factor was found to account for this difference. At the time of drain removal, however, there was no significant difference in pain intensity between the 2 groups. It is possible that the baseline differences in pain intensity and low plasma fentanyl concentrations contributed to the study's failure to demonstrate a significant difference in VAS scores during drain removal. When baseline VAS scores were included as a covariate in the random-effects model, fentanyl was associated with significant pain relief compared with placebo from the time of drain removal through 1 hour after removal $(p=0.006)$.

Intranasal fentanyl was generally well tolerated compared with placebo. There was a significant difference in systolic blood pressure between groups at baseline $(p=$ 0.046), possibly related to the numerically higher baseline pain intensity and numerically greater heart rate in the fentanyl group [20]. Blood pressure decreased after drug administration in the fentanyl group, consistent with the reported safety profile of fentanyl.

The therapeutic window of fentanyl has been reported to be between 0.2 and 1.2 $\mathrm{ng} / \mathrm{mL}[18,19]$. The mean measured $C_{\max }$ in this study was $0.22 \mathrm{ng} / \mathrm{mL}$, whereas the estimated $C_{\max }$ was $0.18 \mathrm{ng} / \mathrm{mL}$. However, the correlation between measured and estimated concentrations was high $\left(R^{2}=0.85\right)$. Other studies have reported a higher $\mathrm{C}_{\max }(0.36-0.47 \mathrm{ng} / \mathrm{mL})$ after intranasal administration of fentanyl $0.05 \mathrm{mg}[5,9,21,22]$. The discrepancy may be explained by differences in the spray device used; differences in the formulation, ionization, dosage, or volume; and differences in analytic methods [23]. The solution used in the present study was not buffered, whereas other studies 
employed a buffer to reach a desirable $\mathrm{pH}$ for intranasal administration $(\mathrm{pH} 6-8$ (from less than to approximately equal to the acid dissociation constant)) $[5,9,21]$. In addition, patients in this study were in a semirecumbent position, with the head of the bed elevated $45^{\circ}$, which may have led to reduced absorption of fentanyl as a result of runoff through the pharynx. The $t_{\max }$ in this study (13.8 minutes) was consistent with reports from other studies (5-16 minutes) $[5,21]$. The $t_{1 / 2}$ was 65.83 minutes, compared with 30 to 31 minutes in the study by Lim et al [5] and 89 to 179 minutes in the study by Christrup et al [21].

Removal of drains after breast reduction or augmentation surgery appeared to be a useful model for testing the efficacy of intranasal fentanyl, as mean VAS scores in the placebo group at the time of drain removal were $>30$ (moderate pain). However, plasma fentanyl concentrations in this study were too low to show a significant effect on pain intensity caused by the removal of surgical drains. Furthermore, the pain stimulus may have been too low and of too short a duration. At baseline, the groups started with numerically different VAS scores. In addition, the $\mathrm{pH}$ of the 2 study solutions differed. However, local adverse effects were mild and appeared comparable between groups, with no patients reporting nasal itching, irritation, pain, or burning or a change in taste. Therefore, it is unlikely that the difference in $\mathrm{pH}$ resulted in differences in the tolerability of the 2 formulations. The foregoing factors limit extrapolation of the results beyond this small, selected population.

\section{Conclusions}

In these women who had undergone breast reduction or augmentation surgery, a single preprocedural dose of intranasal fentanyl $0.05 \mathrm{mg}$ was significantly more effective than placebo in reducing pain intensity over the hour after removal of surgical drains. However, there was no significant difference in pain intensity at the time of drain removal between fentanyl and placebo. Intranasal fentanyl was generally well tolerated. At the dose used, plasma fentanyl concentrations were below the reported therapeutic window. 


\section{References}

1. Barnard J, Thompson J, Dunning J. Can any intervention effectively reduce the pain associated with chest drain removal? Interact Cardiovasc Thorac Surg. 2004;3:229-232.

2. Friesner SA, Curry DM, Moddeman GR. Comparison of two pain-management strategies during chest tube removal: relaxation exercise with opioids and opioids alone. Heart Lung. 2006;35:269-76.

3. Tveita $\mathrm{T}$, Thoner J, Klepstad $\mathrm{P}$, et al. A controlled comparison between single doses of intravenous and intramuscular morphine with respect to analgesic effects and patient safety. Acta Anaesthesiol Scand. 2008;52:920-925.

4. Striebel HW, Kramer J, Luhmann I, et al. Pharmacokinetic study of intranasal fentanyl [in German]. Schmerz. 1993; 7:122-125.

5. Lim SC, Paech MJ, Sunderland VB, et al. Pharmacokinetics of nasal fentanyl. J Pharm Pract Res. 2003;33:59-63.

6. Striebel HW, Oelmann T, Spies C, et al. Patient-controlled intranasal analgesia: A method for noninvasive postoperative pain management. Anesth Analg. 1996;83:548-551.

7. Huynh NH, Tyrefors N, Ekman L, Johansson M. Determination of fentanyl in human plasma and fentanyl and norfentanyl in human urine using LC-MS/MS. J Pharm Biomed Anal. 2005;37:1095-1100.

8. Schouten HJ. Klinische Statistiek: Een Praktische Inleiding in Methodologie en Analyse. Houten/Diegem: Bohn Stafleu Van Loghum; 1999.

9. Foster D, Upton R, Christrup L, Popper L. Pharmacokinetics and pharmacodynamics of intranasal versus intravenous fentanyl in patients with pain after oral surgery. Ann Pharmacother. 2008;42:1380-1387.

10. Mantha S, Thisted R, Foss J, et al. A proposal to use confidence intervals for visual analog scale data for pain measurement to determine clinical significance [published correction appears in Anesth Analg. 1994;78:1035]. Anesth Analg. 1993;77:1041-1047.

11. Sommer M, Geurts JW, Stessel B, et al. Prevalence and predictors of postoperative pain after ear, nose, and throat surgery. Arch Otolaryngol Head Neck Surg. 2009;135:124-130.

12. Field AP. Discovering Statistics Using SPSS: And Sex and Drugs and Rock ' $n$ ' Roll. Los Angeles, Calif: Sage Publications; 2009.

13. Krueger C, Tian L. A comparison of the general linear mixed model and repeated measures ANOVA using a dataset with multiple missing data points. Biol Res Nurs. 2004;6:151-157.

14. Proost JH, Meijer DK. MW/Pharm, an integrated software package for drug dosage regimen calculation and therapeutic drug monitoring. Comput Biol Med. 1992;22:155-163.

15. Jelliffe RW, Schumitzky A, Bayard D, et al. Model-based, goal-oriented, individualised drug therapy. Linkage of population modelling, new 'multiple model' dosage design, bayesian feedback and individualised target goals. Clin Pharmacokinet. 1998;34:57-77.

16. Jelliffe RW, Schumitzky A, Van Guilder M, et al. Individualizing drug dosage regimens: Roles of population pharmacokinetic and dynamic models, Bayesian fitting, and adaptive control. Ther Drug Monit. 1993;15:380-393.

17. Bonate PL. A brief introduction to Monte Carlo simulation. Clin Pharmacokinet. 2001;40:15-22.

18. Gourlay GK, Kowalski SR, Plummer JL, et al. Fentanyl blood concentration- analgesic response relationship in the treatment of postoperative pain. Anesth Analg. 1988;67:329-337.

19. Peng PW, Sandler AN. A review of the use of fentanyl analgesia in the management of acute pain in adults. Anesthesiology. 1999;90:576-599.

20. Hummel P, van Dijk M. Pain assessment: Current status and challenges. Semin Fetal Neonatal Med. 2006;11:237-245.

21. Christrup LL, Foster D, Popper LD, et al. Pharmacokinetics, efficacy, and tolerability of fentanyl following intranasal versus intravenous administration in adults undergoing third- molar extraction: A randomized, double-blind, double-dummy, twoway, crossover study. Clin Ther. 2008;30:469-481. 
22. Moksnes K, Fredheim OM, Klepstad P, et al. Early pharmacokinetics of nasal fentanyl: Is there a significant arterio-venous difference? Eur J Clin Pharmacol. 2008;64:497-502.

23. Veldhorst-Janssen NM, Fiddelers AA, van der Kuy PH, et al. A review of the clinical pharmacokinetics of opioids, benzodiazepines, and anti- migraine drugs delivered intranasally. Clin Ther. 2009;31:29542987. 


\section{CHAPTER 5}

\section{Dual pathway absorption after intranasal drug administration: a new pharmacokinetic model}

Veldhorst-Janssen NML, Punt NC, Fiddelers AAA, van der Kuy P-HM, Marcus MAE, Neef C Submitted 


\section{Abstract}

Context: Intranasally (IN) administered drugs show a specific pharmacokinetic profile, with absorption occurring via the nasal mucosa and the gastrointestinal tract. Classic compartmental pharmacokinetic models are not really suitable for modelling a dual pathway absorption.

Objectives: The main aim of this study was to develop and validate a pharmacokinetic model to describe the concentration-time profile of an IN administered drug and to establish which absorption parameter is most important for dual pathway absorption. Additional aims were to analyse individual data using a population model approach, and to model data from the literature.

Methods: A dual pathway absorption model was developed to describe the pharmacokinetics of drugs administered IN and was validated with Monte Carlo simulations. Data sets for dual pathway absorption from the literature were fitted to the model.

Results: The model described the pharmacokinetics of a drug administered IN, and both individual data and data for dual pathway absorption from the literature showed a good fit to the model.

Conclusion: This model can adequately predict the concentration-time profile of drugs administered IN and can be used to analyse individual data using a population model approach. 


\section{Introduction}

Pharmacokinetic modelling has an important role in the development of new drug formulations. Some models have been developed for a particular dosage form, such as intranasally (IN) administered drugs. These drugs have specific pharmacokinetic characteristics, and especially when the drug is to have a systemic effect [1]. IN drug administration has several advantages [2,3]. First, the rich vasculature and numerous microvilli in the nasal cavity provide a direct route into the blood stream, thereby avoiding first-pass elimination of the drug, its metabolism in the gut wall, or its breakdown by gastrointestinal fluids. The direct availability of the drug in the circulation results in a time to peak plasma concentration between that seen with intravenous and oral drug administration [4]. Second, drugs administered in a nasal spray are distributed to the brain quicker than drugs administered by other routes, potentially leading to rapid drug action [5]. Third, IN drug administration is non-invasive, does not require sterile techniques, and is easy, allowing patients or bystanders to administer drugs $[2,3,5]$.

Drugs administered IN are absorbed by two pathways, namely, via the nasal mucosa (direct) and via gastrointestinal absorption following ciliary clearance and subsequent swallowing of the drug [1-5]. This means that the pharmacokinetics of IN administered substances reflect direct absorption into the bloodstream (early absorption), oral uptake via the gastrointestinal tract (late absorption), or a combination of both (nasoral absorption) [6]. Examples of these three absorption pathways can be found in the literature. The absorption of IN administered hydroxocobalamin [6-8], dihydroergotamine [9], and alniditan [10] can be regarded as direct, or early, absorption. Two peaks can be distinguished during the absorption of zolmitriptan [11] and midazolam [12], reflecting a combination of early and late, or nasoral, absorption. Metoclopramide shows comparable absorption profiles when administered IN or orally, indicating that it is absorbed by gastrointestinal, or late, absorption [13].

The main aim of this study was to develop and validate a pharmacokinetic model to describe the individual concentration-time profile of IN administered drugs and to establish which absorption parameter is most important for dual pathway absorption. Other aims were to analyse individual data using a population model approach and to test the model with data from the literature 


\section{Methods}

\section{Modelling strategy}

As first step, the theoretical basis of the model for dual pathway absorption was described and then the model was implemented using the SimLab Excel application [14] (Medimatics, Maastricht, The Netherlands). A poly-exponential equation was embedded in a Visual Basic for applications class module (TModel). A second VBA class module (TModelDual) was equipped with two instances of the TModel class (Model 1 and Model 2) and a parameter (FDose) dividing a given dose over intranasal absorption (Model 1) and gastrointestinal absorption (Model 2). The output concentration of the dual pathway absorption model was calculated as the sum of the individual model concentrations (superposition principle). This design is represented by the diagram below.

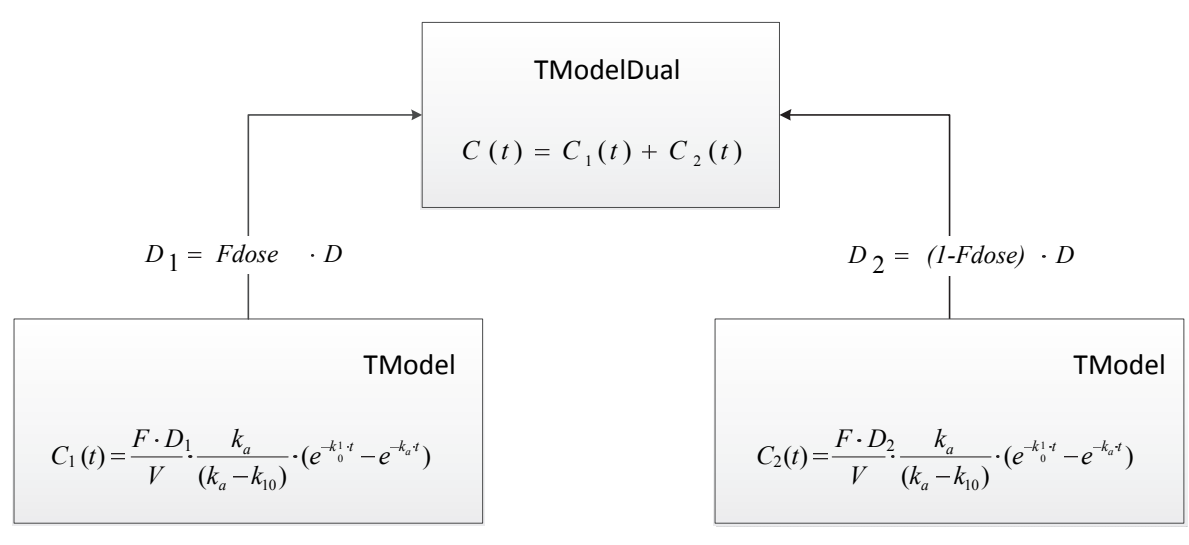

Where $\mathrm{C}$ is the plasma concentration at a time point, $\mathrm{F}$ is the fraction of the dose absorbed, $\mathrm{D}$ is the given dose, $\mathrm{V}$ is the volume of distribution, $\mathrm{k}_{\mathrm{a}}$ is the absorption rate constant, $\mathrm{k}_{10}$ is the elimination rate constant and Fdose is the fraction of the dose divided over intranasal absorption (Model 1) and gastrointestinal absorption (Model 2).

The equations in the diagram above were simplified, whereby the actual model supports multiple compartments (up to 3), multiple dosing and absorption lag time $\left(\mathrm{t}_{0}\right)$.

\section{Parameter estimation}

Midazolam nasal spray was used as a relevant example for this model. The model parameters were fitted to observations, using Excel's build in Solver component. We obtained the IN and oral absorption parameters $\left(k_{a}, F, t_{0}\right)$ from an earlier study [15] and from unpublished data, using the KinBes deconvolution software (Mediware, Gro- 
ningen, The Netherlands). Disposition parameters ( $\mathrm{V}, \mathrm{k} 10)$ were obtained by fitting intravenous data series [15] using KinFit [16] (Mediware, Groningen, The Netherlands). These parameters were then merged into the dual absorption model.

\section{Validation}

In total, 1000 Monte Carlo simulations were performed [17], based on the estimated midazolam model parameters with a coefficient of variance of $30 \%$ to validate the final pharmacokinetic model. Outcomes were generated at the same time points as plasma samples were taken [15]. Each individual curve from these 1000 simulations was stored. The results of these simulations were plotted as plasma concentration-time profiles, showing the median concentration and the 5th-95th percentile ranges.

The relationship between the coefficient of variance of the model parameters and the proportion of concentration-time curves that had two peaks was studied by performing Monte Carlo simulations (1000 simulations), using increasing coefficients of variance $(0 \%-50 \%)$ of the model parameters.

In the absorption phase, the parameters $k_{a}$ and $t_{0}$ determine the rate and extent of absorption after IN drug administration. The difference between $t_{0,1}$ and $t_{0,2}$ or the difference between $k_{a, 1}$ and $k_{a, 2}$ was increased from 0 to 2 times the value to determine the contribution of these parameters to dual pathway absorption.

\section{Individual data}

Data sets showing dual pathway absorption described by Veldhorst et al [15] were fitted to the population model described above. The area under the curve (AUC) was calculated using the trapezium rule to compare differences between observed and estimated concentration-time plots.

\section{Fit of the model to data from the literature}

Burstein et al [12] reported data clearly showing the dual pathway absorption of IN midazolam. Data from this study were manually extracted from the plasma concentration-time plot and incorporated into the pharmacokinetic model.

\section{Results}

\section{Modelling and parameter estimation}

When the IN midazolam observations were fitted to a one-compartment model of dual pathway absorption, the flip-flop phenomenon occurred in many cases. The fitted absorption rate was slower than the estimated elimination rate, and the elimination rate was unrealistic. Under these conditions, the terminal phase of the plasma curve 
would be governed by absorption instead of elimination $[18,19]$. To prevent this flipflop phenomenon, previously published midazolam absorption and elimination parameters were used [15]. The dual pathway absorption model was developed as described in the Methods section. Table I gives an overview of the absorption and disposition parameters of IN midazolam.

Table I Estimated parameters (Midazolam)

\begin{tabular}{|c|c|c|c|c|c|c|}
\hline Type & Name & Unit & Value & $\begin{array}{c}\text { Source } \\
\text { Data }\end{array}$ & $\begin{array}{l}\text { Program } \\
\text { for Analysis }\end{array}$ & Description \\
\hline \multirow[t]{2}{*}{ Disposition (shared) } & V1 & $\mathrm{L}$ & 0.035 & IV & KinFit & Volume of distribution \\
\hline & $\mathrm{k}_{10}$ & $1 / \mathrm{h}$ & 0.457 & IV & KinFit & Elimination rate constant \\
\hline \multirow[t]{3}{*}{ Absorption 1 (early \& fast) } & $\mathrm{F}$ & - & 0.84 & IN & KinBes & Bioavailability \\
\hline & $t_{0}$ & $\mathrm{~h}$ & 0.035 & IN & KinBes & Lag-time (early) \\
\hline & $\mathrm{k}_{\mathrm{a}}$ & $1 / \mathrm{h}$ & 15.0 & IN & KinBes & Absorption rate (fast) \\
\hline \multirow[t]{3}{*}{ Absorption 2 (late \& slow) } & $\mathrm{F}$ & - & 0.93 & $\mathrm{PO}$ & KinBes & Bioavailability \\
\hline & $t_{0}$ & $\mathrm{~h}$ & 0.197 & $\mathrm{PO}$ & KinBes & Lag-time (late) \\
\hline & $\mathrm{k}_{\mathrm{a}}$ & $1 / \mathrm{h}$ & 3.35 & $\mathrm{PO}$ & KinBes & Absorption rate (slow) \\
\hline
\end{tabular}

IV observed plasma concentration - time data adapted ${ }^{[15]}$

IN observed plasma concentration - time data adapted ${ }^{[15]}$

PO observed plasma concentration - time data (unpublished)

\section{Validation}

One thousand Monte Carlo simulations were performed to generate a plasma concentration-time profile, showing the median concentration and the 5th-95th percentile ranges. The outcome of these simulations with a parameter error of $30 \%$ is shown in Figure 1. Dual peaks were not detected. However, examination of each individual curve from 1000 simulations for the presence of a local minimum, indicating the presence of two peaks or dual pathway absorption, revealed that $3.4 \%$ of the individual curves had a local minimum. 


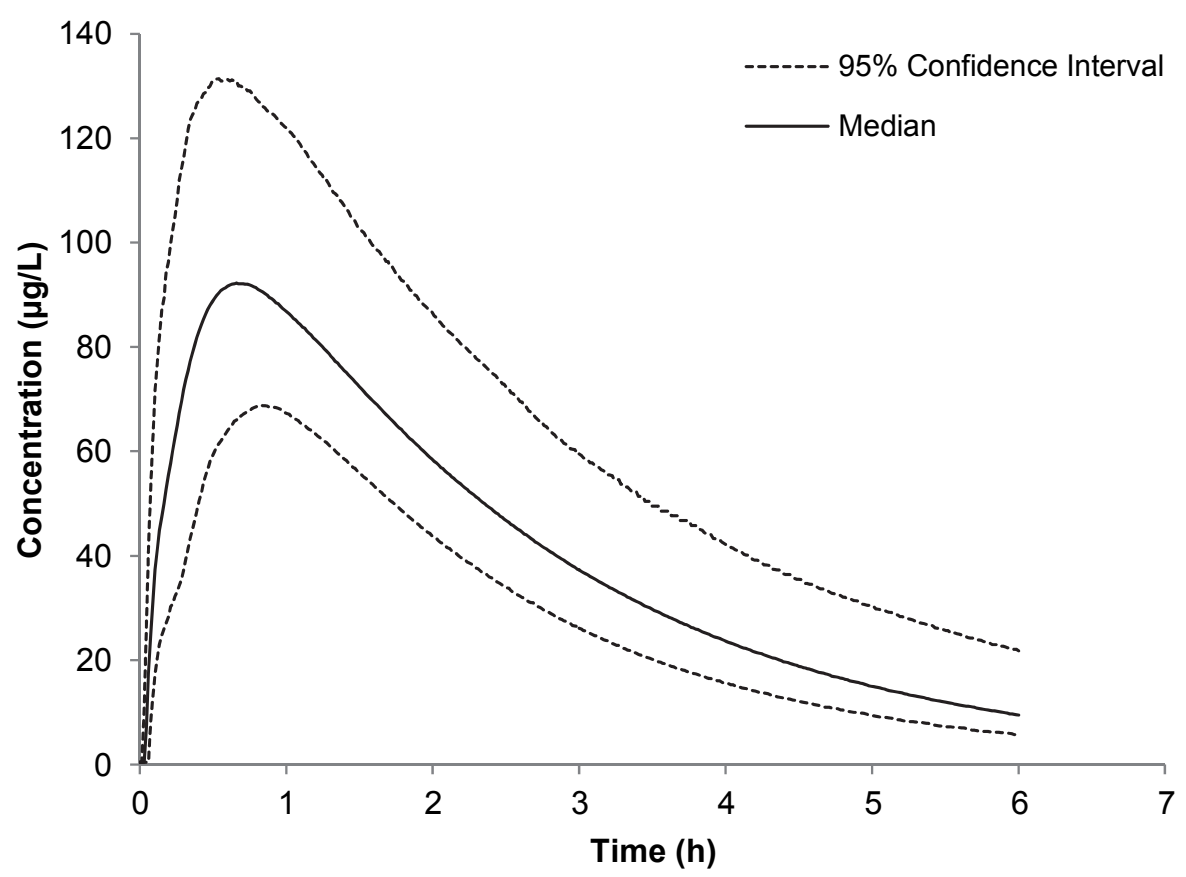

Figure 1. Monte Carlo simulation of a prototype IN midazolam $5 \mathrm{mg}$

Figure 2 shows the relationship between the coefficient of variance (parameter error) and the proportion of concentration-time curves that had two peaks. Biphasic profiles were observed that began to deviate from zero at a parameter error of $15 \%$, increasing to $13.6 \%$ at a parameter error of $50 \%$.

When the difference between the parameters $t_{0,1}$ and $t_{0,2}$ in Model 1 (IN) and Model 2 (gastrointestinal) was increased, and when the difference between the parameters $\mathrm{k}_{\mathrm{a}, 1}$ and $\mathrm{k}_{\mathrm{a}, 2}$ in Model 1 (IN) and Model 2 (gastrointestinal) was increased, the contribution of the difference between the parameters $t_{0,1}$ and $t_{0,2}$ to a local minimum exceeded the contribution of the difference between the parameters $k_{a, 1}$ and $k_{a, 2}$, as plotted in Figure 3. 


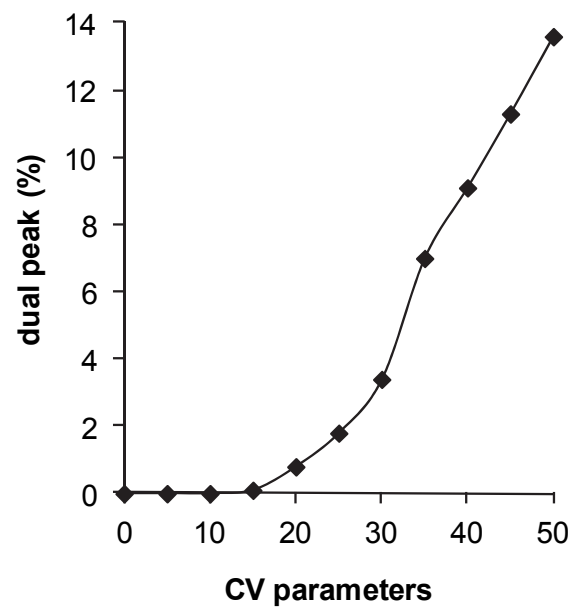

Figure 2. Number of dual peaks (\%) in 1000 simulations versus parameter error of coefficients of variance

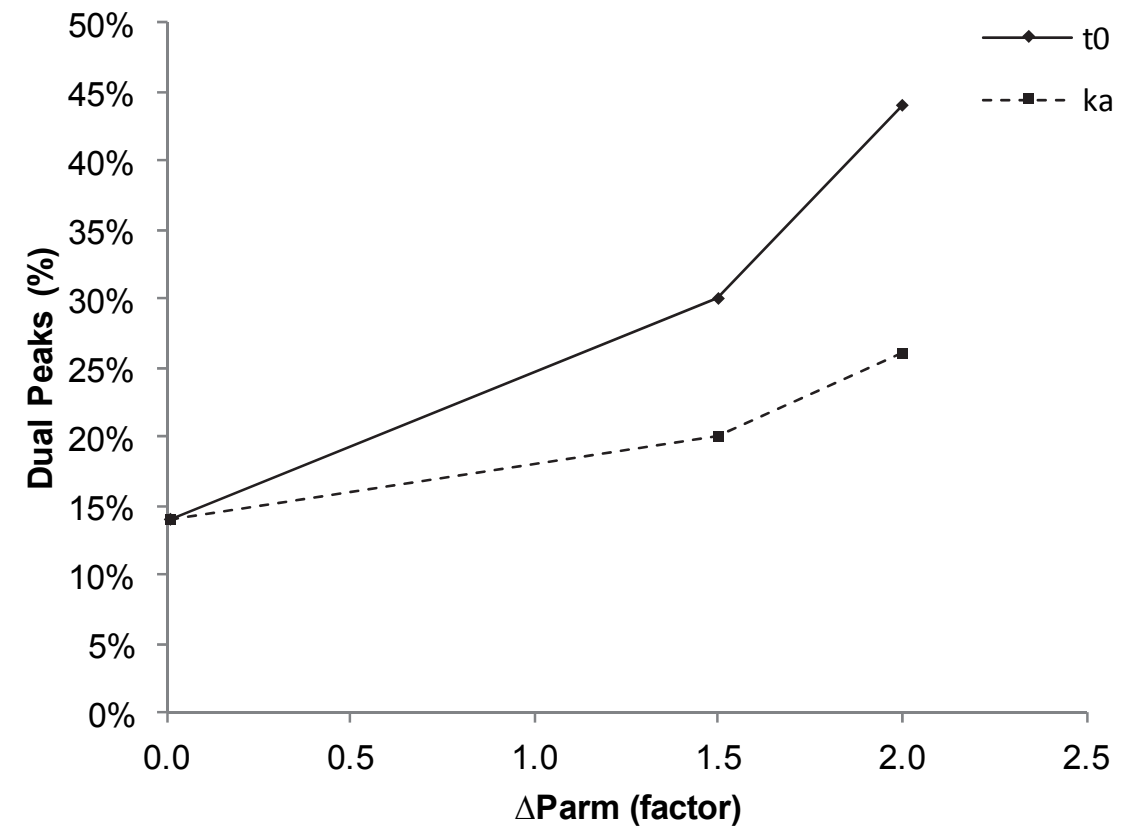

Figure 3. Contribution of increasing difference of $t_{0}$ and $k_{a b s}$ between model 1 (intranasal) and model 2 (gastrointestinal) to the number of dual peaks (\%) in 1000 simulations. $\Delta$ Parm $=$ difference in parameter 


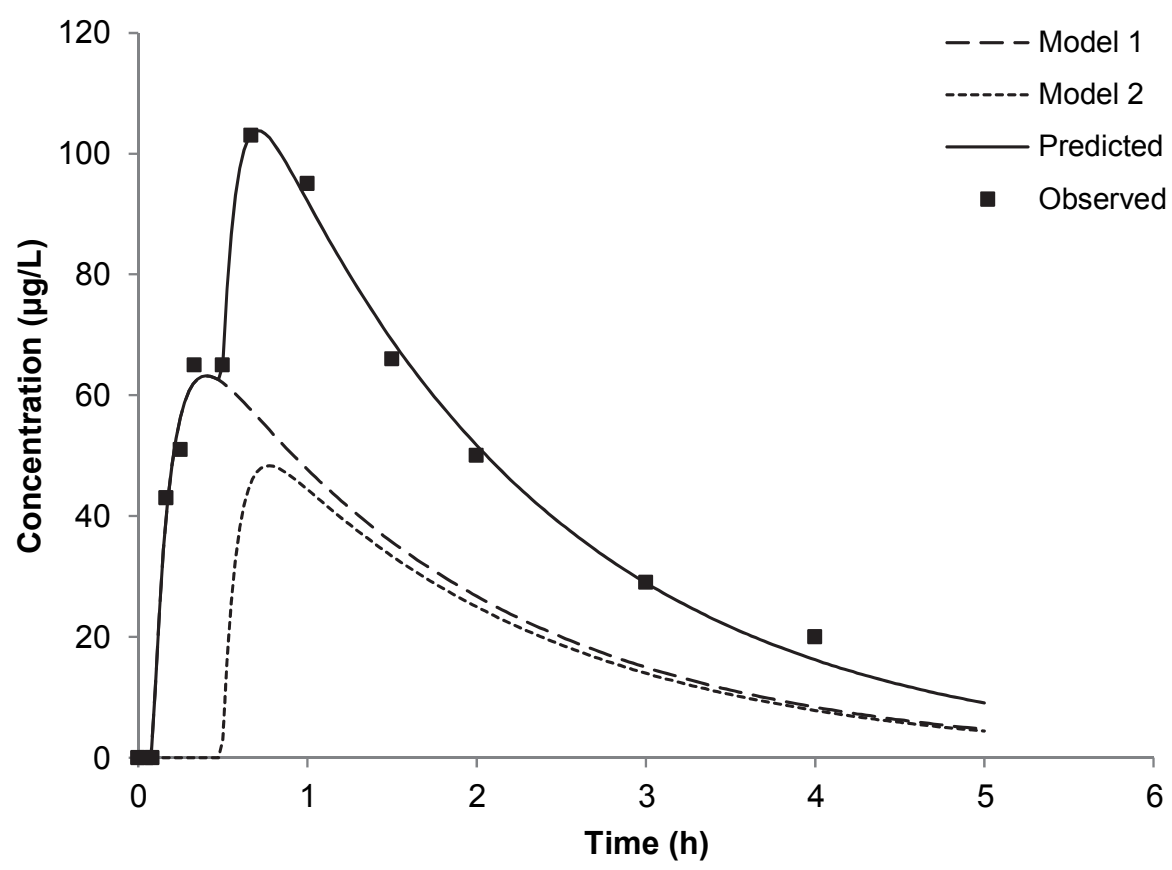

Figure 4. Simulated plasma concentration-time profile (using the dual absorption pharmacokinetic model) and observed plasma concentrations of midazolam $5 \mathrm{mg}$ after intranasal administration Model 1, Intranasal absorption; Model 2, gastrointestinal absorption. The curves describing Model 1 and Predicted, overlap each other in the first part of the figure.

\section{Individual data}

Concentration-time plots for midazolam after IN administration were analysed using the dual pathway absorption model, where absorption takes place from different sites (intranasal and gastrointestinal tract) and with different lag-times and $k_{a}$. Figure 4 shows the fit obtained by this method. The AUC of the measured and estimated curve was $201.63 \mu \mathrm{g} / \mathrm{L}^{*} \mathrm{~h}$ and $201.27 \mu \mathrm{g} / \mathrm{L}^{*} \mathrm{~h}$, respectively.

\section{Fit of the model to data from the literature}

Data extracted from the study of Burstein et al [12] showed a good fit to the dual pathway absorption model (Figure 5). 


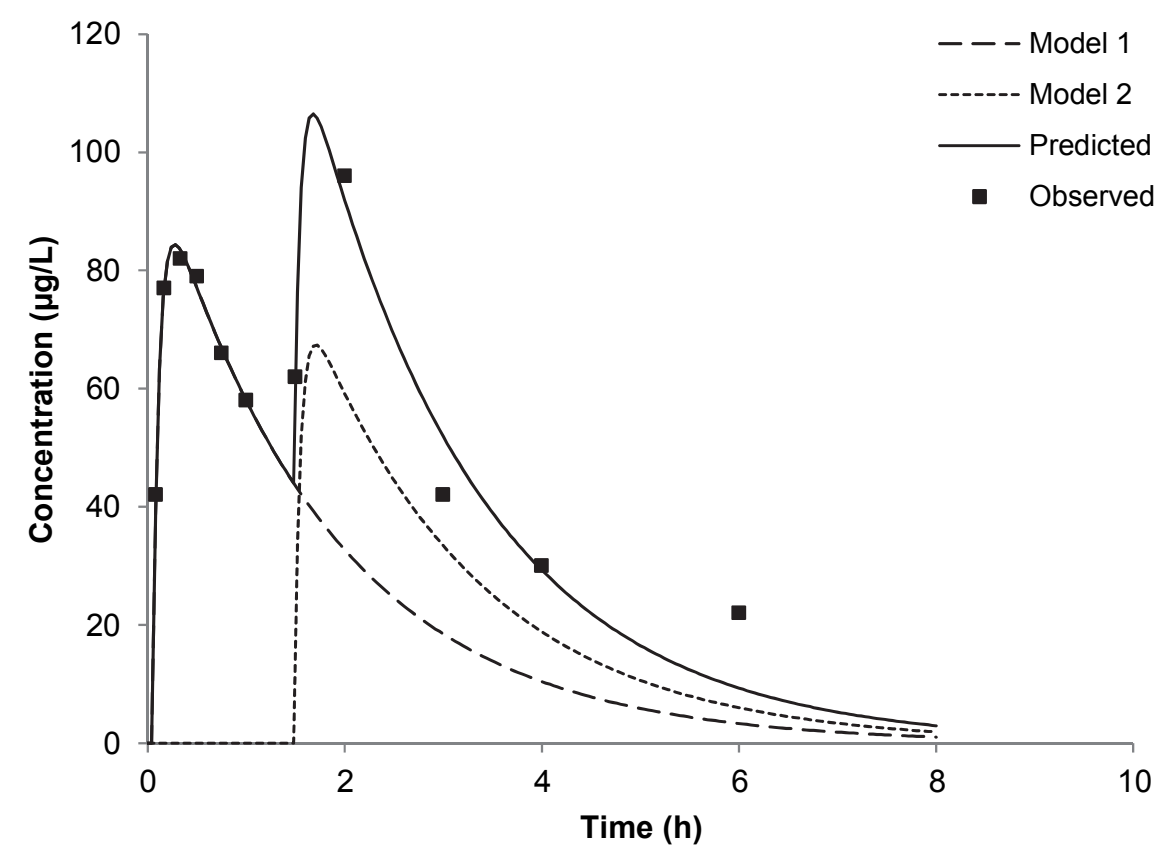

Figure 5. Simulated plasma concentration-time profile (using the dual absorption pharmacokinetic model) and observed plasma concentrations of midazolam after intranasal administration (data adapted by Burstein et al [12])

Model 1, intranasal absorption; Model 2, gastrointestinal absorption. The curves describing Model 1 and Predicted, overlap each other in the first part of the figure.

\section{Discussion}

Our results demonstrate that the dual pathway absorption of midazolam after IN administration can be predicted by our validated pharmacokinetic model. Using Monte Carlo simulations, we were able to demonstrate that although a population model of IN midazolam did not show a dual pathway absorption profile (fig 1), two peaks were seen in some cases as a result of biological variation (fig 2). Moreover, data from the literature that clearly demonstrated IN midazolam to be absorbed via a dual pathway had a good fit to our model.

Using data for intravenously and orally administered midazolam, we were able to generate the data needed to describe the elimination and absorption parameters of the model. The flip-flop phenomenon that occurred during model development indicates that absorption $[18,19]$ was slower than elimination as a result of gastrointestinal absorption (late absorption). Dual pathway absorption could be due to enterohepatic recirculation, but then the appearance of the peak would be independent of the route 
of administration. As the concentration-time curves for intravenously [15] and orally administered midazolam did not exhibit two peaks, it can be assumed that the occurrence of two peaks is not the consequence of enterohepatic recirculation but the consequence of the absorption of midazolam from different sites, via both the nasal mucosa and the gastrointestinal tract.

Mahmood et al [20] described the absorption characteristics of oral sustainedrelease diclofenac sodium in humans according to a multi-segment absorption model. The gastrointestinal tract was divided into several segments, in each of which the drug had its own lag-time and absorption rate constants. We considered the nasal compartment and the gastrointestinal tract as two segments, each with their own lag-time and absorption rate constants (see table I).

Variation in physicochemical, formulation, and physiological factors can affect concentration-time profiles and may create double peaks [21]. When the variation in physiological factors was increased to $50 \%$, without there being changes in physicochemical factors and formulation, $14 \%$ of the individual concentration-time curves showed double peaks suggestive of dual pathway absorption. However, when population modelling was performed with the data for IN midazolam, the two absorption peaks were smoothed out in the concentration-time profile (Figure 1), suggesting that dual pathway absorption did not occur. Variation in physicochemical factors and formulation can also cause double peaks [21], as reflected by the lag-time and the absorption rate constants. In this example, the factor lag-time contributed more to the formation of double peaks than the absorption rate constant.

\section{Conclusion}

The model developed could adequately predict individual concentration-time profiles for midazolam absorption after its IN administration. This model can be used to analyse individual data, using a population model approach, and to model data from the literature. 


\section{References}

1. Illum L. Nasal drug delivery-possibilities, problems and solutions. J Control Release. 2003;87(1-3):18798.

2. Chien YW, Chang SF. Intranasal drug delivery for systemic medications. Crit Rev Ther Drug Carrier Syst. 1987;4(2):67-194.

3. Costantino HR, Illum L, Brandt G, et al. Intranasal delivery: physicochemical and therapeutic aspects. Int J Pharm. 2007;337(1-2):1-24.

4. Veldhorst-Janssen NML, Fiddelers AA, van der Kuy PH, et al. A review of the clinical pharmacokinetics of opioids, benzodiazepines, and antimigraine drugs delivered intranasally. Clin Ther. 2009;31(12):295487.

5. Brunton LL, editor. Goodman \& Gilman's The Pharmacological Basis of Therapeutics. 11 ed; 2006.

6. Kuy van der P-H. Studies on intranasal drug delivery in migraine. Leiden: University of Leiden; 2003.

7. Kuy van der P-H, Merkus FW, Russel FG, et al. Pharmacokinetics of intranasal and oral hydroxocobalamin. Br J Clin Pharmacol. 2001;51:505p.

8. Kuy van der P-H, Merkus FW, Lohman JJ, et al. Hydroxocobalamin, a nitric oxide scavenger, in the prophylaxis of migraine: an open, pilot study. Cephalalgia. 2002;22(7):513-9.

9. Kuy van der PH, Lohman JJ, Hooymans PM, et al. Bio-availability of intranasal formulations of dihydroergotamine. Eur J Clin Pharmacol. 1999;55:677-80.

10. Roon KI, Soons PA, Uitendaal MP, et al. Pharmacokinetic profile of alniditan nasal spray during and outside migraine attacks. Br J Clin Pharmacol. 1999;47(3):285-90.

11. Yates R, Nairn K, Dixon R, et al. Preliminary studies of the pharmacokinetics and tolerability of zolmitriptan nasal spray in healthy volunteers. J Clin Pharmacol. 2002;42(11):1237-43.

12. Burstein $\mathrm{AH}$, Modica R, Hatton $\mathrm{M}$, et al. Pharmacokinetics and pharmacodynamics of midazolam after intranasal administration. J Clin Pharmacol. 1997;37(8):711-8.

13. Ormrod D, Goa KL. Intranasal metoclopramide. Drugs. 1999;58(2):315-22; discussion 23-4.

14. Punt N. SimLab. 2011 cited; Available from: www.medimatics.net/projects/simlab

15. Veldhorst-Janssen NML, Fiddelers AA, van der Kuy PH, et al. Pharmacokinetics and tolerability of nasal versus intravenous midazolam in healthy dutch volunteers: a single-dose, randomized-sequence, openlabel, 2-period crossover pilot study. Clin Ther. 2011;33(12):2022-8.

16. Proost JH, Meijer DK. MW/Pharm, an integrated software package for drug dosage regimen calculation and therapeutic drug monitoring. Comput Biol Med. 1992;22(3):155-63.

17. Bonate PL. A brief introduction to Monte Carlo simulation. Clin Pharmacokinet. 2001;40(1):15-22.

18. Boxenbaum H. Pharmacokinetics tricks and traps: flip-flop models. J Pharm Pharm Sci. 1998;1(3):90-1.

19. Wagner JG. Pharmacokinetic absorption plots from oral data alone or oral/intravenous data and an exact Loo-Riegelman equation. J Pharm Sci. 1983;72(7):838-42.

20. Mahmood I. Pharmacokinetic analysis of the absorption characteristics of diclofenac sodium in man by use of a multi-segment absorption model. J Pharm Pharmacol. 1996;48(12):1260-3.

21. Davies NM, Takemoto JK, Brocks DR, et al. Multiple peaking phenomena in pharmacokinetic disposition. Clin Pharmacokinet. 2010;49(6):351-77. 


\section{CHAPTER 6}

\section{Patient satisfaction with intranasal fentanyl for breakthrough pain}

Veldhorst-Janssen NML, Fiddelers AAA, Zandstra H, Kessels AGH, Marcus MAE, Neef C, van der Kuy P-HM

Published as Letter to the editor J. of Pall Med 2012;15(6):631-632 


\section{Abstract}

Context: Pain is a significant source of distress for patients. Few studies have investigated patients' satisfaction with intranasal (IN) fentanyl for the management of severe pain or breakthrough pain in cancer.

Objectives: To investigate patients' satisfaction with IN fentanyl, the reduction in pain achieved, and whether the pain reduction and clinical or demographic characteristics are related to patients' satisfaction with medication.

Methods: Patients older than 18 years who used IN fentanyl were approached for participation by their pharmacist. Patient's satisfaction with IN fentanyl was assessed with the validated 'Treatment Satisfaction Questionnaire for Medication' (TSQM), and pain severity was assessed with a numerical rating scale (NRS). This trial is registered at trial register.nl, NTR2880.

Results: Twenty-five patients returned the TSQM questionnaire. Mean (SD) scores were 65.6 (20.1) for effectiveness, 87.0 (19.5) for side effects, 58.0 (16.9) for convenience, and 53.6 (19.9) for global satisfaction. Higher levels of pain were associated with lower levels of satisfaction with medication effectiveness. Patients experienced significantly less pain with than without IN fentanyl (mean (SD) NRS 4.02 (2.27) and 7.72 (2.31), respectively, $p<0.001)$.

Conclusion: Patients were satisfied with IN fentanyl for the management of severe pain. 


\section{Introduction}

Outpatient pain management is a challenge, perhaps more so than inpatient pain management. The step-wise approach to pain management, the analgesic ladder, proposed by the World Health Organization (WHO) is widely accepted as a fundamental strategy for pain control [1]. The treatment of cancer-related pain has its own specific challenges, and most cancer patients use opioids chronically for background pain, a common symptom of cancer [2-10]. Among cancer patient, 30-40\% experience background pain at diagnosis [7,8], 50-70\% experience pain when undergoing active treatment, and $70-80 \%$ experience pain in advanced disease $[7,11]$. In most cases, background pain can be adequately treated with opioids, as recommended by the WHO guideline [1]. However, in addition to background pain, $40-90 \%$ of patients experience breakthrough pain (BTP) $[8,10,12]$. BTP is defined as a transitory exacerbation that occurs against a background of otherwise controlled, persistent pain [12,13] and is described as severe or excruciating [2,8]. It is typically of rapid onset (mean time from onset to peak pain intensity is 1-3 minutes) and short duration (median duration is 3045 minutes). It is associated with a higher level of pain-related distress and impaired quality of life $[10,13,14]$, and its occurrence has a negative impact on patients' satisfaction with pain control and opioid therapy $[4,10,14]$. BTP can lead to immobility, insomnia, anxiety, depression, and social isolation [4].

BTP is usually managed by adding another formulation of short-acting opioids in addition to the normal around-the-clock medicine $[4,9,15]$. However, the nature (rapid onset and short duration) of BTP makes it very difficult to manage adequately with oral short-acting opioids, since they take too long to produce analgesia [4,9]. For example, short-acting morphine or oxycodone usually takes effect at least 20 minutes after dosing [15], and reaches its maximum analgesic effect after about 1 hour [9]. In contrast, parenterally administered opioids have an onset of effect within 5 minutes, which makes these agents more suitable for BTP. However, this route of drug administration is invasive and can be painful, and drugs have to be administered by trained paramedics; self-administration is not possible [9]. Therefore, an alternative non-invasive way to administer opioids, with the possibility to titrate the dose to the individual patient and to achieve a therapeutic effect rapidly, is required in daily clinical practice.

A non-invasive way to administer opioids is intranasally. Several studies have investigated the pharmacokinetics, efficacy, safety, and tolerability of intranasal (IN) fentanyl as intranasal fentanyl spray (Instany $\left.\right|^{\circledR}$ ) or fentanyl pectin nasal spray (FPNS, Pecfent $\left.{ }^{\circledast}\right)$ in healthy volunteers and patients [8,15-27]. The pharmacokinetic characteristics of fentanyl make it suitable for IN administration. Owing to its high lipophilicity, fentanyl is rapidly absorbed from the nasal mucosa within 5 minutes $[23,28]$ and the mean time to maximum plasma concentration is less than 15 minutes for both IN fen- 
tanyl spray and FPNS [16,29-31]. In general the [16,29-31]. The bioavailability (55-90\%) of IN administered fentanyl is similar to higher to that after oral transmucosal administration and is higher than that after oral administration [16,18,25,27-29,31,32]. This is due to the anatomy of the nasal cavity, with its rich vasculature and numerous microvilli, and the avoidance of the first-pass effect in the liver. IN fentanyl has proven highly effective for the treatment of BTP in cancer patients [15,17, 20-22,25,26], with a mean time to onset of analgesia of 6-8 minutes [16] and a pain reduction significantly greater than that provided by placebo $[8,20]$.

Knowledge of patients' preferences and attitudes toward IN fentanyl is important when deciding whether or not to use IN fentanyl; however, little is known about the acceptability of IN fentanyl. The main goal of our study was to determine patients' satisfaction with IN fentanyl, the pain reduction achieved, and whether clinical or demographic characteristics and the pain reduction achieved are related to patients' satisfaction with pain management with IN fentanyl.

\section{Methods}

\section{Participants}

Patients were considered eligible for inclusion if they were 18 years or older, if they used IN fentanyl (Instanyl ${ }^{\circ}$ ), and if they provided informed consent. Lack of knowledge of Dutch was an exclusion criterion. We mainly focused on patients with cancerrelated BTP, but also included patients with pain that was not related to cancer, but severe enough to warrant the use of rescue medication such as IN fentanyl. The sample size of 25 was determined by using a confidence interval of $20 \%$ and a confidence level of $95 \%$.

\section{Study design}

This study was performed in 2010 and 2011 at the Maastricht University Medical Centre+, The Netherlands. Patients were recruited by their pharmacist or physician and were asked to complete a short questionnaire concerning their satisfaction with treatment at one moment in time. The study protocol was approved by the Medical Ethics Committee of the Maastricht University Medical Centre+ and written informed consent was obtained from all participants.

\section{Measures}

Demographic and clinical characteristics.

A standardized self-report questionnaire was used to obtain demographic and clinical information, namely, age, gender, weight, height, educational attainment, duration of 
pain, pain after treatment with IN fentanyl, and pain at rest and during activity with and without treatment with IN fentanyl (Table 1 and 2). Pain was measured with an 11-point numeric rating scale (NRS).

Treatment satisfaction.

Satisfaction with IN fentanyl was measured by using the 'Treatment Satisfaction Questionnaire for Medication' (TSQM) [33,34]. The validated self-report TSQM questionnaire consists of 14 items in four scales: effectiveness (TSQM effectiveness), side effects (TSQM side effects), convenience (TSQM convenience), and global satisfaction (TSQM global satisfaction). Scores range from 0 (extremely dissatisfied) to 100 (extremely satisfied) and were clustered into four groups: 0-25 (not satisfied), 26-50 (not satisfied or dissatisfied), 51-75 (satisfied), and 76-100 (very satisfied).

\section{Statistical analysis}

Logistic regression analyses were performed to examine the effect of clinical and demographic characteristics and pain reduction on patient satisfaction with medication. All data analyses were performed using the Statistical Package for Social Sciences (SPSS, version 18.0). Multiple data-imputation was used according the method described by van Buuren et al [35], generating five datasets.

\section{Results}

\section{Demographic and clinical characteristics}

During a 9-month period 72 pharmacists approached patients in The Netherlands. Twenty-five patients gave informed consent, and completed and returned the questionnaires. Table I shows the demographic characteristics of the study patients: 15 female and 10 male patients participated, mean (SD) age 59.0 (13.7) years (range 2978), and mean (SD) Body Mass Index (BMI) 24.0 (4.1) (range 17-33). Given the severity of their illness, no patients were currently working.

Descriptive statistics on medication use and illness characteristics are shown in Table 2. Most patients (56\%) described the pain as stinging, $40 \%$ had had BTP for between 1 month and 1 year (range 3 weeks to 6 years), and 68\% experienced pain more than once a day (range 4 times a week to 11 times a day). Most patients (72\%) used IN fentanyl on a daily basis. Fifty-six percent of patients had used IN fentanyl for more than 1 month (range 1 day to 9 months). In most patients, BTP lasted 10 to 30 minutes and was controlled with two sprays of IN fentanyl (range 1 to 10 sprays). The majority of patients (84\%) had previously used other medications for BTP (e.g., sublingual fen- 
tanyl, oxycodone, morphine, tramadol, methadone or acetaminophen), $64 \%$ of whom considered IN fentanyl to be better than the medication they previously used.

Table 1. Demographic Characteristics of Study Sample

\begin{tabular}{lc}
\hline Baseline characteristics & Sample Summary \\
\hline Age (years), mean (SD) & $59.0(13.7)$ \\
Gender, $n$ (\%) & $10(60.0)$ \\
$\quad$ Male & $15(40.0)$ \\
$\quad$ Female & $69.0(12.6)$ \\
Weight (kg), mean (SD) & $1.7(0.1)$ \\
Height (m), mean (SD) & $24.0(4.1)$ \\
Body Mass Index, mean (SD) & \\
Education, $n$ (\%) & $11(44.0)$ \\
$\quad$ High school & $8(32.0)$ \\
Completed High school & $6(24.0)$ \\
$\quad>$ High school & \\
Employment status, $n$ (\%) & $0(0.0)$ \\
Employed (part or full time) & $8(32.0)$ \\
Retired & $11(44.0)$ \\
Quit because of health & $6(24.0)$ \\
Unemployed & \\
\hline
\end{tabular}

Treatment satisfaction

The mean (SD) scores and ranges for treatment satisfaction are shown in Table 3. Figure 1 shows that most patients were (very) satisfied with the effectiveness (80\%), convenience (72\%), and side effects (92\%) of IN fentanyl. Overall, $72 \%$ of patients were globally satisfied with IV fentanyl; no patients were dissatisfied with its effectiveness or side effects.

\section{Relationship of Demographic and Clinical Variables to Study Variables}

TSQM effectiveness and TSQM side effects were not significantly related to any clinical or demographic characteristic. TSQM convenience was significantly related to age and to the number of sprays patients used. Older patients had a lower score on TSQM convenience ( 0.6 points for each increasing year of age; $p<0.05$ ), and each extra spray increased TSQM convenience by 3.0 points $(p<0.05)$. Patients who were more satisfied with IN fentanyl than with previously used medication had higher scores on TSQM global satisfaction ( 0.2 points; $p<0.05$ ). 
Table 2. Descriptive statistics of medication and illness characteristics

\begin{tabular}{|c|c|}
\hline Clinical characteristics & Sample Summary \\
\hline \multicolumn{2}{|l|}{ Type of pain, $n(\%)$} \\
\hline Nagging pain & $2(8.0)$ \\
\hline Stinging pain & $14(56.0)$ \\
\hline Burning pain & $3(12.0)$ \\
\hline Other & $6(24.0)$ \\
\hline \multicolumn{2}{|c|}{ How long breakthrough pain has been experienced, $n$ (\%) } \\
\hline$\leq 1$ month & $7(28.0)$ \\
\hline 1 month - 1 year & $10(40.0)$ \\
\hline$\geq 1$ year & $8(32.0)$ \\
\hline \multicolumn{2}{|l|}{ Pain frequency, $n$ (\%) } \\
\hline$\leq 1 \times$ per day & $8(32.0)$ \\
\hline$>1 \times$ per day & $17(68.0)$ \\
\hline \multicolumn{2}{|c|}{ Frequency daily use IN fentanyl, $n(\%)$} \\
\hline Always & $18(72.0)$ \\
\hline Halftime & $6(24.0)$ \\
\hline Never & $1(4.0)$ \\
\hline \multicolumn{2}{|c|}{ Period of using IN fentanyl, $n(\%)$} \\
\hline$\leq 1$ month & $11(44.0)$ \\
\hline$>1$ month & $14(56.0)$ \\
\hline \multicolumn{2}{|c|}{ Number of sprays during breakthrough pain, $n$ (\%) } \\
\hline 0 spray & $1(4.0)$ \\
\hline 1 spray & $6(24.0)$ \\
\hline 2 sprays & $10(40.0)$ \\
\hline 3 sprays & $1(4.0)$ \\
\hline 4 sprays & $3(12.0)$ \\
\hline 6 sprays & $3(12.0)$ \\
\hline 10 sprays & $1(4.0)$ \\
\hline \multicolumn{2}{|c|}{ Duration of breakthrough pain, $n(\%)$} \\
\hline$<10$ minutes & $6(24.0)$ \\
\hline $10-30$ minutes & $10(40.0)$ \\
\hline $30-60$ minutes & $5(20.0)$ \\
\hline$>60$ minutes & $4(16.0)$ \\
\hline \multicolumn{2}{|c|}{ Other (previously used) analgesics for breakthrough pain, $n(\%)$} \\
\hline Yes & $21(84.0)$ \\
\hline No & $4(16.0)$ \\
\hline \multicolumn{2}{|c|}{$\begin{array}{l}\text { IN fentanyl compared to previously used medication for breakthrough pain, } \\
n(\%)\end{array}$} \\
\hline Much better & $8(32.0)$ \\
\hline Little better & $8(32.0)$ \\
\hline No difference & $3(12.0)$ \\
\hline Worse & $2(8.0)$ \\
\hline N/A & $4(16.0)$ \\
\hline
\end{tabular}


Table 3. Satisfaction with IN fentanyl

\begin{tabular}{lll}
\hline TSQM scales* & Mean (SD) & range \\
\hline Effectiveness & $65.6(20.1)$ & $33.3-100.0$ \\
Side effects & $87.0(19.5)$ & $43.8-100.0$ \\
Convenience & $58.0(16.9)$ & $16.7-94.4$ \\
Global satisfaction & $53.6(19.9)$ & $14.3-78.6$ \\
\hline
\end{tabular}

*Scales from 0-100 in which ' 0 ' means not satisfied at all and ' 100 ' means extremely satisfied

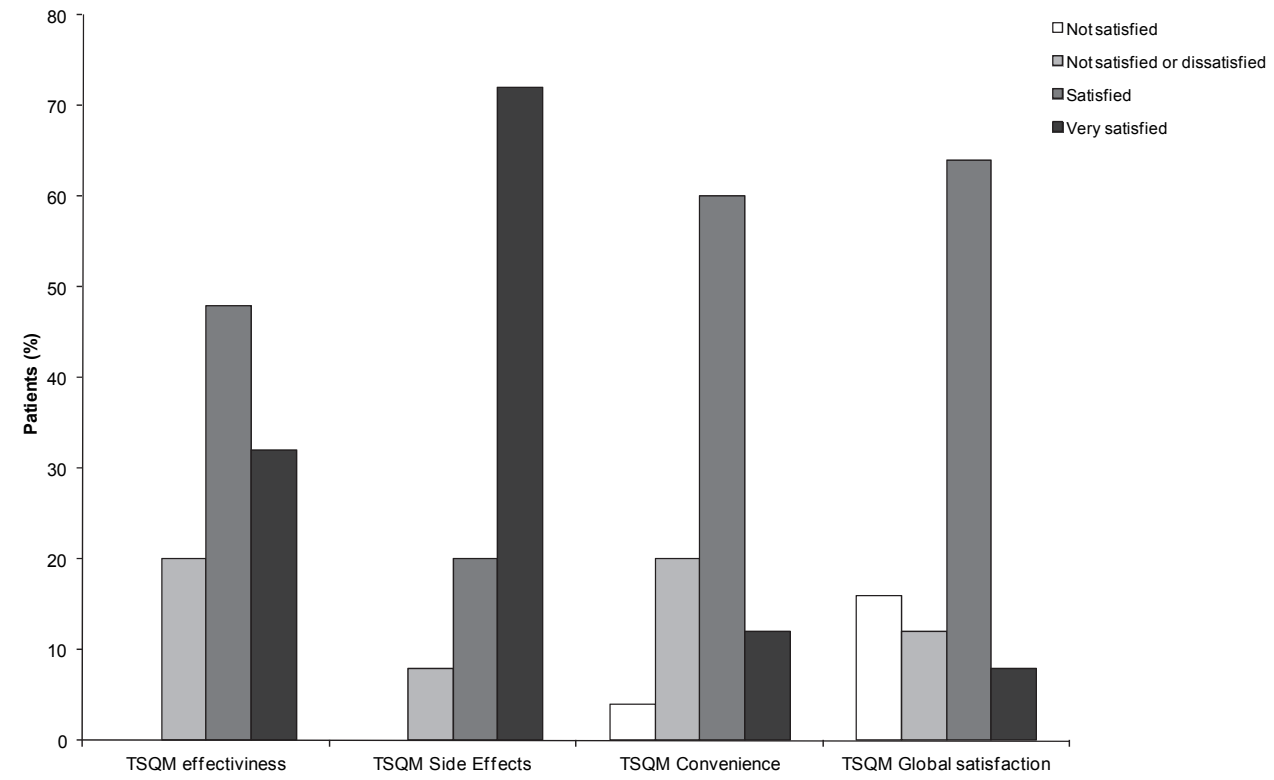

Figure 1. Overall patient TSQM scores of a fentanyl spray

\section{Pain reduction}

Patients experienced significantly $(p<0.005)$ less pain after using IN fentanyl than before they used it, both at rest and during activity (Table 4). The mean change in pain intensity at rest was $3.70(95 \% \mathrm{Cl} 3.3-5.5)(48 \%)$ and during activity $4.38(95 \% \mathrm{Cl} 2.3-$ 5.1) (52\%). IN fentanyl provided clinically meaningful pain relief ( $\geq 2$-points reduction in pain intensity) [36] in 20 patients (80\%). When patients were clustered into two groups (one group less than 2 points and one group $\geq 2$ points in reduction in pain intensity), the TSQM effectiveness was significantly related to reduction in pain intensity $(p<0.05)$. 
Table 4. Measurement of pain intensity (NRS) (0-11)

\begin{tabular}{ll}
\hline & Mean (SD) \\
\hline Pain in rest & $7.72(2.30)$ \\
Pain during movement & $8.40(1.41)$ \\
Pain after using IN fentanyl & $4.02(2.27)^{*}$ \\
\hline
\end{tabular}

$* p<0.005$ to pain in rest and pain during movement

\section{Discussion}

This survey investigated patients' satisfaction with IN fentanyl for severe pain. Overall, patients appeared to be satisfied with IN fentanyl treatment, with $72 \%$ of the patients awarding scores of 51 or higher on the TSQM convenience scale. This is comparable with data reported by Mercadante et al [21], who investigated ease of use compared to oral transmucosal fentanyl citrate for BTP. Patients found IN Fentanyl (instanyl ${ }^{\circledR}$ ), when compared to oral transmucosal fentanyl citrate, easy/very easy to administer ( $90.1 \%$ versus $39.8 \%$ respectively). And it is comparable with Taylor et al [8], who measured the ease (68.5\%) and convenience (69.9\%) of using fentanyl pectin nasal spray. TSQM side effects were not related to any demographic or clinical variables. Patients were very satisfied about the side effects of IN fentanyl, which indicates that they did not experience many or serious side effects. TSQM convenience was related to patients' age, with younger patients finding IN fentanyl more convenient to use than did older patients. Some individuals may find a nasal spray difficult to use, because we found that patients who used more sprays considered the nasal spray convenient, and for this reason it might be appropriate to instruct people to use the nasal spray.

Breivik et al [37], in a survey of more than 5000 patients, showed that treatment of cancer is suboptimal in Europe and Israel. They found that BTP or inadequate pain relief was common in patients on prescription medications, occurring in $63 \%$ of patients, of which $58 \%$ reported inadequate pain relief. We found that IN fentanyl provided clinically meaningful pain relief ( $\geq 2$-point reduction in pain intensity) [36] in $80 \%$ of the patients, with pain intensity decreasing by about $50 \%$ [38].

Our study has some limitations. First, our findings could have been influenced by selection bias, as many patients who used IN fentanyl were too ill to fill in the questionnaire and some had died before they could complete and return the questionnaire. IN fentanyl was approved in The Netherlands in July 2010, and physicians may initially have been reluctant to prescribe the drug, and probably prescribed it as a last resort for coping with BTP. Another potential source of bias is that pharmacists may not always have given the questionnaire to patients who came to fill their prescriptions. 
Lastly, pain was reported retrospectively by the patients, which might have influenced its perceived severity. However, even if the absolute pain reduction is not known with certainty, the data clearly show that patients considered IN fentanyl to be effective in providing pain relief.

In conclusion, patients were satisfied with IN fentanyl as treatment for BTP. 


\section{References}

1. Schug SA, Zech D, Dorr U. Cancer pain management according to WHO analgesic guidelines. J Pain Symptom Manage. 1990;5:27-32.

2. Caraceni A, Martini C, Zecca E. Breakthrough pain characteristics and syndromes in patients with cancer pain. An international survey. Palliat Med. 2004;18:177-83.

3. Dahl JL. Pain: impediments and suggestions for solutions. J Natl Cancer Inst Monogr. 2004;124-6.

4. Davis MP. Recent development in therapeutics for breakthrough pain. Expert Rev Neurother. 2010;10:757-73.

5. Lossignol DA, Dumitrescu C. Breakthrough pain: progress in management. Curr Opin Oncol. 2010;22:302-6.

6. Mishra S, Bhatnagar S, Chaudhary P, Rana SP. Breakthrough cancer pain: review of prevalence, characteristics and management. Indian J Palliat Care. 2009;15:14-8.

7. Svendsen KB, Andersen S, Arnason S, et al. Breakthrough pain in malignant and non-malignant diseases: a review of prevalence, characteristics and mechanisms. Eur J Pain. 2005;9:195-206.

8. Taylor D, Galan V, Weinstein SM, et al. Fentanyl pectin nasal spray in breakthrough cancer pain. J Support Oncol. 2010;8:184-90.

9. Zeppetella G. Opioids for cancer breakthrough pain: a pilot study reporting patient assessment of time to meaningful pain relief. J Pain Symptom Manage. 2008;35:563-7.

10. Zeppetella G, O'Doherty CA, Collins S. Prevalence and characteristics of breakthrough pain in cancer patients admitted to a hospice. J Pain Symptom Manage. 2000;20:87-92.

11. Portenoy RK, Thaler HT, Kornblith $A B$, et al. Symptom prevalence, characteristics and distress in a cancer population. Qual Life Res. 1994;3:183-9.

12. Mercadante S, Radbruch L, Caraceni A, et al. Episodic (breakthrough) pain: consensus conference of an expert working group of the European Association for Palliative Care. Cancer. 2002;94:832-9.

13. Portenoy RK, Hagen NA. Breakthrough pain: definition, prevalence and characteristics. Pain. 1990;41:273-81.

14. Portenoy RK, Payne D, Jacobsen P. Breakthrough pain: characteristics and impact in patients with cancer pain. Pain. 1999;81:129-34.

15. Portenoy RK, Burton AW, Gabrail N, Taylor D. A multicenter, placebo-controlled, double-blind, multiplecrossover study of Fentanyl Pectin Nasal Spray (FPNS) in the treatment of breakthrough cancer pain. Pain. 2010;151:617-24.

16. Christrup LL, Foster D, Popper LD, Troen T, Upton R. Pharmacokinetics, efficacy, and tolerability of fentanyl following intranasal versus intravenous administration in adults undergoing third-molar extraction: a randomized, double-blind, double-dummy, two-way, crossover study. Clin Ther. 2008;30:469-81.

17. Crellin D, Ling RX, Babl FE. Does the standard intravenous solution of fentanyl ( $50 \mathrm{microg} / \mathrm{mL})$ administered intranasally have analgesic efficacy? Emerg Med Australas. 2010;22:62-7.

18. Grape S, Schug SA, Lauer S, Schug BS. Formulations of fentanyl for the management of pain. Drugs. 2010;70:57-72.

19. Kaasa S, Moksnes K, Nolte T, et al. Pharmacokinetics of intranasal fentanyl spray in patients with cancer and breakthrough pain. J Opioid Manag. 2010;6:17-26.

20. Kress HG, Oronska A, Kaczmarek Z, et al. Efficacy and tolerability of intranasal fentanyl spray 50 to 200 microg for breakthrough pain in patients with cancer: a phase III, multinational, randomized, doubleblind, placebo-controlled, crossover trial with a 10-month, open-label extension treatment period. Clin Ther. 2009;31:1177-91.

21. Mercadante S, Radbruch L, Davies A, et al. A comparison of intranasal fentanyl spray with oral transmucosal fentanyl citrate for the treatment of breakthrough cancer pain: an open-label, randomised, crossover trial. Curr Med Res Opin. 2009;25:2805-15. 
22. Middleton PM, Simpson PM, Sinclair G, et al. Effectiveness of morphine, fentanyl, and methoxyflurane in the prehospital setting. Prehosp Emerg Care. 2010;14:439-47.

23. Panagiotou I, Mystakidou K. Intranasal fentanyl: from pharmacokinetics and bioavailability to current treatment applications. Expert Rev Anticancer Ther. 2010;10:1009-21.

24. Portenoy RK, Raffaeli W, Torres LM, et al. Long-term safety, tolerability, and consistency of effect of fentanyl pectin nasal spray for breakthrough cancer pain in opioid-tolerant patients. J Opioid Manag. 2010;6:319-28.

25. Veldhorst-Janssen NM, Fiddelers AA, van der Kuy PH, Neef C, Marcus MA. A review of the clinical pharmacokinetics of opioids, benzodiazepines, and antimigraine drugs delivered intranasally. Clin Ther 2009;31:2954-87.

26. Vissers D, Stam W, Nolte T, Lenre M, Jansen J. Efficacy of intranasal fentanyl spray versus other opioids for breakthrough pain in cancer. Curr Med Res Opin 2010;26:1037-45.

27. Leppert W. Role of intranasal fentanyl in breakthrough pain management in cancer patients. Cancer Management and Research 2010;2:225-232.

28. Paech MJ, Lim CB, Banks SL, Rucklidge MW, Doherty DA. A new formulation of nasal fentanyl spray for postoperative analgesia: a pilot study. Anaesthesia 2003;58:740-4.

29. Lim SCB, Paech MJ, Sunderland VB, et al. Pharmacokinetics of nasal fentanyl. Journal od Pharmacy Practice and Research 2003;33:59-63.

30. Moksnes K, Fredheim OM, Klepstad P, et al. Early pharmacokinetics of nasal fentanyl: is there a significant arterio-venous difference? Eur J Clin Pharmacol 2008;64:497-502.

31. Veldhorst-Janssen NM, Fiddelers AA, van der Kuy PH, et al. Pharmacokinetics, analgesic effect, and tolerability of a single preprocedural dose of intranasal fentanyl in patients undergoing drain removal after breast reduction or augmentation surgery: A prospective, randomized, double-blind, placebocontrolled study. Clin Ther 2010;32:1427-36.

32. Striebel HW, Kramer J, Luhmann I, Rohierse-Hohler I, Rieger A. [Pharmacokinetics of intranasal Fentanyl.]. Schmerz 1993;7:122-5.

33. Atkinson MJ, Kumar R, Cappelleri JC, Hass SL. Hierarchical construct validity of the treatment satisfaction questionnaire for medication (TSQM version II) among outpatient pharmacy consumers. Value Health 2005;8 Suppl 1:S9-S24.

34. Atkinson MJ, Sinha A, Hass SL, et al. Validation of a general measure of treatment satisfaction, the Treatment Satisfaction Questionnaire for Medication (TSQM), using a national panel study of chronic disease. Health Qual Life Outcomes 2004;2:12.

35. van Buuren S, Boshuizen HC, Knook DL. Multiple imputation of missing blood pressure covariates in survival analysis. Stat Med 1999;18:681-94.

36. Farrar JT, Berlin JA, Strom BL. Clinically important changes in acute pain outcome measures: a validation study. J Pain Symptom Manage 2003;25:406-11.

37. Breivik H, Cherny N, Collett B, et al. Cancer-related pain: a pan-European survey of prevalence, treatment, and patient attitudes. Ann Oncol 2009;20:1420-33.

38. Farrar JT, Polomano RC, Berlin JA, Strom BL. A comparison of change in the $0-10$ numeric rating scale to a pain relief scale and global medication performance scale in a short-term clinical trial of breakthrough pain intensity. Anesthesiology 2010;112:1464-72. 


\section{CHAPTER 7}

Patient satisfaction with intranasal midazolam versus rectal diazepam as fast-working rescue medication in epilepsy

Veldhorst-Janssen NML, Fiddelers AAA, van der Kuy P-HM, Majoie MHJM, Kessels AGH, Neef C, Marcus MAE

Submitted 


\section{Abstract}

Background: Fast-acting rescue medication is often needed to control persistent or acute epileptic seizures, and rectally administered diazepam is currently used for this purpose in The Netherlands. An alternative rescue medication is intranasal (IN) midazolam. In deciding which medication to use, it is important to know patients' preferences and attitudes towards IN midazolam and rectal diazepam. In this study patients' satisfaction with IN midazolam was compared with rectal diazepam in twenty-five patients.

Methods: Patients completed the Treatment Satisfaction Questionnaire for Medication (TSQM), which scores the effectiveness, side effects, and convenience of treatment, and patients' global satisfaction. Baseline patient characteristics were recorded. Student's t-test was used to estimate a difference in satisfaction between the two groups.

Results: Satisfaction with the effectiveness and convenience of drug administration and global satisfaction were higher with IN midazolam than with rectal diazepam, whereas mean satisfaction with side effects was higher with rectal diazepam. However, none of the differences were statistically significant.

Conclusions: Although not statistically significant, patients who used IN midazolam were overall more satisfied than were patients who used rectal diazepam; however, the side effects of rectal diazepam were more tolerable than those of IN midazolam. This trial is registered at trial register.nl, NTR2881. 


\section{Introduction}

Fast-acting rescue medication is needed to control prolonged epileptic seizures. In The Netherlands, rectally administered diazepam is mainly used for this indication, being highly effective and safe in children [1,2] and adults [3-11]. While it is cheap and has a long shelf life, the effect is not always predictable because of administration and/or resorption problems, and, patients especially may find its use socially embarrassing.

An alternative rescue medication for the acute treatment of epileptic seizures is intranasally administered midazolam, which is rapid, has a relatively short duration of action, has a non-invasive route of administration and is effective when used as rescue medication in epilepsy [12-17]. However, only a few studies have compared diazepam with midazolam and found comparable results $[17,18]$. When deciding which medication to use, it is important to know patients' preferences and attitudes towards IN or rectal routes of drug administration as well. In the study of De Haan et al [17], patients and their caregivers were asked whether they preferred one of the study drugs. While IN midazolam was found easier to use than rectal diazepam and $76 \%$ of the patients and caregivers preferred IN midazolam [17], their preferences were not measured using validated instruments. The aim of this study was to evaluate whether patients are more satisfied with IN midazolam than with rectal diazepam.

\section{Methods}

\section{Participants}

This survey was performed in 2010 at the Maastricht University Medical Centre+ in collaboration with the epilepsy expertise centre Kempenhaeghe in Heeze, The Netherlands after approval by the Medical Ethics Committee of both centres. Medication was changed nor randomized during this survey.

Only fluently speaking Dutch patients over 18 years, with epilepsy using rectally administered diazepam or intranasally administered midazolam were asked a written informed consent before inclusion in the study.

\section{Satisfaction questionnaire}

Subjects were asked to complete one questionnaire on their satisfaction with IN midazolam or rectal diazepam, if they used IN midazolam or rectal diazepam respectively. The questionnaire consisted of two sections, one about baseline patient characteristics (i.e. age, social position, education, form of epilepsy), and the second the 'Treatment Satisfaction Questionnaire for Medication' (TSQM) [19,20], which is a validated questionnaire on patients' satisfaction with medication. The TSQM questionnaire consists 
of 14 items to assess patients' satisfaction with medication, providing scores on effectiveness, side effects, convenience, and global satisfaction [19-21]. The TSQM is a generic measure of satisfaction with medication, generating scores from 0 (extremely dissatisfied) to 100 (extremely satisfied) [19-21]. The scores are divided into four groups, namely 0-25 (not satisfied), 26-50 (satisfied nor dissatisfied), 51-75 (satisfied), and 76-100 (very satisfied).

\section{Statistical analysis}

The number of patients required for this study was based on an expected difference between the two groups of $20 \%$. In order to reach an effect size and estimated standard deviation of $20 \%$, and to detect a power of $80 \%$ with a two-tailed significance level of $0.05,24$ patients (12 patients per treatment group) were needed.

Student's t-test or non-parametric test was used to estimate the difference in satisfaction between the two groups. Missing data were replaced by multiple data imputation. All data analyses were performed with the Statistical Package for Social Sciences (SPSS, version 15.0).

\section{Results}

\section{Study population}

During a 1-year period, 25 patients were recruited; 12 who used rectal diazepam and 13 who used IN midazolam as rescue medication to control acute and/or persistent seizures.

Table I shows the baseline characteristics of the patients in the two groups. Patients in the IN midazolam group were older, had a higher body mass index (BMI), and a higher level of education than patients in the rectal diazepam group. Baseline medication and illness characteristics were comparable in the two groups. However, the patients in the rectal diazepam group had significantly more seizures per year and a longer duration of medication use. In the rectal diazepam group, 33\% of patients always used their medication and $50 \%$ used the medication for half of their seizures, whereas most patients (77\%) always used the midazolam nasal spray to control their seizures. 
Table I Baseline patient characteristics

\begin{tabular}{|c|c|c|}
\hline & Intranasal Midazolam & Rectal Diazepam \\
\hline Mean age \pm SD & $51.2 \pm 15.4$ & $40.8 \pm 16.6$ \\
\hline No. of male patients (\%) & $4(30.8)$ & $5(41.7)$ \\
\hline No. of female patients (\%) & $9(69.2)$ & $7(58.3)$ \\
\hline Mean Body Mass Index \pm SD & $26.1 \pm 4.4$ & $23.2 \pm 3.4$ \\
\hline \multicolumn{3}{|l|}{ School education } \\
\hline Lower education level (\%) & $3(23.1)$ & $4(33.3)$ \\
\hline Secondary education level (\%) & $4(30.8)$ & $8(66.7)$ \\
\hline Higher education level (\%) & $6(46.2)$ & 0 \\
\hline \multicolumn{3}{|l|}{ Type of epilepsy } \\
\hline Partial epilepsy (\%) & $4(30.8)$ & $3(25.0)$ \\
\hline Generalized epilepsy (\%) & $4(30.8)$ & $5(41.7)$ \\
\hline Not classified (\%) & $3(23.1)$ & $2(16.7)$ \\
\hline Special syndromes (\%) & $1(7.7)$ & $1(8.3)$ \\
\hline Other (\%) & $1(7.7)$ & $1(8.3)$ \\
\hline Mean duration of epilepsy (years) \pm SD & $16.9 \pm 17.6$ & $27.5 \pm 17.6$ \\
\hline Mean number of seizures per year* \pm SD & $21.4 \pm 42.8$ & $145.1 \pm 213.8$ \\
\hline Mean duration of medication use* (years) \pm SD & $2.8 \pm 2.1$ & $13.1 \pm 8.8$ \\
\hline \multicolumn{3}{|l|}{ Duration of last seizure (\%) } \\
\hline$<5$ minutes & $7(53.9)$ & $5(41.7)$ \\
\hline $5-10$ minutes & $4(30.8)$ & $4(33.3)$ \\
\hline$>10$ minutes & $2(15.4)$ & $3(25.0)$ \\
\hline Questionnaire completed by proxy (\%) & $2(15.4)$ & $2(16.7)$ \\
\hline
\end{tabular}

$* p<0.05$

\section{Satisfaction with medication}

Table II shows the TSQM scale scores for the IN midazolam and rectal diazepam groups. The differences in scale scores between the two groups were not statistically significant. Figure 1 shows the results when satisfaction is divided into the four score groups. 
Table II Mean (SD) TSQM scale scores

\begin{tabular}{llllll}
\hline TSQM scales* & \multicolumn{2}{l}{ Intranasal midazolam } & \multicolumn{2}{l}{ Rectal diazepam } & \\
& Mean \pm SD & Range & Mean \pm SD & Range & p value \\
\hline Effectiveness & $74.4 \pm 19.1$ & $38.9-100$ & $55.6 \pm 30.7$ & $0.0-100$ & 0.063 \\
Side effects & $72.6 \pm 28.1$ & $12.5-100$ & $85.4 \pm 19.4$ & $50.0-100$ & 0.191 \\
Convenience & $71.4 \pm 15.4$ & $44.4-100$ & $58.5 \pm 28.4$ & $22.2-100$ & 0.160 \\
Global satisfaction & $67.6 \pm 23.3$ & $14.3-100$ & $56.2 \pm 28.1$ & $0-92.9$ & 0.270 \\
\hline
\end{tabular}

*Scales from 0-100 in which '0' means extremely dissatisfied and ' 100 ' means extremely satisfied

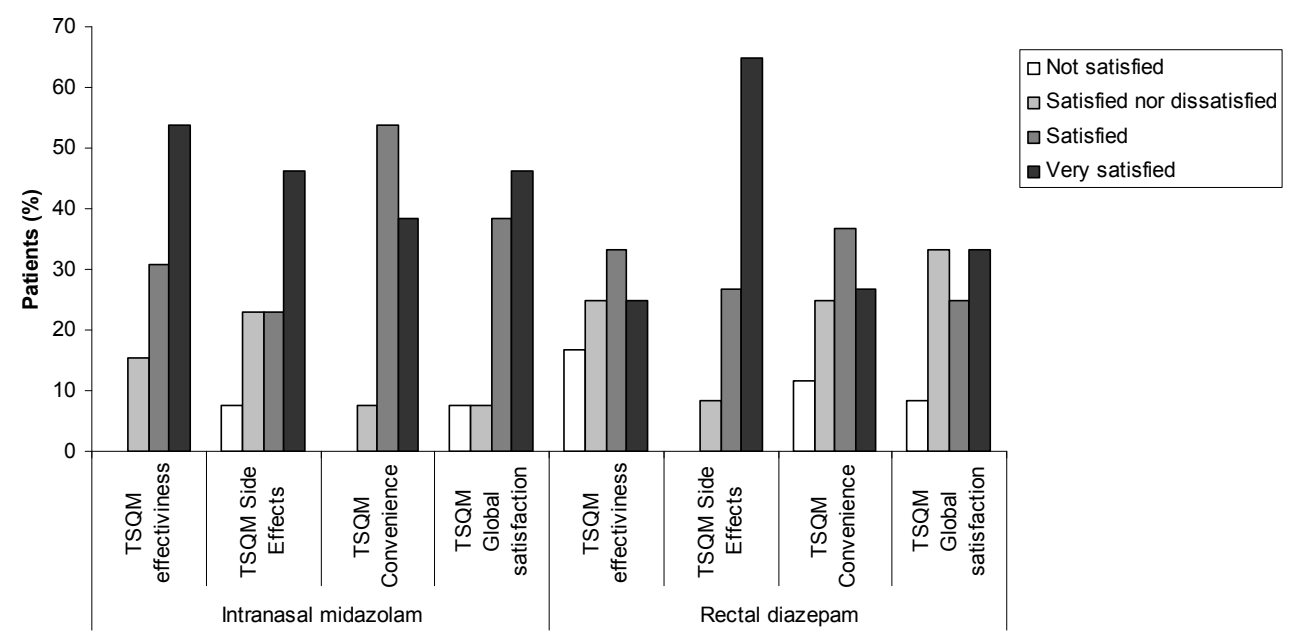

Figure 1. Overall patient TSQM scale scores

\section{Discussion}

This is the first study to investigate adult patients' satisfaction with IN midazolam versus rectal diazepam as epilepsy rescue medication, using a validated questionnaire. Overall, patients were as satisfied with IN midazolam as with rectal diazepam.

De Haan et al [17] suggested a higher preference for IN midazolam than rectal diazepam, but didn't use a validated method. Furthermore, Noll et al [22] found patients who used IN midazolam had a better quality of life than did patients who used rectal diazepam, although the difference was not statistically significant [22]. Scores for adverse effects were comparable between the two groups [22], whereas we found that patients on rectal diazepam were more satisfied with the side effects of treat- 
ment. This discrepancy might be because in our study most patients filled in the questionnaire themselves, whereas in the study of Noll et al most questionnaires were completed by proxies [22]. Patients may experience the local side effects of IN midazolam as unpleasant, but caregivers might not notice this.

A limitation of our study is that the two groups were rather heterogeneous, partly due to selection bias which was probably caused by recruiting at the outpatient departments. This selection bias accounts for the significantly higher seizure rate in the rectal diazepam group compared with the IN midazolam group (145 versus 21 per year). Moreover, the patients in the IN midazolam group had a higher level of education than did the patients in the rectal diazepam group. Educational background is considered an important factor that influences the ability to seek and understand health information [23], and thus higher educated epilepsy patients might be more aware of the availability of alternatives to rectal diazepam. Another notable difference was the longer use of rectal diazepam compared with IN midazolam (13.1 versus 2.8 years, $p<0.005)$. IN midazolam has only been in use as rescue medication for epilepsy for a few years, whereas rectal diazepam has been in use for much longer [24].

In conclusion, patients who used IN midazolam were as satisfied as patients who used rectal diazepam. 


\section{References}

1. Wolf P. Acute Drug Administration in Epilepsy: A Review. CNS Neurosci Ther. 2011;17:442-448.

2. Wolf P. Acute Administration of Benzodiazepines as Part of Treatment Strategies for Epilepsy. CNS Neurosci Ther. 2011;17:214-220.

3. Cereghino JJ, Cloyd JC, Kuzniecky RI. Rectal diazepam gel for treatment of acute repetitive seizures in adults. Arch Neurol. 2002;59:1915-20.

4. Dreifuss FE, Rosman NP, Cloyd JC, Pellock JM, Kuzniecky RI, Lo WD, Matsuo F, Sharp GB, Conry JA, Bergen DC, Bell WE. A comparison of rectal diazepam gel and placebo for acute repetitive seizures. $\mathrm{N}$ Engl J Med. 1998;338:1869-75.

5. Fakhoury T, Chumley A, Bensalem-Owen M. Effectiveness of diazepam rectal gel in adults with acute repetitive seizures and prolonged seizures: a single-center experience. Epilepsy Behav. 2007;11:357-60.

6. Fitzgerald BJ, Okos AJ, Miller JW. Treatment of out-of-hospital status epilepticus with diazepam rectal gel. Seizure. 2003;12:52-5.

7. Kapur J. Prehospital Treatment of Status Epilepticus with Benzodiazepines Is Effective and Safe. Epilepsy Curr. 2002;2:121-124.

8. Mitchell WG, Conry JA, Crumrine PK, Kriel RL, Cereghino JJ, Groves L, Rosenfeld WE. An open-label study of repeated use of diazepam rectal gel (Diastat) for episodes of acute breakthrough seizures and clusters: safety, efficacy, and tolerance. North American Diastat Group. Epilepsia. 1999;40:1610-7.

9. Pellock JM. Safety of Diastat, a rectal gel formulation of diazepam for acute seizure treatment. Drug Saf. 2004;27:383-92.

10. Remy C, Jourdil N, Villemain D, Favel P, Genton P. Intrarectal diazepam in epileptic adults. Epilepsia. 1992;33:353-8

11. Rey E, Treluyer JM, Pons G. Pharmacokinetic optimization of benzodiazepine therapy for acute seizures. Focus on delivery routes. Clin Pharmacokinet. 1999;36:409-24.

12. Kendall JL, Reynolds M, Goldberg R. Intranasal midazolam in patients with status epilepticus. Ann Emerg Med. 1997;29:415-7.

13. Lahat E, Goldman M, Barr J, Bistritzer T, Berkovitch M. Comparison of intranasal midazolam with intravenous diazepam for treating febrile seizures in children: prospective randomised study. BMJ. 2000;321:83-6.

14. O'Regan ME, Brown JK, Clarke M. Nasal rather than rectal benzodiazepines in the management of acute childhood seizures? Dev Med Child Neurol. 1996;38:1037-45.

15. Scheepers M, Scheepers B, Clarke M, Comish S, Ibitoye M. Is intranasal midazolam an effective rescue medication in adolescents and adults with severe epilepsy? Seizure. 2000;9:417-22.

16. Scheepers M, Scheepers B, Clough P. Midazolam via the intranasal route: an effective rescue medication for severe epilepsy in adults with learning disability. Seizure. 1998;7:509-12.

17. De Haan GJ, Van der Geest P, Doelman G, Bertram E, Edelbroek P. A comparison of midazolam nasal spray and diazepam rectal solution for the residential treatment of seizure exacerbations. Epilepsia. 2010;51:478-82.

18. Ivaturi VD, Riss JR, Kriel RL, Cloyd JC. Pharmacokinetics and tolerability of intranasal diazepam and midazolam in healthy adult volunteers. Acta Neurol Scand. 2009;120:353-7.

19. Atkinson MJ, Kumar R, Cappelleri JC, Hass SL. Hierarchical construct validity of the treatment satisfaction questionnaire for medication (TSQM version II) among outpatient pharmacy consumers. Value in Health. 2005;8 Suppl 1:S9-S24.

20. Atkinson MJ, Sinha A, Hass SL, Colman SS, Kumar RN, Brod M, Rowland CR. Validation of a general measure of treatment satisfaction, the Treatment Satisfaction Questionnaire for Medication (TSQM), using a national panel study of chronic disease. Health Qual Life Outcomes. 2004;2:12. 
21. Bharmal M, Payne K, Atkinson MJ, Desrosiers MP, Morisky DE, Gemmen E. Validation of an abbreviated Treatment Satisfaction Questionnaire for Medication (TSQM-9) among patients on antihypertensive medications. Health Qual Life Outcomes. 2009;7:36.

22. Noll CR, Verweij SL, Van der Hoeven RTM. Het effect van midazolam neusspray en diazepam rectiole op de kwaliteit van leven van epilepsiepatiënten. PWWetenschappelijk Platform. 2011;5:25-28.

23. Jordan JE, Buchbinder R, Osborne RH. Conceptualising health literacy from the patient perspective. Patient Educ Couns. 2010;79:36-42.

24. Beran RG. An alternative perspective on the management of status epilepticus. Epilepsy Behav. 2008;12:349-53. 



\section{CHAPTER 8}

General Discussion 


\section{Summary and discussion}

Pharmaceutical innovation is necessary for the development of new drugs. The availability of new drugs and biological products often leads to new treatment options and advances in health care. Drug development can be divided into two phases: the preregistration and the post-registration phases, with the registration of a drug by the government being a critical step. The registration procedure requires that a product meets all governmental requirements regarding effectiveness and safety. The preregistration phase can be divided into a preclinical phase and a clinical phase. Creativity controls the first phase: scientists synthesize thousands of chemical substances and they are tested for effects and toxicity in cell-lines and animals. The clinical phase, which can extend into the post-registration phase, can be divided into four phases.

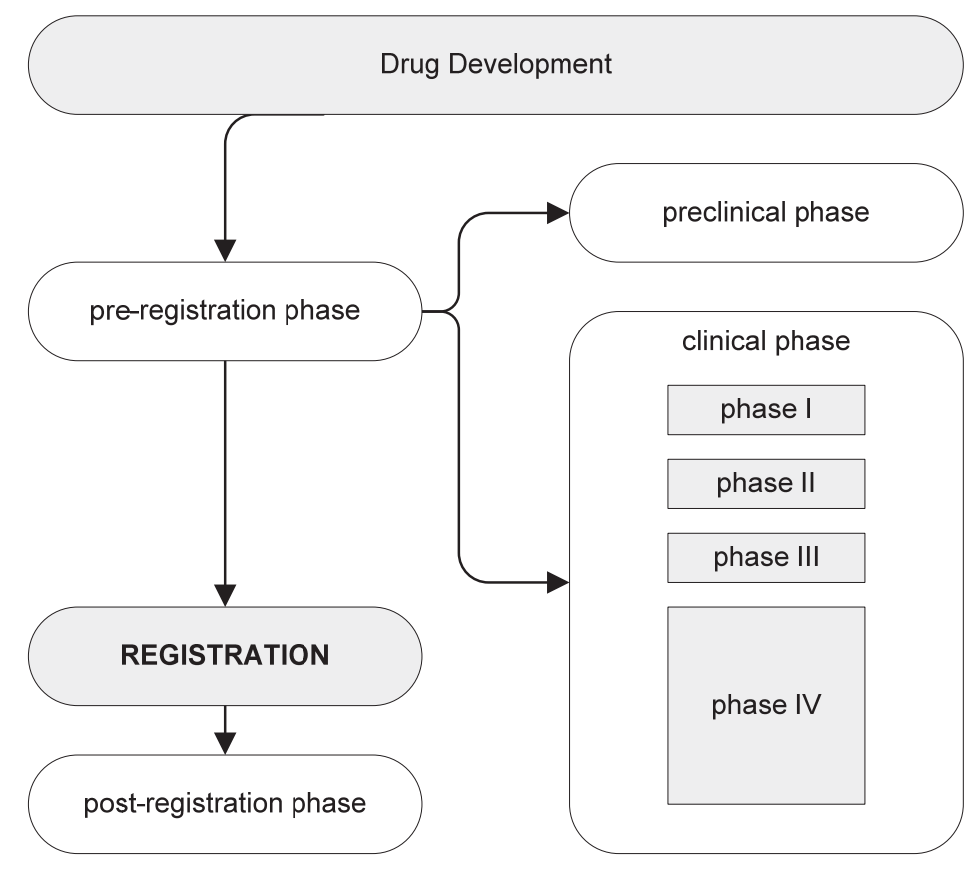

In phase one, the new drug is tested in healthy volunteers to determine its efficacy, dose-response relation, duration of action, pharmacokinetics, and possible toxicity. In phase two, studies with a small, select group of patients are carried out to investigate in detail the drug's pharmacokinetics (absorption, bioavailability, distribution, metabolism, and elimination) and formulation. In phase three, the drug is investigated in a larger group of patients, preferably in a double blind, randomized clinical trial. In phase four, the safety of the pharmaceutical drug is monitored after it has been released 
onto the market. Since drugs are approved on the basis of clinical trials involving relatively small numbers of people selected for this purpose, post-marketing surveillance can further define the safety of a drug once it has been used by large numbers of people with a wide variety of medical conditions [1].

The studies described in this thesis investigated some of these aspects of drug development. The main goal of these studies was to increase knowledge about the pharmacokinetics, clinical effectiveness, and/or tolerability of, and patient satisfaction with, two intranasally (IN) administered drugs, fentanyl and midazolam.

\section{Formulations}

Most drugs are administered orally, but in some cases the oral route is not desirable, for example, because of poor drug absorption. The IN route is a less obvious route of drug administration, but has advantages similar to those of oral administration, namely, it is a non-invasive route and patients can administer drugs themselves (chapter 2 ). Another advantage is that the pharmacokinetic properties of IN administered drugs lie between those of orally and intravenously administered drugs. This implies that IN administration of opioids, benzodiazepines, and antimigraine drugs would be suitable for indications that require a more rapid drug effect than can be achieved with oral administration or when intravenous administration is not appropriate (chapter 2). At this time, IN benzodiazepine sprays have not been registered, even though some benzodiazepines are suitable (in terms of their pharmacokinetics) for intranasal administration. For example, midazolam can be administered IN and this formulation is currently prepared in community pharmacies.

Despite the promising results of various studies, there are few systemically active drugs that can be administered IN: of 170 nasal sprays registered in the Netherlands [2], only 21 contain 8 systemically active agents. These drugs can be classified into three categories: hormonal agents, antimigraine agents, and analgesics. The hormonal agents were developed between 1985 and 2001, the antimigraine drugs between 1996 and 2001, and only in 2009 did the first analgesic, fentanyl nasal spray, enter the market. It is important to understand why a non-invasive dosage form such as a nasal spray, which is easy to use by patients themselves, has not been extensively developed, especially because drugs administered IN have a rapid onset of action and do not undergo first-pass elimination. For example, an insulin nasal spray has been under development since the 1980s, and several absorption enhancers and various formulations have been tested to improve absorption and bioavailability. However, the discouraging clinical results as well as questions about the local nasal tolerability of the formulation suggest that this route of insulin delivery may have limited potential $[3,4]$. 


\section{Dosing and concentration}

The administration volume of a nasal spray is limited to $150 \mu$ llarger volumes may lead to irritation and run-off into the pharynx, which can lead to first-pass effects) [5]. This means that drug solutions have to be concentrated in order to achieve an appropriate amount of drug. For example, the IN fentanyl spray $(500 \mu \mathrm{g} / \mathrm{ml})$ used in the study described in chapter 4 was more concentrated than the fentanyl solution (50 $\mu \mathrm{g} / \mathrm{ml}$ ) administered IN in other studies $[6,7]$. The midazolam spray used in the study reported in chapter 3 was concentrated to minimize the administration volume, such that a therapeutic dose could be administered in two instead of four sprays, which makes the drug easier to use. However, the IN absorption of the more concentrated drug was slower than that of the standard IN midazolam spray, possibly because of drug diffusion, and consequently the pharmacokinetic profile changed.

\section{Pharmacokinetic profile}

Although the maximal concentration of midazolam was reached later after IN administration of a more concentrated and smaller volume, this might have been due to dual pathway absorption, with the drug being absorbed via the nasal mucosa and the intestinal mucosa. A number of IN administered drugs display dual pathway absorption $[8,9]$, and this phenomenon was also seen in the above-mentioned studies of IN midazolam and IN fentanyl (chapters 3 and 4). For this reason, a pharmacokinetic model was developed to adequately predict individual concentration-time profiles for midazolam absorption after its IN administration (chapter 5). This model can also be used to analyze individual data, using a population model approach, and to model data from the literature.

In general, data showing the dependence of plasma-drug concentrations on time after administration are analyzed by compartmental analysis, assuming first-order absorption and elimination. The dual pathway absorption model is a multisegment absorption model that is suitable for the pharmacokinetic analysis of plasma drug concentrations with irregular or multipeak absorption profiles. Murata et al. [10] reported multifraction absorption models to describe the absorption of orally administered drugs in the gastrointestinal tract. For example, this multisegment absorption model has been used to analyze the pharmacokinetics of an oral sustained-release preparation of diclofenac sodium [11]. The first part of the pharmacokinetic profile, the absorption phase, is especially important for drugs that are administered IN in order to achieve a rapid effect. The dual pathway absorption model allows researchers to investigate the absorption phase of IN administered drugs in more detail. On the 
basis of the Monte Carlo analysis reported in chapter 5, 14\% of the individual concentration-time curves showed double peaks, suggesting dual pathway absorption. However, when population modeling was performed with the data for IN midazolam, the two absorption peaks in the concentration-time profile were smoothed out, suggesting that dual pathway absorption did not occur. On the other hand, possible individual differences, such as a faster or a slower effect, might have occurred.

Dual pathway absorption may reflect different pathways of absorption, such as absorption directly through the nasal mucosa, avoiding the first-pass effect, or through different segments of the gastrointestinal tract. The pharmacokinetic model of dual pathway absorption could be used to accurately predict the different routes of absorption and facilitate nasal spray development. The model could also be used for other administration routes that might show dual pathway absorption, such as sublingual or rectal administration.

\section{Therapeutic concentration}

The highly concentrated IN midazolam spray $(50 \mathrm{mg} / \mathrm{ml})$ used in the study described in chapter 3 was tested in healthy volunteers and was found to have a delayed $t_{\max }$ compared with that of the standard IN midazolam spray $(28 \mathrm{mg} / \mathrm{mL})$ that is regularly prescribed, but not registered, in the Netherlands. Even so, the therapeutic concentration of midazolam ( $>30 \mathrm{ng} / \mathrm{mL}$ ) was reached within 5 minutes, comparable to that of the less concentrated standard IN midazolam spray. When a drug needs to have a rapid effect, such as for the treatment of epileptic insults or breakthrough pain, it is debatable whether $t_{\max }$ or the therapeutic concentration is the most important parameter, especially when dual pathway absorption plays a role in the pharmacokinetics and is smoothed out in the concentration-time profile. Although the $t_{\max }$ is delayed, which may cause physicians to question the suitability of the formulation, therapeutic concentrations are reached in the same time as with the standard spray.

\section{Efficacy}

A drug is developed to be efficacious and safe to administer for various conditions; however, efficacy is not necessarily associated with the concentration of the drug in plasma. Ultimately, a drug has to be tested in phase three studies against another treatment, for example, placebo. Fentanyl was investigated as a nasal spray in patients undergoing drain removal after breast reduction or augmentation surgery (chapter 4). Compared with patients using a placebo, patients receiving IN fentanyl reported less 
pain and tolerability was acceptable, although plasma fentanyl concentrations were below the therapeutic window.

While the fentanyl nasal sprays tested had promising tolerability and pharmacokinetics, the dosage of IN fentanyl $(50 \mu \mathrm{g})$ needs to be increased to improve its clinical efficacy (chapter 4). This is also the case for two commercially available fentanyl nasal sprays, which have since been developed: Instanyl ${ }^{\circledR}$ and Pecfent ${ }^{\circledR}$. Both nasal sprays are registered for breakthrough pain in cancer patients. These fentanyl nasal sprays use high dosages to achieve a sufficient therapeutic effect, namely, $400 \mu \mathrm{g}$ and $800 \mu \mathrm{g}$ for Instany $\left.\right|^{\circledR}$ and Pecfent ${ }^{\circledR}$, respectively.

IN fentanyl has been shown to be a worthy alternative to other drugs, such as morphine, for the treatment of breakthrough pain [12,13], and has been evaluated in several clinical trials for cancer-related breakthrough pain and postoperative pain. It has also been compared with morphine in several painful clinical conditions. The two fentanyl nasal sprays available in the Netherlands are registered for cancer-related breakthrough pain only, but the results of clinical trials with IN fentanyl are promising for other indications, such as third molar extraction [14] and pain relief after orthopedic $[7,15]$, abdominal, or thyroid surgery [15]. Future studies should compare nasal administration with other pain control procedures in a double-blind manner, and identify groups or subgroups of patients that may benefit from opioids for adequate pain control.

Single-dose units of fentanyl nasal spray are now available, which diminishes the risk of overdose while allowing patients to self-administer fentanyl in a safe manner. Safety and tolerability are important aspects of drugs but may hamper the development of efficacious drugs.

\section{Tolerability}

Undesirable effects, such as typical opioid adverse reactions, are to be expected with the fentanyl nasal spray (chapter 4), Instanyl ${ }^{\circledR}$, and Pecfent ${ }^{\circledR}$. Local adverse events occurred in $1 \%$ to $10 \%$ of patients, regardless of the formulation used: nasal tingling, rhinorrhea, and nasal dryness with the fentanyl spray; epistaxis, rhinorrhea, and nasal discomfort with Pecfent ${ }^{\circledR}$; and throat irritation with Instany $I^{\circledR}$. Epistaxis and rhinorrhea occurred in $0.1 \%$ to $1 \%$ (uncommon events) of patients receiving Instanyl ${ }^{\circledR}$, and throat irritation occurred in $0.1 \%$ to $1 \%$ of patients receiving Pecfent ${ }^{\circledR}$ [2]. Too few patients were included in the IN fentanyl group to be able to determine whether a local adverse event was common or uncommon. Neither Pecfent ${ }^{\circledR}$ nor the IN fentanyl spray are buffered, in contrast to Instanyl ${ }^{\circledR}$ [2], and it is possible that the $\mathrm{pH}$ of the formulation influenced the occurrence of undesirable effects in the nose and throat. 
The formulation of IN midazolam (chapter 3) needs to be improved, to eliminate the local 'burning' sensation. If this can be achieved, then IN midazolam could be used for multiple indications. During an epileptic attack, patients notice the burning sensation caused by IN midazolam less than when they are conscious, and thus patients administered IN midazolam when conscious might be less satisfied with the medication. For the moment, IN midazolam could be used as premedication when rapid sedation and retrograde amnesia is required, for instance, for surgery and anesthesia. IN midazolam could also be used to treat sudden anxiety, such as agoraphobia, which requires a short $t_{\max }$. However, with both indications, patients are conscious and the local burning sensation needs to be 'neutralized'. The development of new midazolam nasal sprays should focus on eliminating or diminishing the burning sensation, so that the formulation can be used for both indications and be acceptable to patients.

\section{Patient satisfaction}

While parameters, such as pharmacokinetics, efficacy, and tolerability, are important in drug development, ultimately patient satisfaction determines whether a drug is developed further. Patients appeared to be satisfied with IN fentanyl in general and with the convenience of this route of drug administration (chapter 6). They were very satisfied with the effectiveness and side effects of IN fentanyl. Patients with epilepsy were similarly satisfied with IN midazolam and rectal diazepam in terms of general satisfaction, effectiveness, convenience, and side effects (chapter 7). Detailed feedback about patient satisfaction can be used to improve products. For example, if it is found that a nasal spray is difficult to use and that this major cause of dissatisfaction with the medication, then the applicator can be redesigned to make it easier to handle. Satisfaction with medication is associated with patient adherence or compliance with treatment [16-20].

The results regarding satisfaction with IN fentanyl and IN midazolam support the use of these formulations, although data on satisfaction should be collected from a larger group of patients to obtain conclusive results. A potential limitation of measuring patient satisfaction with medication as described in the above-mentioned studies (chapters 6 and 7) is that satisfaction was measured only once. In addition, the fact that patients' expectations about illness and treatment can change, because patients change their definition of satisfaction, was not taken into consideration. For example, when the symptoms of an illness disappear as a result of medical treatment, the undesirable effects of the medication may become more prominent than the actual symptoms of the disease. As a result, patients might become less satisfied with a medication than they were originally. Medication satisfaction should be measured repeatedly, and 
it should be investigated whether patients' beliefs or values change with time [17]. Only then will it be possible to take patients' expectations into account in satisfaction research.

\section{Where do we go from here?}

Interest in patient satisfaction reflects the slow change in how patients are perceived, with patients no longer being seen as passive recipients but instead active consumers of healthcare services [17]. The concept patient empowerment reflects this development and encourages people to take care of their own health and to choose which type of care they would like to receive from among the options identified by the physician [21]. Satisfaction with medical products will have a place in making these choices about care. Providers of healthcare services and pharmaceutical companies have become increasingly interested in obtaining feedback about their products from the primary consumers of these products [17]. Feedback can be a measure of satisfaction, but also a means of obtaining knowledge. Nowadays, satisfaction with medication often is measured in clinical phase three or four studies; however, since the product has already been developed at this stage, it is difficult to translate the results of assessments of medication satisfaction into product changes. A more obvious moment to measure satisfaction would be during phase one or two studies, in a stage early enough to allow results to be incorporated into product development.

Patient empowerment and a wide range of information via Internet and social media have made the public more aware of the healthcare products, such as medications, that are available. In the future, patients could contribute directly to drug development, by providing (via Internet or other social media) valuable information about their satisfaction with specific medical products. 


\section{References}

1. Baasb. Cited 2012; Available from: http://wetenschap.infonu.nl

2. College ter Beoordeling van Geneesmiddelen. Cited 2012; Available from: http://www.cbgmeb.nl/cbg/nl

3. Owens DR. New horizons--alternative routes for insulin therapy. Nat Rev Drug Discov. 2002;1:529-40.

4. Arcadia Capital Advisors L. CPEX Pharmaceuticals' Phase 2a Nasulin trial fails, Arcadia Capital Advisors issues statement. 2010.

5. Bhattacharyya M, Kalra V, Gulati S. Intranasal midazolam vs rectal diazepam in acute childhood seizures. Pediatric neurology. 2006;34:355-9.

6. Striebel HW, Oelmann T, Spies C, Rieger A, Schwagmeier R. Patient-controlled intranasal analgesia: a method for noninvasive postoperative pain management. Anesthesia and analgesia. 1996;83:548-51.

7. Striebel HW, Olmann T, Spies C, Brummer G. Patient-controlled intranasal analgesia (PCINA) for the management of postoperative pain: a pilot study. Journal of clinical anesthesia. 1996;8:4-8.

8. Burstein AH, Modica R, Hatton M, Forrest A, Gengo FM. Pharmacokinetics and pharmacodynamics of midazolam after intranasal administration. J Clin Pharmacol. 1997;37:711-8.

9. Yates R, Nairn K, Dixon R, Seaber E. Preliminary studies of the pharmacokinetics and tolerability of zolmitriptan nasal spray in healthy volunteers. J Clin Pharmacol. 2002;42:1237-43.

10. Murata K, Noda K, Kohno K, Samejima M. Pharmacokinetic analysis of concentration data of drugs with irregular absorption profiles using multi-fraction absorption models. Journal of pharmaceutical sciences. 1987;76:109-13.

11. Mahmood I. Pharmacokinetic analysis of the absorption characteristics of diclofenac sodium in man by use of a multi-segment absorption model. The Journal of pharmacy and pharmacology. 1996;48:1260-3.

12. Kress HG, Oronska A, Kaczmarek Z, Kaasa S, Colberg T, Nolte T. Efficacy and tolerability of intranasal fentanyl spray 50 to 200 microg for breakthrough pain in patients with cancer: a phase III, multinational, randomized, double-blind, placebo-controlled, crossover trial with a 10-month, open-label extension treatment period. Clin Ther. 2009;31:1177-91.

13. Mercadante S, Radbruch L, Davies A, Poulain P, Sitte T, Perkins P, et al. A comparison of intranasal fentanyl spray with oral transmucosal fentanyl citrate for the treatment of breakthrough cancer pain: an open-label, randomised, crossover trial. Curr Med Res Opin. 2009;25:2805-15.

14. Christrup LL, Foster D, Popper LD, Troen T, Upton R. Pharmacokinetics, efficacy, and tolerability of fentanyl following intranasal versus intravenous administration in adults undergoing third-molar extraction: a randomized, double-blind, double-dummy, two-way, crossover study. Clin Ther. 2008;30:469-81.

15. Toussaint S, Maidl J, Schwagmeier R, Striebel HW. Patient-controlled intranasal analgesia: effective alternative to intravenous PCA for postoperative pain relief. Canadian journal of anaesthesia = Journal canadien d'anesthesie. 2000;47:299-302.

16. Albrecht $\mathrm{G}$, Hoogstraten J. Satisfaction as a determinant of compliance. Community dentistry and oral epidemiology. 1998;26:139-46.

17. Shikiar R, Rentz AM. Satisfaction with medication: an overview of conceptual, methodologic, and regulatory issues. Val Health. 2004;7:204-15.

18. Christensen AJ JJ. Patient adherence with medical treatment regimens: an interactive approach. Curr Dir psych Sci. 2002;11:94-7.

19. Morris LS, Schulz RM. Patient compliance--an overview. J Clin Pharm Ther. 1992;17:283-95.

20. Morris LS, Schulz RM. Medication compliance: the patient's perspective. Clin Ther. 1993;15:593-606.

21. Lau DH. Patient empowerment--a patient-centred approach to improve care. HKMJ. 2002;8:372-4. 



\section{Summary}


The first studies of intranasally (IN) administered systemically acting drugs, such as corticotrophin and mammary tumor milk factor, were published in peer-reviewed journals in the early 1950s. Since then, increasingly more IN formulations of systemically acting drugs have been developed, and IN drug delivery has proven suitable for various indications. For example, IN drug administration may be preferable when ease of dosing, without the need for assistance, and rapid drug absorption and action are essential. Therapeutic groups of drugs developed for IN administration include analgesics (mainly opioids), benzodiazepines, and antimigraine drugs. These drugs are lipophilic, have a low molecular weight, and are mainly used as 'rescue medication'. The studies described in this thesis investigated several characteristics of IN administered lipophilic drugs, such as pharmacokinetics, clinical effectiveness, tolerability, and patient satisfaction. These characteristics also influence patient's adherence to medication and the ability of a drug to improve patients' health and may contribute to our knowledge of IN drugs.

A systematic review was carried out to determine the suitability of opioids, benzodiazepines, and antimigraine drugs for IN administration, and to compare the pharmacokinetic properties of IN, intravenous (IV), and oral formulations of these agents (chapter 2). A search of the literature for pharmacokinetic studies of drugs that might be suitable for IN delivery identified 45 studies eligible for inclusion. Most of the opioids formulated as an IN spray had a $t_{\max }$ within 25 minutes and the bioavailability was high. IN benzodiazepines had an overall $t_{\max }$ that varied from 10 to 25 minutes, and bioavailability was between $38 \%$ and $98 \%$. $t_{\max }$ for most IN antimigraine drugs varied from 25 to 90 minutes, and bioavailability varied from $5 \%$ to $40 \%$. This review found that all three classes of drugs are suitable for IN administration for indications that require a rapid drug action. However, the intended effect of a drug will ultimately determine which drug formulation is to be preferred, given that the pharmacokinetics of drugs differ by route of administration (IV > IN > oral).

Benzodiazepines are often used to treat epileptic seizures in children and adults. As treatment needs to be administered acutely and it is difficult to administer drugs IV during an epileptic seizure, alternative routes of drug administration are needed. In the Netherlands, rectally administered diazepam is currently used for this purpose, but it has several disadvantages such as the embarrassment, for both patients and bystanders, accompanying its use. Investigation of clonazepam, diazepam, and midazolam as IN therapeutics for epileptic seizures suggested IN midazolam to be as effective as rectally administered diazepam for treating epileptic seizures. In the study described in chapter 3 , the pharmacokinetics and tolerability of IN midazolam (5 mg) compared with IV midazolam $(2.5 \mathrm{mg}$ ) were studied in healthy adult volunteers. In this single- 
dose, randomized-sequence, open-label, two-period crossover pilot study, subjects were randomly assigned to IN or IV midazolam, with a washout period of at least 5 days between treatments. The IN midazolam dose was administered once in one nostril, and the IV midazolam solution was infused over 10 seconds. Blood samples were taken before and at regular intervals up to 240 minutes after dosing. Pharmacokinetic data were analyzed using a two-compartment model. Seven volunteers completed the study. The mean (SD) $\mathrm{C}_{\max }$ of $78(40) \mathrm{ng} / \mathrm{mL}$ was reached 44 minutes after IN administration, whereas the mean (SD) $C_{\max }$ was 51 (5) $\mathrm{ng} / \mathrm{mL}$ direct after IV administration. The mean (SD) estimated $C_{t=5}$ min was 31 (28) ng/mL after IN administration. The $t_{1 / 2}$ was $1.9(0.41)$ hours for IN midazolam and $2.3(0.19)$ hours for IV midazolam. The bioavailability of IN midazolam was $82 \%$. There were few adverse events, with a local burning sensation in the nose being the most reported event ( 6 of 7 subjects). The therapeutic concentration of midazolam (>30 ng/mL) was reached within 5 minutes, which is comparable to that of less concentrated midazolam solutions. Additional research is needed to evaluate the safety profile, convenience, satisfaction, and efficacy of IN midazolam in the treatment of adults with seizures.

Of the opioids, fentanyl in particular lends itself to IN administration in patients undergoing short painful procedures, because of its rapid onset and short duration of action. These properties make IN fentanyl suitable for patients with cancer-related breakthrough pain, which typically has a rapid onset and lasts up to 30 minutes. Fentanyl is also used to treat chronic pain conditions, when it is administered via transdermal patches to provide sustained drug release. Chapter 4 describes a randomized, doubleblind, prospective study involving healthy women (ASA I or II) between the ages of 18 and 65 years who were scheduled to undergo surgical drain removal 1 to 4 days after breast reduction or augmentation surgery. A single dose of fentanyl nasal spray $(0.05$ $\mathrm{mg} / 0.1 \mathrm{~mL}$ ) or placebo $(0.1 \mathrm{~mL})$ was administered 10 minutes before drain removal. Because drain removal is generally carried out without specific analgesia, no rescue medication was provided. Pain intensity was measured on a visual analog scale (VAS, from $0=$ no pain at all to $100=$ worst pain possible) immediately before administration of the study medication $(t=0)$, at the time of drain removal $(t=10)$, and up to 70 minutes after administration of the study medication. Safety measures included oxygen saturation, respiratory rate, heart rate, and blood pressure. The participants were asked about local and systemic adverse events throughout the study. Blood samples for pharmacokinetic analysis were collected at baseline until 120 minutes after study medication administration. The population pharmacokinetic parameters of fentanyl were calculated according to a one-compartment open model with an iterative twostage Bayesian fitting procedure. Thirty-three women completed the study. Mean (SD) VAS scores at baseline were 14.8 (17.8) for the fentanyl group and 6.0 (9.7) for the 
placebo group ( $p=\mathrm{NS}$ ); at the time of drain removal, the corresponding VAS scores were 31.0 (20.6) and 33.8 (25.7) ( $p=N S$ ). Analysis of a random-effects model with mean VAS scores as a function of time as the dependent variable indicated a significant difference in mean VAS scores between the fentanyl and placebo groups $(p=0.006)$. The overall incidence of adverse events was $39 \%$. One or more adverse events were reported by 8 of the 17 patients in the fentanyl group, and by 9 of the 16 patients in the placebo group. A mean (SD) estimated $C_{\max }$ of $0.184(0.069) \mathrm{ng} / \mathrm{mL}$ was reached at 13.76 (3.56) minutes after administration of IN fentanyl. The mean (SD) $C_{\max }$ was 0.22 $(0.088) \mathrm{ng} / \mathrm{mL}$. In these women who had undergone breast reduction or augmentation surgery, a single preprocedural dose of IN fentanyl $(0.05 \mathrm{mg}$ ) was significantly more effective than placebo in reducing pain throughout the period after drain removal. However, there was no significant difference in pain intensity at the time of drain removal between fentanyl and placebo. IN fentanyl was generally well tolerated; however, the plasma fentanyl concentrations were below the therapeutic window.

In the studies described in chapters 3 and 4, the phenomenon of dual pathway absorption was observed, with IN administered drugs being absorbed via the nasal mucosa and the gastrointestinal tract. To date, this multipeak phenomenon has not been described in a pharmacokinetic model for IN drugs. The main aim of the study described in chapter 5 was to develop and validate a pharmacokinetic model to describe the concentration-time profile of an IN administered drug and to establish which absorption parameter is most important for dual pathway absorption. Additional aims were to analyze individual data using a population model approach, and to model data from the literature.

The dual pathway absorption model developed to describe the pharmacokinetics of drugs administered IN was validated with Monte Carlo simulations. Both individual data for IN midazolam and data sets for dual pathway absorption from the literature were fitted to the model. Results demonstrated that the pharmacokinetic model could predict the dual pathway absorption of midazolam after IN administration. Monte Carlo simulations showed that although a population model of IN midazolam did not show a dual pathway absorption profile, two peaks were seen in some cases as a result of biological variation. Moreover, data from the literature that clearly demonstrated IN midazolam to be absorbed via two pathways had a good fit with the pharmacokinetic model. Thus, this model can adequately predict the concentration-time profile of drugs administered IN and can be used to analyze individual data, using a population model approach. 
Even if all parameters, such as pharmacokinetics, efficacy, and tolerability, make the further development of a drug attractive, the final decision on whether to proceed with drug development depends on the patients using the drug. For this reason, the last part of this thesis focused on two studies of patient satisfaction with IN fentanyl and IN midazolam, measured using a validated satisfaction questionnaire, and on possible predictors of patient satisfaction.

Chapter 6 described a study investigating patient satisfaction with IN fentanyl, the reduction in pain achieved, and whether the pain reduction and clinical or demographic characteristics were related to patient satisfaction with medication. Patients older than 18 years who used IN fentanyl for severe pain, such as breakthrough pain, were approached for participation by their pharmacist. The patients' satisfaction with IN fentanyl was assessed with the validated 'Treatment Satisfaction Questionnaire for Medication' (TSQM), which scores the effectiveness, side effects, and convenience of treatment, and patients' global satisfaction. Pain severity was assessed with a numerical rating scale (NRS). Twenty-five patients returned the TSQM questionnaire. Mean (SD) scores were 65.6 (20.1) for effectiveness, 87.0 (19.5) for side effects, 58.0 (16.9) for convenience, and 53.6 (19.9) for global satisfaction. Higher levels of pain were associated with lower levels of satisfaction with medication effectiveness. Patients experienced significantly less pain with than without IN fentanyl (mean (SD) NRS 4.02 (2.27) and 7.72 (2.31), respectively, $p<0.005)$. On the basis of these findings, it can be concluded that the patients were satisfied with IN fentanyl for the management of severe pain. The study described in chapter 7 investigated the satisfaction of patients with IN midazolam and rectal diazepam for controlling acute and/or persistent seizures. Twenty-five patients completed the TSQM questionnaire, and baseline patient characteristics were recorded. Student's t-test was used to estimate a difference in satisfaction between the two groups. Satisfaction with the effectiveness (mean (SD) 74.4 (19.1) versus 55.6 (30.7)) and convenience (mean (SD) 71.4 (15.4) versus 58.5 (28.4)) of drug administration and global satisfaction (mean (SD) 67.6 (23.3) versus 56.2 (28.1)) were higher with IN midazolam than with rectal diazepam, whereas satisfaction with side effects (mean (SD) 72.6 (28.1) versus 85.4 (19.4)) was higher with rectal diazepam. In conclusion, patients who used IN midazolam were as satisfied as patients who used rectal diazepam.

Interest in patient satisfaction reflects the slow change in how patients are perceived, with patients no longer being seen as passive recipients but instead active consumers of healthcare services. The concept 'patient empowerment' reflects this development and encourages people to take care of their own health and to choose which type of care they would like to receive from among the options identified by their physicians. 
Satisfaction with medical products will have a place in these choices. Moreover, providers of healthcare services and pharmaceutical companies have become increasingly interested in obtaining feedback about their products from the primary consumers of these products. 
Samenvatting 
De eerste studies over intranasaal (IN) toegediende geneesmiddelen voor systemisch gebruik, zoals corticotropin, werden begin jaren vijftig gepubliceerd. Sindsdien werden steeds meer intranasale formuleringen voor systemisch werkende geneesmiddelen ontwikkeld en bleek de IN toedieningroute geschikt te zijn voor diverse indicaties.

IN toediening van geneesmiddelen kan de voorkeur verdienen doordat het zonder hulp eenvoudig is toe te dienen of wanneer snelle opname en werking gewenst is. Er zijn verschillende therapeutische groepen ontwikkeld voor IN toediening zoals analgetica (vooral opiaten), benzodiazepinen en geneesmiddelen voor migraine. Deze geneesmiddelen zijn lipofiel, hebben een klein molecuulgewicht en kunnen een snelle werking hebben. In dit proefschrift staat een aantal studies, waarin verschillende eigenschappen van IN toegediende geneesmiddelen zijn onderzocht, zoals farmacokinetiek, klinische effectiviteit, veiligheid en patiënttevredenheid. Zij kunnen van belang zijn voor de therapietrouw van patiënten en kunnen bijdragen aan onze kennis over IN toegediende geneesmiddelen.

Een literatuuronderzoek is uitgevoerd om te bepalen welke opiaten, benzodiazepinen en geneesmiddelen voor migraine geschikt zijn op basis van hun farmacokinetische eigenschappen bij IN versus intraveneuze (IV) en orale formuleringen, beschreven in hoofdstuk 2. In de literatuur zijn 45 geschikte farmacokinetiekstudies over IN toediening gevonden. Hierin hadden de opiaten een hoge biologische beschikbaarheid en een $t_{\max }$ die binnen 25 minuten lag, de benzodiazepinen haalden een biologische beschikbaarheid die lag tussen $38 \%$ en $98 \%$ en een $t_{\max }$ variërend van 10 tot 25 minuten. De geneesmiddelen voor migraine lieten een biologische beschikbaarheid variërend van $5 \%$ tot $40 \%$ zien met een $t_{\max }$ variërend van 25 tot 90 minuten. Uit dit literatuuronderzoek blijkt dat deze drie geneesmiddelgroepen alle geschikt zijn voor IN toediening bij indicaties die een snel effect behoeven. Uiteindelijk zal het beoogde effect van een geneesmiddel bepalen welke formulering de voorkeur heeft, omdat de verschillende farmacokinetische eigenschappen van een geneesmiddel afhankelijk zijn van de toedieningrouten (IV > IN > oraal).

Benzodiazepinen worden gebruikt om epileptische aanvallen bij kinderen en volwassenen te behandelen. Vaak is het lastig om geneesmiddelen IV toe te dienen gedurende een epileptische aanval en is spoed gewenst. Het is in Nederland gebruikelijk om hiervoor diazepam rectaal toe te dienen, maar dit heeft als nadeel dat de toediening voor patiënten en omstanders tamelijk gênant kan zijn. Verschillende studies van clonazepam, diazepam en midazolam IN toegediend bij epileptische aanvallen geven aan dat midazolam IN toegediend net zo effectief zou kunnen zijn als rectaal toegediende diazepam. In het onderzoek, beschreven in hoofdstuk 3, wordt de farmacokinetiek en 
veiligheid van IN midazolam (5 mg) vergeleken met IV midazolam (2,5 mg) bij gezonde volwassen vrijwilligers. In deze open, gerandomiseerde, cross-over pilot studie kregen proefpersonen eenmalig midazolam IN of IV toegediend met een periode van 5 dagen tussen de toedieningen. De IN midazolam werd met één spray toegediend in één neusgat, en de IV toediening duurde 10 seconden. Bloedmonsters werden afgenomen voor de toediening tot 4 uur daarna. Farmacokinetische data werden geanalyseerd met een tweecompartimenten model. Zeven vrijwilligers voltooiden de studie. $\mathrm{Na}$ IN toediening werd de gemiddelde (SD) $C_{\max }$ bereikt na 44 minuten en was $78(40) \mathrm{ng} / \mathrm{ml}$, terwijl de gemiddelde (SD) $C_{\max }$ direct na IV toediening 51 (5) $\mathrm{ng} / \mathrm{ml}$ was. De $t_{1 / 2}$ was $1,9(0,41)$ uur bij IN toegediende midazolam en $2,3(0,19)$ uur voor IV toegediende midazolam. De biologische beschikbaarheid van IN midazolam was $82 \%$. Er waren een paar bijwerkingen, waarvan een brandend gevoel in de neus het vaakst werd gemeld ( 6 van de 7 vrijwilligers). De therapeutische concentratie van midazolam (> $30 \mathrm{ng} / \mathrm{ml}$ ) werd binnen 5 minuten bereikt, hetgeen te vergelijken is met de resultaten bij minder geconcentreerde midazolam oplossingen die IN zijn toegediend. Aanvullend onderzoek is nodig om de veiligheid, het gemak, de tevredenheid en de effectiviteit van IN midazolam te evalueren bij de behandeling van volwassen patiënten met epileptische aanvallen.

Fentanyl is binnen de groep van opiaten een uitgelezen middel voor IN toediening bij patiënten waarbij een korte pijnlijke handeling moet worden uitgevoerd, omdat fentanyl een snel en kortdurend effect heeft. Deze eigenschappen maken IN fentanyl daarmee geschikt voor patiënten met kankergerelateerde doorbraakpijn, die zich typeert door een snelle start en een maximale duur van 30 minuten. Fentanyl wordt ook gebruikt om chronische pijn te behandelen, maar wordt dan transdermaal toegediend met behulp van een pleister, waaruit langzaam fentanyl vrijkomt. Hoofdstuk 4 beschrijft een gerandomiseerde, dubbelblinde, prospectieve studie met gezonde vrouwen (ASA I of II) tussen 18 en 65 jaar waarbij een drain wordt weggehaald 1 tot 4 dagen na een borst vergroting -of verkleining. Een enkele spray van fentanyl neusspray $(0,05 \mathrm{mg} / 0,1 \mathrm{ml})$ of placebo $(0,1 \mathrm{ml})$ werd toegediend 10 minuten vóór de verwijdering van de drain. Voor de evaluatie van de pijnintensiteit werd een $100 \mathrm{~mm}$ visueel analoge schaal (VAS) gebruikt. Dit is een continu schaal van $0 \mathrm{~mm}$ ('geen pijn') tot $100 \mathrm{~mm}$ ('maximaal denkbare pijn'), die frequent gebruikt wordt voor studies omtrent pijn. De VAS werd gemeten voor de toediening van de studiemedicatie $(t=0)$, op het moment van het trekken van de drain $(t=10)$, en daarna gedurende een uur. Veiligheidsmaatregelen tijdens de studie waren het meten van zuurstofsaturatie, snelheid van ademhaling, hartritme en bloeddruk. Aan de deelnemers werd op gezette tijden gevraagd of zij bijwerkingen ondervonden. Bloedmonsters voor de farmacokinetische analyse werden direct voor en tot 2 uur na toediening van de neusspray verzameld. De farmacoki- 
netische populatie parameters van fentanyl werden berekend met een ééncompartiment open model met behulp van Bayesiaanse fitting. Drieëndertig vrouwen hebben het onderzoek afgemaakt. Gemiddelde (SD) VAS scores op $t=0$ waren 14,8 $(17,8)$ voor de fentanyl groep en $6,0(9,7)$ voor de placebo groep (dit verschil was niet significant); op het moment dat de drain getrokken werd, waren de VAS scores respectievelijk $31,0(20,6)$ and $33,8(25,7)$, waarvan het verschil ook niet significant was. Na analyse met behulp van een mixed random effect model bleek er een significant verschil te zijn in de gemiddelde VAS scores over de hele periode tussen de fentanyl en placebo groep $(p=0,006)$. De incidentie van bijwerkingen was in de hele studie $39 \%$. Eén of meer bijwerkingen werden gemeld bij 8 van de 17 patiënten in de fentanyl groep en bij 9 van de 16 patiënten in de placebo groep. Een gemiddelde (SD) gefitte $\mathrm{C}_{\max }$ van $0,184(0,069) \mathrm{ng} / \mathrm{ml}$ werd bereikt na $13,76(3,56)$ minuten na IN toediening van fentanyl. De gemiddelde $(S D)$ gemeten $C_{\max }$ was $0,22(0,88) \mathrm{ng} / \mathrm{ml}$. Bij deze vrouwen die een borstverkleining -of vergroting hadden ondergaan was een eenmalige dosis IN fentanyl $(0,05 \mathrm{mg})$ significant effectiever dan placebo in het reduceren van pijn gedurende de periode na het trekken van de drain. Echter, er was geen significant verschil in pijn op het moment van het trekken van de drain tussen fentanyl en placebo. IN fentanyl werd over het algemeen goed verdragen, met dien verstande dat de plasmaconcentraties onder het therapeutische venster lagen.

In de hierboven beschreven farmacokinetiek studies werd duale absorptie gezien, waarbij IN toegediende geneesmiddelen werden geabsorbeerd via de nasale mucus en via het maagdarmkanaal. Dit fenomeen was nog niet beschreven in een farmacokinetisch model voor IN toegediende geneesmiddelen. Het doel van de studie, beschreven in hoofdstuk 5, was het ontwikkelen en valideren van een farmacokinetisch model waarmee het concentratie - tijd profiel van een IN toegediend geneesmiddel beschreven kan worden als ook het vaststellen welke absorptieparameters het belangrijkste zijn voor de duale absorptie. Bijkomende doelen waren het analyseren van individuele data met behulp van een populatiemodel en om het model te testen met data uit de literatuur.

Het duale absorptiemodel werd gevalideerd met Monte Carlo simulaties. Zowel individuele data met IN toegediende midazolam als data uit de literatuur werden gefit met het model. Resultaten lieten zien dat het farmacokinetisch model de duale absorptie van midazolam IN kon voorspellen. Maar ook liet Monte Carlo simulatie zien dat, hoewel op populatieniveau geen duale absorptie te zien is, er wel bij een aantal individuele gevallen twee pieken te zien waren door biologische variatie. Het bleek dat dit model het concentratietijd profiel van IN toegediende geneesmiddelen adequaat kan voorspellen en dit model gebruikt kan worden om individuele data te analyseren met behulp van een populatiemodel. 
Zelfs als alle parameters, zoals farmacokinetiek, effectiviteit en veiligheid, zodanig zijn dat verdere ontwikkeling van een geneesmiddel attractief is, hangt het uiteindelijke besluit om verder te gaan met productontwikkeling af van de patiënten die het geneesmiddel gebruiken. Om hier inzicht in te krijgen is het laatste deel van dit proefschrift gericht op twee patiënttevredenheidsstudies met fentanyl en midazolam IN neussprays. Hiervoor is gebruik gemaakt van een gevalideerde vragenlijst en rekening gehouden met mogelijke predictoren voor patiënttevredenheid.

Hoofdstuk 6 beschrijft de patiënttevredenheidsstudie van fentanyl neusspray en van de bereikte pijnreductie. Patiënten ouder dan 18 jaar die fentanyl IN gebruikten voor ernstige pijn, zoals doorbraakpijn, werden benaderd om deel te nemen aan de studie door hun apotheker. De patiënttevredenheid met fentanyl IN werd gemeten met de gevalideerde 'Treatment Satisfaction Questionnaire for Medication' (TSQM), die de effectiviteit, bijwerkingen, gebruiksvriendelijkheid en de algehele tevredenheid van de patiënt meet. Pijn werd gemeten met een numerieke schaal (numerical rating scale NRS). Vijfentwintig patiënten stuurden de TSQM vragenlijst terug. Voor fentanyl neusspray waren de gemiddelde (SD) scores $65,6(20,1)$ voor effectiviteit, $87,0(19,5)$ voor bijwerkingen, 58,0 $(16,9)$ voor gebruiksvriendelijkheid en 53,6 $(19,9)$ voor algehele tevredenheid. Meer pijn werd geassocieerd met een lage mate van tevredenheid over de effectiviteit. Patiënten hadden significant minder pijn wanneer fentanyl werd toegediend dan zonder fentanyl toediening (gemiddelde (SD) NRS 4,02 (2,27) en 7,72 $(2,31)$, respectievelijk , $p<0,005)$. Op basis hiervan kan geconcludeerd worden dat de patiënten tevreden waren met de behandeling van ernstige pijn door het IN toedienen van fentanyl. De studie in hoofdstuk 7 beschreef het onderzoek naar de patiënttevredenheid van midazolam IN toediening ten opzichte van diazepam rectale toediening voor de behandeling van epileptische aanvallen. Vijfentwintig patiënten vulden de TSQM vragenlijst in en de patiëntparameters werden vastgelegd. Student's t-test werd gebruikt om het verschil in tevredenheid te bepalen tussen de twee groepen. Tevredenheid met de effectiviteit (gemiddelde (SD) $74,4(19,1)$ versus $55,6(30,7)$ ), gebruiksvriendelijkheid (gemiddelde (SD) $71,4(15,4)$ versus $58,5(28,4)$ ) en algehele tevredenheid (gemiddelde (SD) 67,6 $(23,3)$ versus $56,2(28,1)$ ), voor midazolam versus diazepam, waren hoger met midazolam IN dan met diazepam rectaal toegediend maar niet significant. De patiënten waren meer tevreden met diazepam rectaal (gemiddelde (SD) $85,4(19,4)$ ) dan met midazolam IN (gemiddelde (SD) $72,6(28,1)$ ) wat betreft bijwerkingen (het verschil was niet significant). Concluderend waren patiënten uit beide groepen even tevreden.

De benadering van patiënten in de gezondheidszorg laat een langzame verandering zien, waarbij patiënten niet langer worden gezien als passieve gebruikers maar als 
actieve consumenten van de gezondheidzorg. Het concept 'patient empowerment' beschrijt deze ontwikkeling en moedigt mensen aan om te zorgen voor hun eigen gezondheid en te kiezen welk type men wil van de aangeboden zorg. Bij deze keuzes zal tevredenheid over medische producten een rol spelen. Aanbieders van gezondheidszorg en farmaceutische bedrijven zijn dan ook meer en meer geïnteresseerd om feedback van de consumenten over hun producten te krijgen. 
Dankwoord 
Het tastbaar maken van dit proefschrift, geeft mij het besef dat ik vele mensen dankbaar ben voor de hulp, het enthousiasme en de interesse die ik de afgelopen jaren heb ondervonden. Velen om mij heen speelden en spelen nu nog ieder een eigen rol, maar allemaal hebben ze het mogelijk gemaakt dat dit boekje er ligt.

Samen, met een clubje mensen hebben we dit voor elkaar gekregen. Vanaf het begin waren mijn trouwe partners Hugo en Marco en later kwam daar Kees bij.

Hugo, in het begin was je al enthousiast over het onderwerp neussprays. Zelf in Sittard gepromoveerd op Studies on intranasal drug delivery in migraine, kwam je in Maastricht en we pakten samen het onderwerp op. Toen je zelf promoveerde wenste je me toe dat ik de volgende in de rij zou zijn. Dat is niet gelukt, het heeft wel wat meer dagen geduurd dan voorzien. Telkens weer waren er andere zaken die voorrang kregen, en telkens probeerde je daar begrip voor op te brengen. Ik bewonder je voor je geduld en enthousiasme die je altijd getoond hebt. Je probeerde altijd weer te helpen of een creatieve uitweg te vinden om toch de voortgang te houden. Je vertrek uit het azM, betekende voor mij dat ik een fijne collega kwijt was. Toch wist je altijd op kritische wijze vanuit Sittard mijn werk te volgen. Als co-promotor zorgde je voor de eerste screening van de artikelen en leverde aanvullingen, waardoor de artikelen telkens weer groeiden en verbeterden.

Marco, jij kwam in Maastricht en zag wat een leuk en interessant onderwerp dit was. Je wilde graag samenwerken met de afdeling Klinische Farmacie en voerde gesprekken met mijn opleider. Je zag het zitten om een co-promotie te doen, jammer genoeg is het dat niet geworden. Ik denk dat jij ook soms dacht, waar moet dit naar toe. Je toonde begrip voor mijn moederschap, het parttime werken, de onrust bij de afdeling die mij erg vertraagde. Allemaal factoren die er telkens tussendoor kwamen.

In de apotheek ben ik gesteund door Kees, onze prof en mijn tweede promotor. Altijd voor de vragen over Mwpharm was ik bij Kees aan het goede adres. Kees leerde me met het programma te werken en wist me weer tips aan de hand te doen. Kees, zonder jou kinetische input hadden we dit niet voor elkaar gekregen.

Bij de afdeling anesthesie vond ik een soort schuilkelder, al ligt de afdeling 4 etages boven de klinische Farmacie. Hier kon ik overdenken, abstraheren, en tegelijkertijd werd op de achtergrond door Audrey aan mijn onderzoek gewerkt. Op de kamer samen met Maurice en Audrey hebben we heel wat inhoudelijke zaken besproken en Maurice heeft ons met raad en daad bijgestaan in de diepe gronden van de statistiek. Niet alleen de statistische raad van Maurice was een welkome aanvulling, ook in de uitvoering van het onderzoek heb ik veel aan Maurice te danken. Zonder zijn inzet, 
plichtsbesef en doorzettingsvermogen, had ik lang niet zoveel data kunnen verzamelen als nu het geval is. Audrey is een steun geweest voor het ordenen, het schrijven van protocollen en artikelen. Audrey, zonder je hulp weet ik niet of ik dit ooit voor elkaar had gekregen. We hebben een hele poos op een fijne manier samengewerkt, en ik hoop dat dit voortduurt en je bij de afdeling anesthesie een mooie loopbaan in onderzoek kunt voortzetten.

Nieko Punt en Fons Kessels wil ik bedanken voor de prettige samenwerking en hun vakspecifieke knowhow en bijdrage aan mijn onderzoek.

De leden van de manuscriptcommissie wil ik bedanken voor het bestuderen en beoordelen van dit proefschrift.

Afke en Marielle, ik vind het super dat jullie als paranimfen achter mij willen staan. Afke, al jaren lang werken we samen in de apotheek. Dank je wel voor je inzet en loyaliteit, en zeker ook voor de gezelligheid in ons team. Marielle, iets minder lang werken we samen in de apotheek, maar ook al een hele tijd. Ik waardeer je prettige en oprechte manier van omgang en je staat altijd klaar voor een koffiepauze.

Frank, Jan, Karin, Leo, Lotte, Rogier, Sander, Thomas, Veronique en Wim, jullie hebben mij geholpen door regelmatig te informeren hoe het ging met het onderzoek, en het in een paar periodes het mogelijk te maken dat ik meer tijd kreeg voor de beroemde eindspurt. De flexibiliteit, betrokkenheid en interesse in onderzoek die jullie hebben, is voor mij een fijn klimaat om in te werken. Zonder de steun van Ellen om dit traject af te ronden, had ik, denk ik nog wel een paar jaartjes er voor uit kunnen trekken. Ellen, ik ben blij dat je naar Maastricht bent gekomen. Dikwijls hebben we het er samen over gehad of een promotie nu zinvol is of niet, alles afhankelijk van je uiteindelijke doel.

De analisten van het Laboratorium en met name Karin Hoogtanders wil ik hartelijk bedanken voor het ontwikkelen van de bepaling. Zonder jullie was dat nooit gelukt! Bedankt hiervoor.

Ons management wil ik bedanken, Carola, Peter en Judith, door jullie inzet is het voor mij makkelijker om soms tijd te hebben voor onderzoek. John, dank je wel voor je meedenken in allerlei human resourceachtige zaken, zowel privé als in het ziekenhuis en omdat je een fijne collega bent.

Dames van het secretariaat, Diana, Jacqueline en Marlien, met jullie ben ik al heel lang een team. Jullie staan altijd klaar en zijn mijn soms verstrooide manier van doen wel 
gewend. Jullie weten er op in te spelen en horen mijn successen en frustraties aan. Dank je wel.

Lieve familie en vrienden, sommigen waren verrast door mijn promotie, anderen waren alweer vergeten dat ik er mee bezig was of dachten 'eindelijk'. Dat kan ik me ook heel goed voorstellen, want de periode was ook wel heel lang en in die tijd hebben we veel meegemaakt. Lieve allemaal, dank jullie wel voor jullie interesse en betrokkenheid in de afgelopen jaren.

Mama, heel veel dank dat je me samen met papa hebt geleerd niet je talenten in de kast te laten liggen. Papa, helaas ben je er niet meer, want je had dit graag willen meemaken en zou ook heel trots zijn geweest. Aan jullie beiden draag ik dit boekje op.

Matice, Eva en Friso, lieve kleintjes, jullie zorgen altijd weer voor mijn realiteit. Al die jaren naar huis fietsend, veranderden mijn gedachten aan het onderzoek naar gedachten aan jullie. Dank jullie wel voor jullie liefde, humor en reflectie.

Lieve Arend Jan, met jou is het leven een avontuur. Beide houden we van nieuwe stappen en afwisseling. Dank je wel dat je bent wie je bent. Zonder jou steun op alle fronten had ik dit niet kunnen afronden. Benieuwd ben ik naar wat nog komen gaat! 
Curriculum Vitae 

Nicole Maria Lambertina Veldhorst-Janssen werd op 29 november 1969 geboren te Geldrop. Ze groeide op in Nuenen en behaalde in 1988 het gymnasium diploma aan de katholieke scholengemeenschap Augustinianum te Eindhoven. Aansluitend werd begonnen met de studie Farmacie aan de Universiteit Utrecht. Ter afsluiting van de doctoraal opleiding volgde ze een wetenschappelijke stage aan het st. Mary's Hospital te Londen, waar zij onderzoek verrichtte naar de invloed van een aantal groeifactoren op de groei van tumorcellen. In 1993 behaalde zij haar doctoraal examen met de afstudeerscriptie: groeihormoon in relatie tot botgroei en twee jaar later het apothekersdiploma. Vervolgens ging zij werken als projectapotheker in het St Jans Gasthuis te Weert, alwaar zij een productie-ondersteunend computersysteem implementeerde en het gebruik van de mogelijkheden van het apotheek informatiesysteem uitbreidde. Daarna ging zij werken in het Slotervaart ziekenhuis in Amsterdam om een certificaat Good Manufacturing Practice te verkrijgen voor een productie-unit waar trialgeneesmiddelen werden geproduceerd. In 1997 werkte zij als apotheker in het Gemini Ziekenhuis te Den Helder en in 1998 als projectapotheker bij de Stichting Apotheek Haarlemse Ziekenhuizen om de distributie op te zetten in twee verpleeghuizen, Stichting Epilepsie Instellingen Nederland en het Centrum voor Alcohol en andere Drugsverslavingen (CAD). Later in dit jaar begon zij de opleiding tot ziekenhuisapotheker in het academisch ziekenhuis Maastricht (MUMC) en rondde deze in 2003 met de registratie af.

Van 2003 tot nu heeft Nicole gewerkt als ziekenhuisapotheker in het MUMC met verschillende aandachtsgebieden. Begonnen als klinisch apotheker in het PsychoMedisch Centrum Vijverdal vanuit het MUMC en later in het MUMC afwisselend verantwoordelijk voor het elektronisch voorschrijfsysteem, de sectie distributie \& logistiek en de sectie productie en nu als duaal manager/apotheker en lid van het managementteam.

Gedurende de opleiding tot ziekenhuisapotheker startte zij met het onderzoek naar fentanyl en midazolam geformuleerd als een neusspray, hetgeen leidde tot dit proefschrift. Het research werd uitgevoerd samen met de afdeling Anesthesie.

Nicole is getrouwd met Arend Jan Veldhorst en samen hebben ze drie prachtige kinderen Friso, Eva en Matice. 



\section{List of publications}


Veldhorst-Janssen NML et al. Dual pathway absorption after intranasal drug administration: a new pharmacokinetic model. 2012 Submitted Eur J Pharm Sci.

Mens WBJ, Plas, van de A, Veldhorst-Janssen NML, Frankfort E. Continu Verbeteren in de ziekenhuisapotheek: volop mogelijkheden en kansen. 2012 Accepted Pharm Weekbl.

Veldhorst-Janssen NML et al. Patients' satisfaction with intranasal midazolam versus rectal diazepam as fast-working rescue medication in epilepsy. 2012 Submitted The Neurologist.

Veldhorst-Janssen NML et al. Patient satisfaction with intranasal fentanyl for breakthrough pain. J of Pall Med 2012;15(6):631-632.

Veldhorst-Janssen NML et al. Pharmacokinetics and tolerability of nasal versus intravenous midazolam in healthy Dutch volunteers: a single-dose, randomized-sequence, open-label, 2-period crossover pilot study. Clin Ther. 2011;33(12):2022-8.

Veldhorst-Janssen NML et al. Pharmacokinetics, Analgesic Effect, and Tolerability of a Single Preprocedural Dose of Intranasal Fentanyl in Patients Undergoing Drain Removal After Breast Reduction or Augmentation Surgery: A Prospective, Randomized, DoubleBlind, Placebo-Controlled Study Clin Ther 2010;32(7):1427.

Veldhorst-Janssen NML et al. A Review of the Clinical Pharmacokinetics of Opioids, Benzodiazepines, and antimigraine Drugs delivered intranasally. Clin Ther 2009;31(12): 2954-2987.

Onzenoort, van H, Plas, van de A, Kessels AG, Veldhorst-Janssen NML, Kuy, van der, $\mathrm{PHM}$ and Neef $\mathrm{C}$. Factors influencing bar-code verification by nurses during medication administration in a Dutch hospital. Am J Health Syst Pharm 2008;65:644-648.

Veldhorst-Janssen NML, Kuy, van der PHM, Neef C, et al. Optimalisation of intranasal midazolam. Anesthesiology. 2006;105:A628.

Veldhorst-Janssen NML, Boersma HH, Krom, de MCTFM, Rijswijk van REN. Phenytoin interacts with a tegafur/ folinic acid chemotherapy regimen. Br J Cancer 2004; 90(3): 745. 
Veldhorst-Janssen NML, Kuy, van der PHM, Boersma HH, As, van HLJ, Hardy ELM, Stolk LML, Krom, de MCTFM, Beysens AJ. Are intranasal pharmacokinetics volume dependent? Conceptuur 2002;32:37.

Veldhorst-Janssen NML, et al. Systematische risicoanalyse levert verbeterpunten op. Het medicatiedistributieproces in het azm. Pharm Weekbl 2002;137(44):1548-1553.

Van der Kuy PH, Lohman JJ, Veldhorst-Janssen NML, et al. Intranasal drug delivery in migraine: State of the art. Ned Tijdschr Neur 1998;1:49-56 